\title{
DIVERSE NEIGHBOURHOODS: AN ANALYSIS OF THE RESIDENTIAL DISTRIBUTION OF IMMIGRANTS IN IRELAND
}

Éamonn Fahey, Helen Russell, Frances McGinnity and Raffaele Grotti

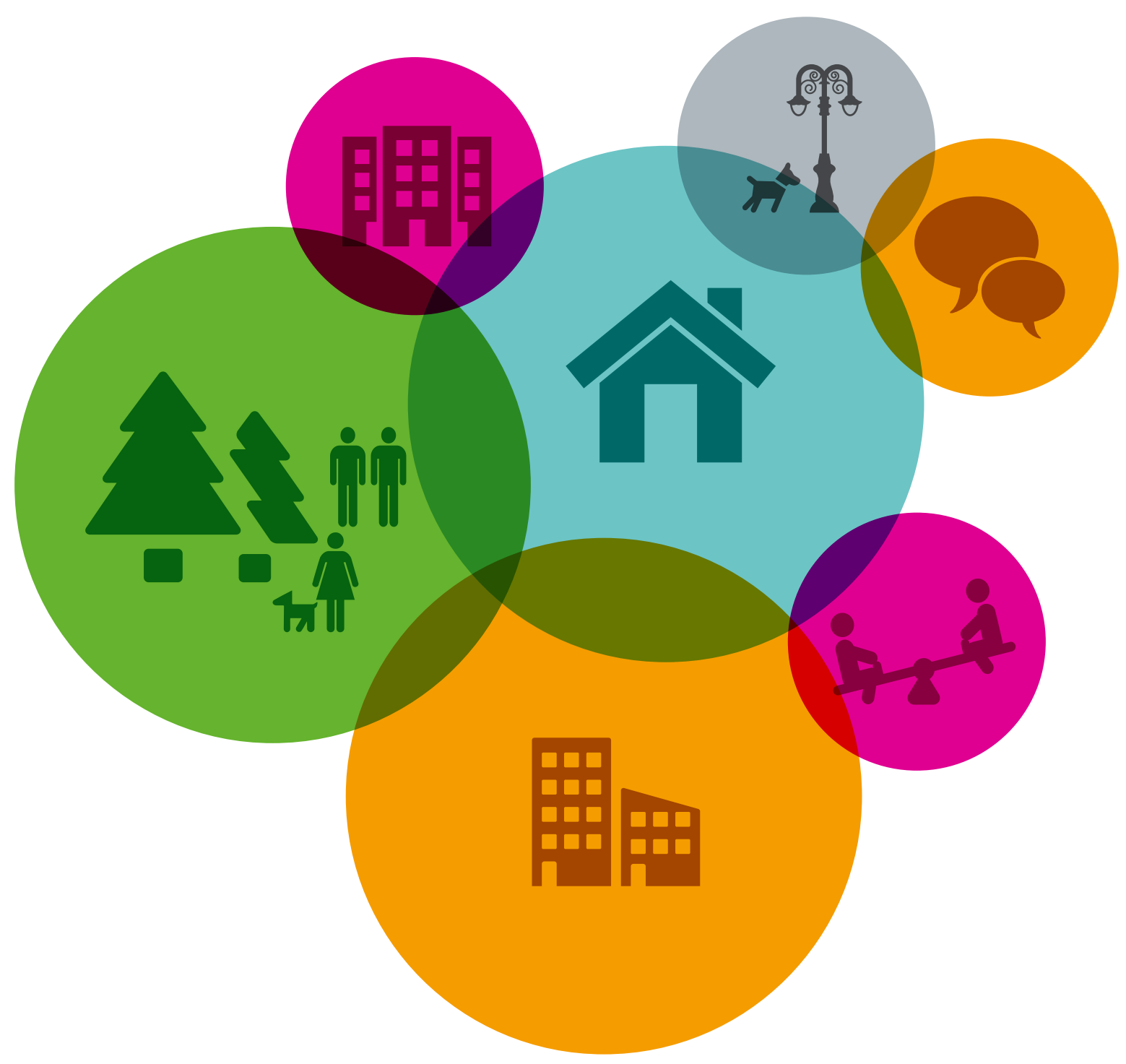


Funded by the Office for the Promotion of Migrant Integration in line with the Migrant Integration Strategy 2017-2020 


\title{
DIVERSE NEIGHBOURHOODS: AN ANALYSIS OF THE RESIDENTIAL DISTRIBUTION OF IMMIGRANTS IN IRELAND
}

\author{
Éamonn Fahey \\ Helen Russell \\ Frances McGinnity \\ Raffaele Grotti
}

June 2019

Economic and Social Research Institute;

Department of Justice and Equality

Available to download from www.esri.ie

(C) The Economic and Social Research Institute

Whitaker Square, Sir John Rogerson's Quay, Dublin 2

ISBN 978-0-7070-0488-4

DOI https://doi.org/10.26504/bkmnext376

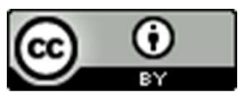

This Open Access work is licensed under a Creative Commons Attribution 4.0 International License (https://creativecommons.org/licenses/by/4.0/), which permits unrestricted use, distribution, and reproduction in any medium, provided the original work is properly credited. 



\section{FOREWORD}

Diverse communities are an integral part of Irish life, with almost 12 per cent of people living here having a nationality other than Irish, and a growing second and third generation of Irish-born children of migrants. Where migrants live is key to their social inclusion: the neighbourhoods they call home.

Ireland's National Migrant Integration Strategy is one way in which we are trying to remove barriers to fully realising the potential and opportunities that diversity can bring. The Strategy is underpinned by the vision that migrants are facilitated to play a full role in Irish society, that integration is a core principle of Irish life and that Irish society and institutions work together to promote social inclusion.

Reliable data are essential if we are to develop appropriate responses to challenges and barriers that migrants and their children may face in participating fully and developing a sense of belonging.

The Department of Justice and Equality is funding an integration research programme with the ESRI that aims to provide good evidence for policy on integration. This is the third report from this research programme, and follows the Monitoring Report on Integration 2018 (November 2018) and Data for Monitoring Integration (March 2019), both of which represent a valuable contribution to the evidence base available to integration policymakers.

Diverse Communities considers integration from the important perspective of place. It provides an overview of the distribution of our migrant population in Ireland and, in doing so, gives us critical insight into integration at the local level. It is widely acknowledged that the local dimension is critical to integration. The daily lived experience of migrants and their children in communities across the country is an important factor in building a sense of belonging. It is also essential that communities be supported in managing diversity, which, for many, is experienced as change and sometimes as rapid change. Supporting communities to be confident in their diversity and to realise its benefits are key objectives of our approach to integration.

This report provides us with important evidence to inform effective policy responses to integration needs. It reveals that while our migrants are concentrated in the urban areas of Dublin, Cork and Limerick, there are large migrant communities in other cities and towns around Ireland and in rural areas too. Overall, the data show that at a national level our new communities are not segregated from the older communities, or from each other. However, there are some areas with high concentrations of immigrants, where targeted policy 
approaches may be beneficial in addressing specific barriers to integration. This research will be helpful to both central and local policymakers in identifying where additional integration supports could be used to best effect.

I welcome this timely research, which can guide our formulation of policy at this critical moment in Irish society, when we have a valuable opportunity to support communities and neighbourhoods that welcome diversity and opportunity for everyone equally.

David Stanton, TD

Minister of State at the Department of Justice and Equality with special responsibility for Equality, Immigration and Integration. 


\section{THE AUTHORS}

Éamonn Fahey is a Research Assistant at the Economic and Social Research Institute (ESRI). Helen Russell is a Research Professor at the ESRI and an Adjunct Professor at Trinity College Dublin (TCD). Frances McGinnity is an Associate Research Professor at the ESRI and Adjunct Professor at TCD. Raffaele Grotti is a Research Fellow in the European University Institute, Florence, and a former PostDoctoral Researcher in the ESRI.

\section{ACKNOWLEDGEMENTS}

This report was completed as part of a programme of research on Equality and Integration funded by the Office for the Promotion of Migrant Integration (OPMI) within the Department of Justice and Equality (DJE). We would like to express our thanks to the members of the steering group for the programme - Úna Ní Dhubhghaill (OPMI), Gurchand Singh (DJE), Bryan Fanning (University College Dublin) and Ann Marie McGauran (National Economic and Social Council). We thank our ESRI colleagues who reviewed the draft report, an external reviewer and Emer Smyth, who acted as editor. We would also like to extend our thanks to the Central Statistics Office for providing the data used in the report, to Brendan O'Brien for copyediting it and to Sarah Burns for managing its publication.

This report has been accepted for publication by the Institute, which does not itself take institutional policy positions. All ESRI Research Series reports are peer reviewed prior to publication. The author(s) are solely responsible for the content and the views expressed. 



\section{CONTENTS}

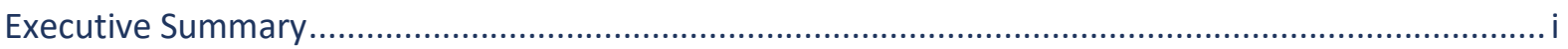

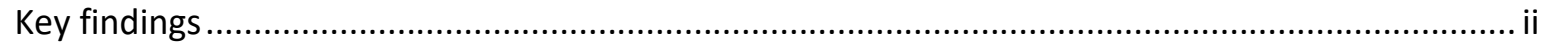

Avenues for future research ...................................................................................................

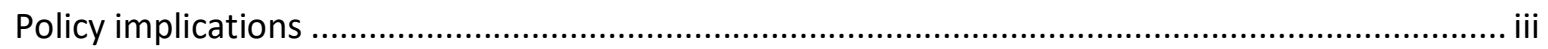

Chapter 1: Introduction, previous literature and background ......................................................... 1

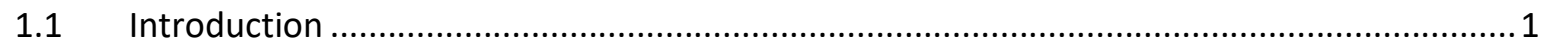

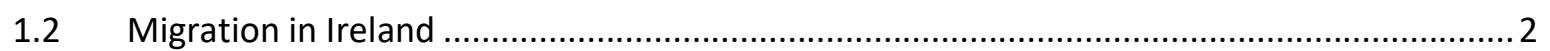

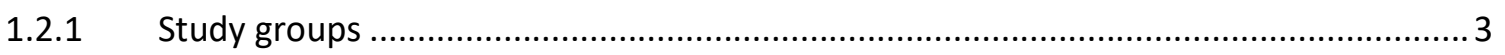

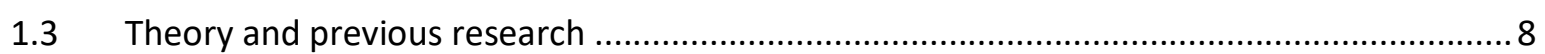

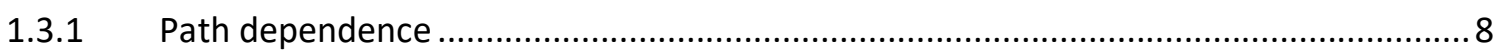

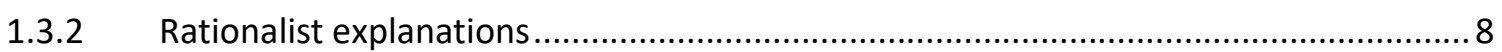

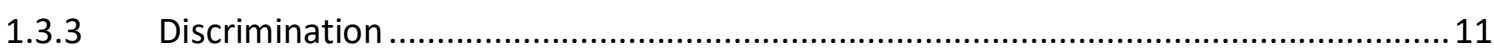

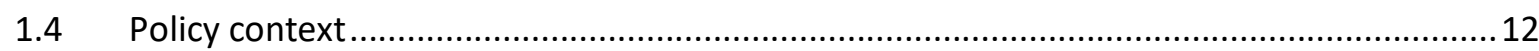

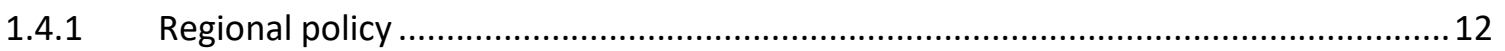

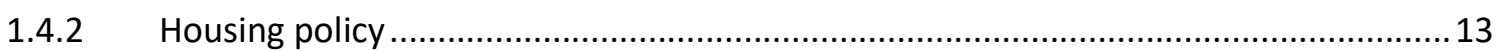

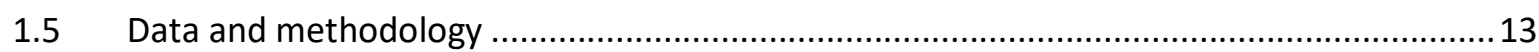

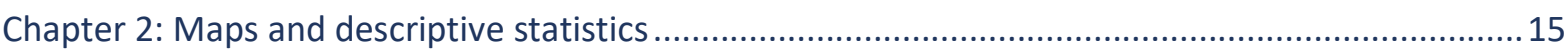

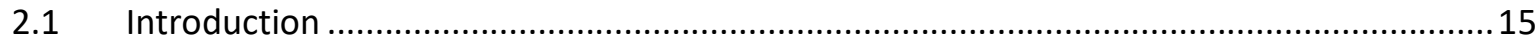

2.2 The distribution of minority groups in Ireland.................................................................. 16

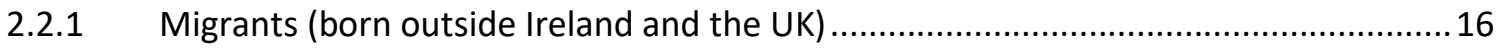

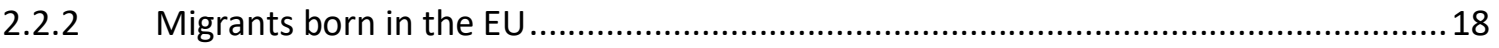

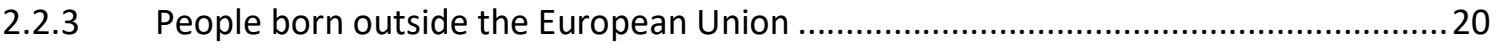

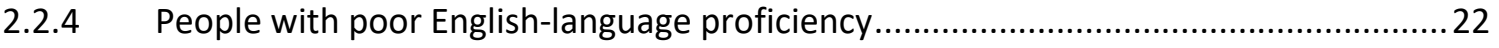

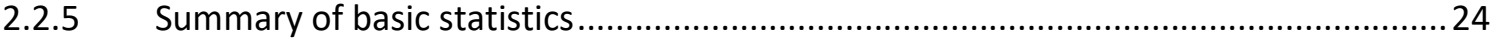

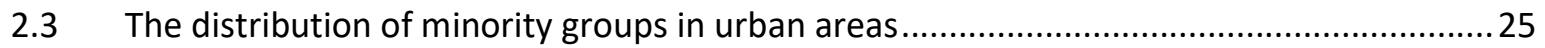

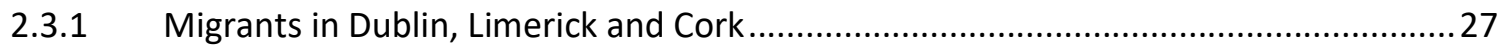

2.3.2 People born outside the EU in Dublin, Limerick and Cork ............................................ 30

2.3.3 People with poor English-language proficiency in Dublin, Limerick and Cork...............33

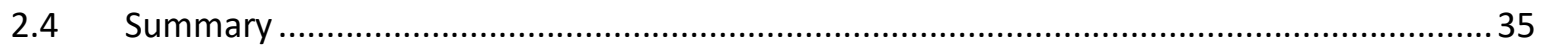

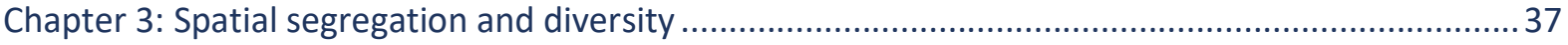

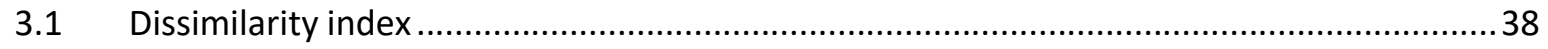

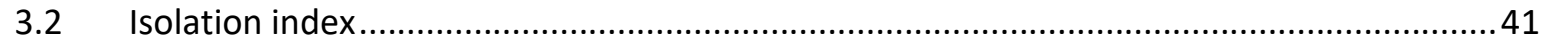

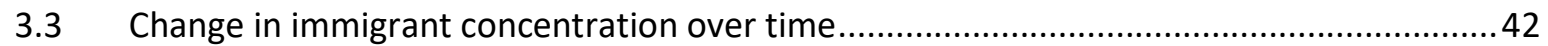




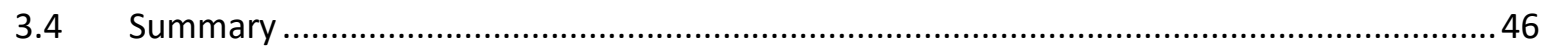

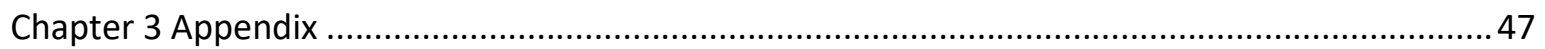

Chapter 4: Characteristics of areas with high immigrant concentrations .......................................... 49

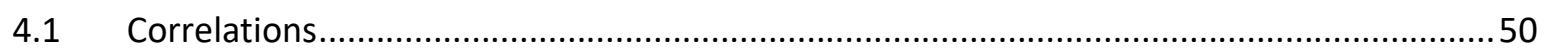

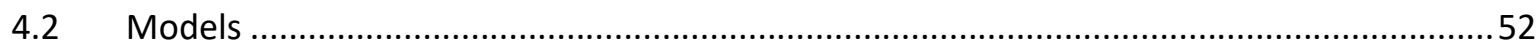

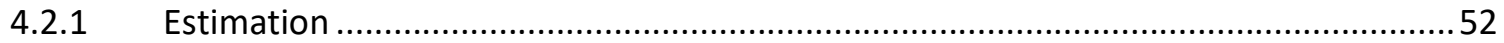

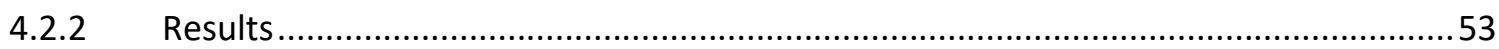

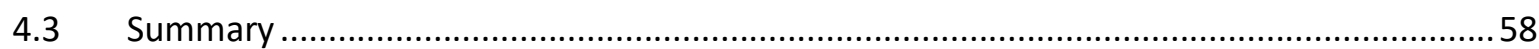

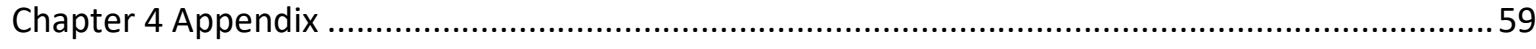

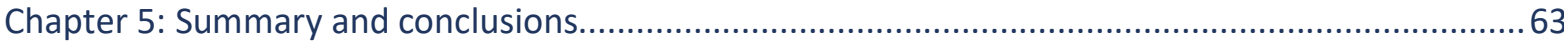

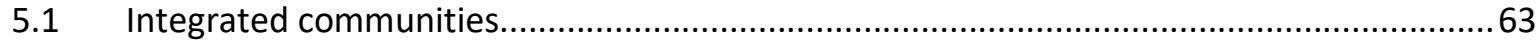

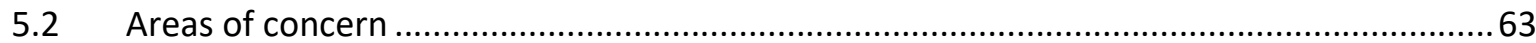

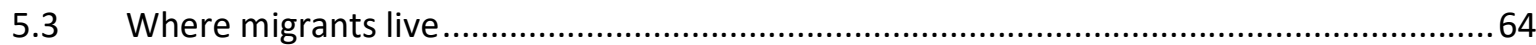

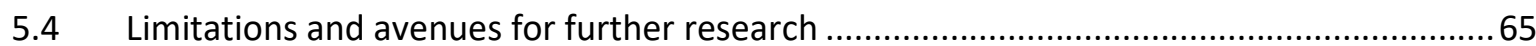

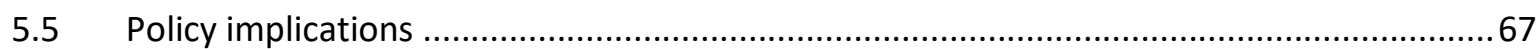

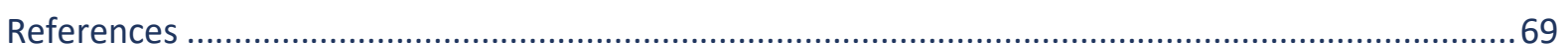




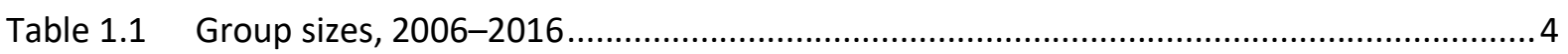

Table 2.1 Ten Electoral Divisions with highest share foreign-born ...............................................18

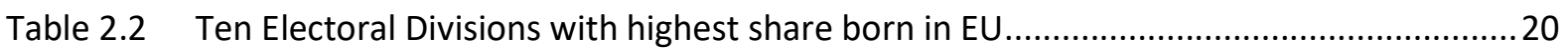

Table 2.3 Ten Electoral Divisions with highest share born outside of EU .....................................22

Table 2.4 Ten Electoral Divisions with highest share of people with poor English-language

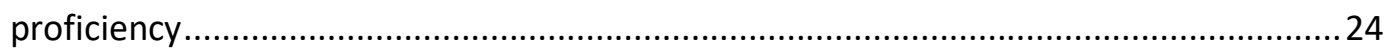

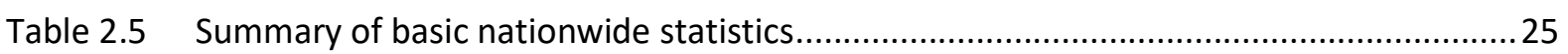

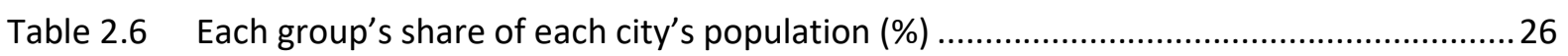

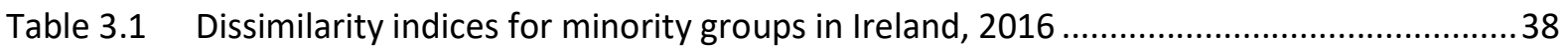

Table 3.2 Dissimilarity index - international comparison with Ireland ......................................... 40

Table 3.3 Isolation indices for minority groups in Ireland .......................................................... 42

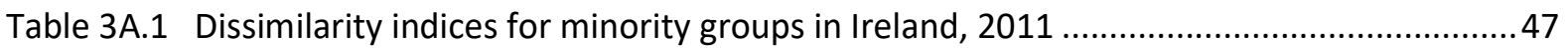

Table 3A.2 Change in dissimilarity indices for minority groups in Ireland, 2011-16 ..........................47

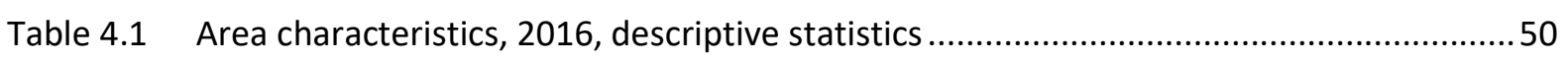

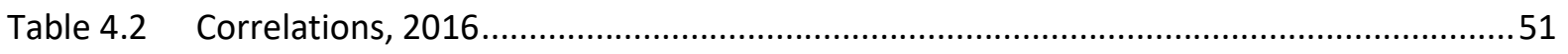

Table A4.1 Mean values of independent variables by residence in Dublin/Cork/Limerick or

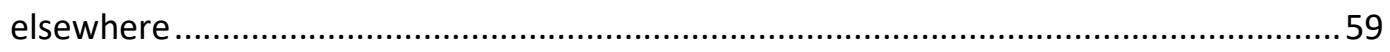


Figure $1.1 \quad$ Immigration, emigration and net migration, 1987-2017 …......................................

Figure 1.2 Immigrant population by country of birth, 2002-2016 .......................................... 6

Figure 2.1 Share of Electoral Division foreign-born (non-Irish/UK), 2016 ..................................17

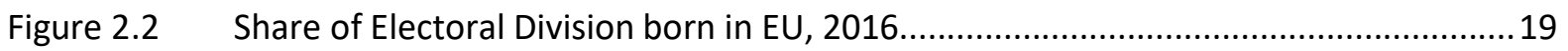

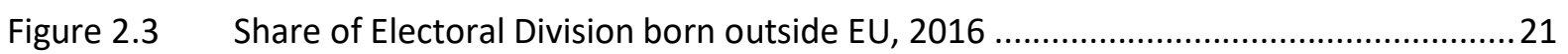

Figure 2.4 Share of Electoral Division with poor English-language proficiency, 2016..................23

Figure 2.5 Share of Electoral Division foreign-born (non-Irish/UK), Dublin 2016 ....................... 27

Figure 2.6 Share of Electoral Division foreign-born (non-Irish/UK), Limerick 2016........................28

Figure 2.7 Share of Electoral Division foreign-born (non-Irish/UK), Cork 2016...........................29

Figure 2.8 Share of Electoral Division born outside EU, Dublin 2016 ..........................................30

Figure 2.9 Share of Electoral Division born outside EU, Limerick 2016 .......................................... 31

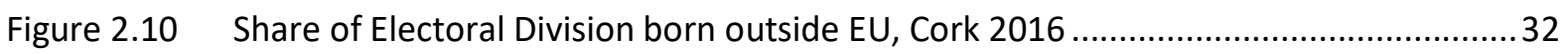

Figure 2.11 Share of Electoral Division with poor English-language proficiency, Dublin 2016 .......33

Figure 2.12 Share of Electoral Division with poor English-language proficiency, Limerick 2016 ....34

Figure 2.13 Share of Electoral Division with poor English-language proficiency, Cork 2016 ..........35

Figure 3.1 Percentage point change in share of population comprising migrants by 2011 quintile, 2011-2016

Figure 3.2 Percentage point change in share of population comprising EU migrants by 2011 quintile, 2011-2016

Figure 3.3 Percentage point change in share of population comprising non-EU migrants by 2011 quintile, 2011-2016

Figure 3.4 Standardised percentage point change in share of population comprising people with poor English-language proficiency by 2011 quintile, 2011-2016.

Figure 4.1 Relationship between private rented accommodation and share of Electoral Division foreign-born .... .52

Figure 4.2 Associations between area characteristics and total migrant (excluding UK-born) population - negative binomial regressions

Figure 4.3 Associations between area characteristics and EU migrant population - negative binomial regressions

Figure 4.4 Associations between area characteristics and non-EU-born population - negative binomial regressions

Figure 4.5 Associations between area characteristics and population with poor English-language proficiency - negative binomial regressions.

Figure A4.1 Associations between area characteristics and migrant (excluding UK-born) population in Dublin, Limerick and Cork - negative binomial regressions

Figure A4.2 Associations between area characteristics and EU-born population in Dublin, Limerick and Cork - negative binomial regressions

Figure A4.3 Associations between area characteristics and non-EU-born population in Dublin, Limerick and Cork - negative binomial regressions.

Figure A4.4 Associations between area characteristics and population with poor English-language proficiency in Dublin, Limerick and Cork - negative binomial regressions 61 


\section{GLOSSARY}

Choropleth A map depicting numerical values with varying shades of colour.

map

Correlation A measure of the relationship between two variables. The correlation coefficient coefficient ranges from -1 to 1 . A positive coefficient means that as the value of one variable increases, so does the value of the other. A negative coefficient means that as the value of one variable increases, the value of the other declines. A coefficient of zero means that there is no relationship between the two variables.

CSO Central Statistics Office.

Dissimilarity A measure of spatial segregation. The proportion of the minority group index $(D) \quad$ that would have to relocate to achieve an even distribution across all districts (Iceland et al., 2002).

ED Electoral Division - one of 3,409 CSO geographical units, with an average population of 1,376 people in 2016.

EEA European Economic Area.

Ethnic An area characterised by high concentration of an ethnic group, which is enclave formed by the group to enhance or protect its economic, social, political or cultural development (Marcuse, 2005).

IHREC Irish Human Rights and Equality Commission.

Isolation A measure of spatial segregation. The extent to which the average index minority group member shares his or her district with other minority members.

LA Local authority

LEA Local Electoral Area - one of 137 CSO geographical units, with an average population of 34,000 in 2016.

Quintiles Segments of a distribution that have been sorted by value and divided into five equal parts.

RIA Reception and Integration Agency.

SAPS Small Area Population Statistics.

Small area One of 18,641 CSO geographical units, with a population incorporating between 80 and 120 households. 



\section{EXECUTIVE SUMMARY}

Rapid immigration during the economic boom of the late 1990s and early 2000s means that Ireland now has one of the highest proportions of foreign-born residents in the EU. This report investigates residential patterns among Ireland's migrant population. Where migrants live has an important influence on their integration prospects: some commentators argue that spatial concentration makes it difficult for migrants and minorities to achieve full social integration into the host society (Massey and Mullen, 1984).

The report seeks to answer the following research questions:

1. How is the migrant population distributed around Ireland and in the major cities?

2. To what extent are migrants residentially segregated from the Irish and UKborn population?

3. Has there been change over time in the level of residential segregation?

4. How can the areas in which immigrants are concentrated be characterised in terms of deprivation/affluence and the housing stock?

The report uses geocoded data for 3,409 Electoral Divisions (EDs) in Ireland from the 2011 and 2016 Censuses. Four broad groups are considered in the analysis; the size of each group as a proportion of the population in 2016 is reported in brackets:

- total migrant population - excluding UK-born (11.4\%)

- EU migrants - excluding UK-born (6.3\%)

- migrants born outside of the EU (5.1\%)

- people with poor self-rated English-language proficiency (1.8\%).

We identify migrants on the basis of country of birth rather than stated nationality in order to include the significant group of migrants who have become Irish citizens. The UK group are excluded because of their distinctive history of migration and because of the significant element of cross-border migration from Northern Ireland. Previous research has also shown that the experience of people from the UK living in Ireland differs from that of other EU nationals (e.g. Barrett et al., 2006; McGinnity et al., 2018a). We look separately at those with poor English-language proficiency because this has been shown to be a crucial factor in migrant integration. Residential clustering of individuals with poor language skills may have implications for service provision. 


\section{KEY FINDINGS}

\section{Segregation and diversity}

We find that the migrant population is highly centralised in urban areas, in particular in the city centres of Dublin, Limerick and Cork, and in the suburbs of West and North Dublin. This is true of both EU and non-EU migrants; however, in a cross-national perspective these groups register relatively low scores on the index of dissimilarity, a standard metric for measuring residential segregation.

The dissimilarity index $(D)$ measures the proportion of individuals in the minority group that would have to move in order to be evenly distributed across Electoral Districts. In 2016, the score was 35 for EU migrants and 34 for non-EU migrants; for all migrants it was 33. The $D$ score is lower than the state average in Dublin and Cork, and is higher than average in Limerick.

By contrast, people with poor English-language proficiency, who account for 1.8 per cent of the population, are less centralised in these three cities. They appear in high concentrations in towns such as Monaghan, Ballyhaunis, New Ross and Roscommon. However, they score more highly on the dissimilarity index (37) than the groups defined by country of birth.

Similar results are found on an alternative measure of segregation, the isolation index, which is the extent to which people share their neighbourhood with fellow members of the minority group. People with poor English-language proficiency register high values on the isolation index. For instance, those with poor Englishlanguage skills living in Limerick typically live in an area in which 8 per cent of the population cannot speak English.

\section{Change over time}

Overall, levels of residential segregation remained relatively stable since the 2011 Census, but there is evidence of a small decrease among some groups. EU migrants became less concentrated between 2011 and 2016. The areas with the highest concentration of EU migrants in 2011 showed no growth in the size of the EU-born population, while the areas with fewer EU migrants in 2011 showed above-average growth. People with poor English-language proficiency also became less segregated over this period.

\section{Area characteristics}

This analysis echoes the findings of previous research which has shown that the non-Irish population tends to live in areas where private rented accommodation is plentiful. Migrants as a whole are also found to live in rather affluent areas, and in particular in districts with advantaged educational profiles.

However, this is not the case for people with poor English-language proficiency. Instead, they tend to live in areas with average affluence/deprivation and below- 
average rates of third-level educational attainment. There is evidence that within the three largest cities, this group is concentrated in EDs with high unemployment rates.

\section{AVENUES FOR FUTURE RESEARCH}

The purpose of this report is to provide a high-level overview of a set of residential outcomes for the migrant population. It does not consider individual country of birth groupings. This is partly because Ireland's foreign-born population is so diverse that it would be difficult to delimit the scope of a study of individual groups - over 200 countries of birth were recorded in the 2016 Census.

Polish migrants are the only non-UK migrant group with a population in excess of 100,000 , and future analysis could focus on these migrants because they are separately identified in the CSO's geocoded data. We might expect greater residential clustering among more tightly defined groups that share linguistic or cultural characteristics.

As the migrant community becomes more settled in Ireland, an ever greater number of second-generation migrants will be born and will record Irish nationality and country of birth. Future research could therefore consider replicating this report's analysis for more durable measures of diversity, such as ethnic/cultural background.

\section{POLICY IMPLICATIONS}

The topics covered in the report are potentially relevant to both integration and regional development policy. The Migrant Integration Strategy (Department of Justice and Equality, 2017) lists segregation as a potential future challenge, and mentions EU nationals as a particularly at-risk group. While a certain level of coresidency can be important for access to support networks for migrants, high levels of residential segregation can have negative implications for integration and access to services. Based on this analysis, there is no evidence that foreign-born groups are very highly concentrated in particular areas, and Irish cities show relatively low levels of residential segregation compared to European and American metropolitan areas.

However, there is evidence that those with poor English skills are by some measures 'at risk' of becoming segregated. They are distributed quite unevenly across the country and their residential concentration is (weakly) associated with some measures of socio-economic disadvantage. We also acknowledge that while the broad groups we have considered do not show signs of residential segregation, individual nationalities or ethnic groups may be more concentrated in particular areas. This is a topic that deserves future research. 
The report also concludes that the migrant population is highly concentrated in urban areas and neighbourhoods where there is a plentiful supply of private rented accommodation. Previous research in this area has suggested that achieving a more balanced regional development of employment opportunities and housing would be an effective way of dispersing the immigrant population (Morgenroth, 2018).

This concentration in areas with high private rented accommodation is likely driven by low levels of home ownership among migrants themselves (see McGinnity et al., 2018a). Given the current dysfunctional state of Ireland's private rented sector, with steeply rising rents and high levels of homelessness, migrant concentration in this type of tenure is problematic from an integration perspective. Resolving issues around supply, affordability and security of tenure would automatically improve the situation of the migrant community in the housing market.

Finally, part of the report's contribution to our understanding of the residential distribution of migrants in Ireland is that it identifies areas of migrant concentration with the most recently collected nationwide data. This information could be used by policymakers to target service provision to migrant communities. 


\section{Introduction, previous literature and background}

\subsection{INTRODUCTION}

Diverse, healthy residential environments are critical to sustaining effective migrant integration policies. Living alongside natives helps immigrants to participate fully in the social life of a country, and reduces the possibility that ethnic groups will become ghettoised in impoverished communities. Iceland et al. (2014, p. 2) report that researchers in this area generally perceive segregation to be 'the antithesis of successful immigrant integration'. And while living close to migrant communities can be a source of social support, diverse neighbourhoods can enhance opportunities for social contact between immigrants and the host population, something that both Irish and international research has shown to be associated with more positive attitudes to diversity (McGinnity et al., 2018c; Pettigrew and Tropp, 2011).

In this report, we use geocoded data from the 2016 and 2011 Irish Censuses to investigate to what extent the migrant population is concentrated in certain residential areas, and evaluate the socio-economic and housing characteristics of the neighbourhoods in which they are most over-represented. In addition, we disaggregate the foreign-born population into those born inside and outside the European Union. We also study residential patterns among people with poor English-language proficiency.

The report is divided into four sections. This chapter is dedicated to framing the analysis with a broad discussion of migration and diversity in Ireland. We also provide an overview of the literature on the causes of residential segregation among various groups and across different contexts. In Chapter 2 we produce a series of maps and descriptive statistics to show where we find the greatest concentrations of the various groups across the country. In addition to nationwide analysis, we pay particular attention to the urban areas of Dublin, Limerick and Cork, where around half of all migrants live. In Chapter 3 we shift focus to formal measures of segregation, including the dissimilarity and isolation indices, and study change over time in the residential concentration of immigrants. Both indices compare the distribution of immigrants to the distribution of the Irish-born population. In Chapter 4 we study the associations between area-level housing and socio-demographic factors on one hand, and migrant group size on the other. We do this by running multivariate models at the Electoral Division (ED) level. Chapter 5 concludes the report with a summary of findings and some reflection on further research and policy implications. 


\subsection{MIGRATION IN IRELAND}

Although Ireland has historically been a country characterised by net emigration with a very small immigrant population, the economic boom known as the 'Celtic Tiger' and the eastward expansion of the European Union in 2004 helped to bring about much greater diversity in the population. Throughout the 20th century emigration far exceeded immigration.

Focusing on the past 30 years, Figure 1.1 shows that in the recession of the late 1980s, between 40,000 and 70,000 people were leaving Ireland every year, while annual inward migration numbered less than 20,000. During the 1990s, levels of emigration stabilised and immigration increased slowly, so that by 1996 net migration became positive, and it continued to increase during the economic boom (from the mid-1990s to 2007).

A second major shift occurred in 2004, when ten new Member States joined the EU and were granted rights to free movement within the Union. EU membership was further expanded when Bulgaria and Romania joined in 2007 and Croatia in 2013. Between 2004 and 2007, over 300,000 people entered the country.

Immigration fell sharply during the Great Recession (2008-2011), and Ireland returned briefly to net outward migration, but this situation was reversed by 2015 . Because substantial inward migration has been largely confined to the 21st century, the population of second-generation immigrants remains relatively small and Ireland lacks substantial, long-established ethnic minority/immigrant populations. One exception to this historical homogeneity is the longer tradition of movement across the border from Northern Ireland and from elsewhere in the UK; another is Irish Travellers, a small Irish-born ethnic minority community. 


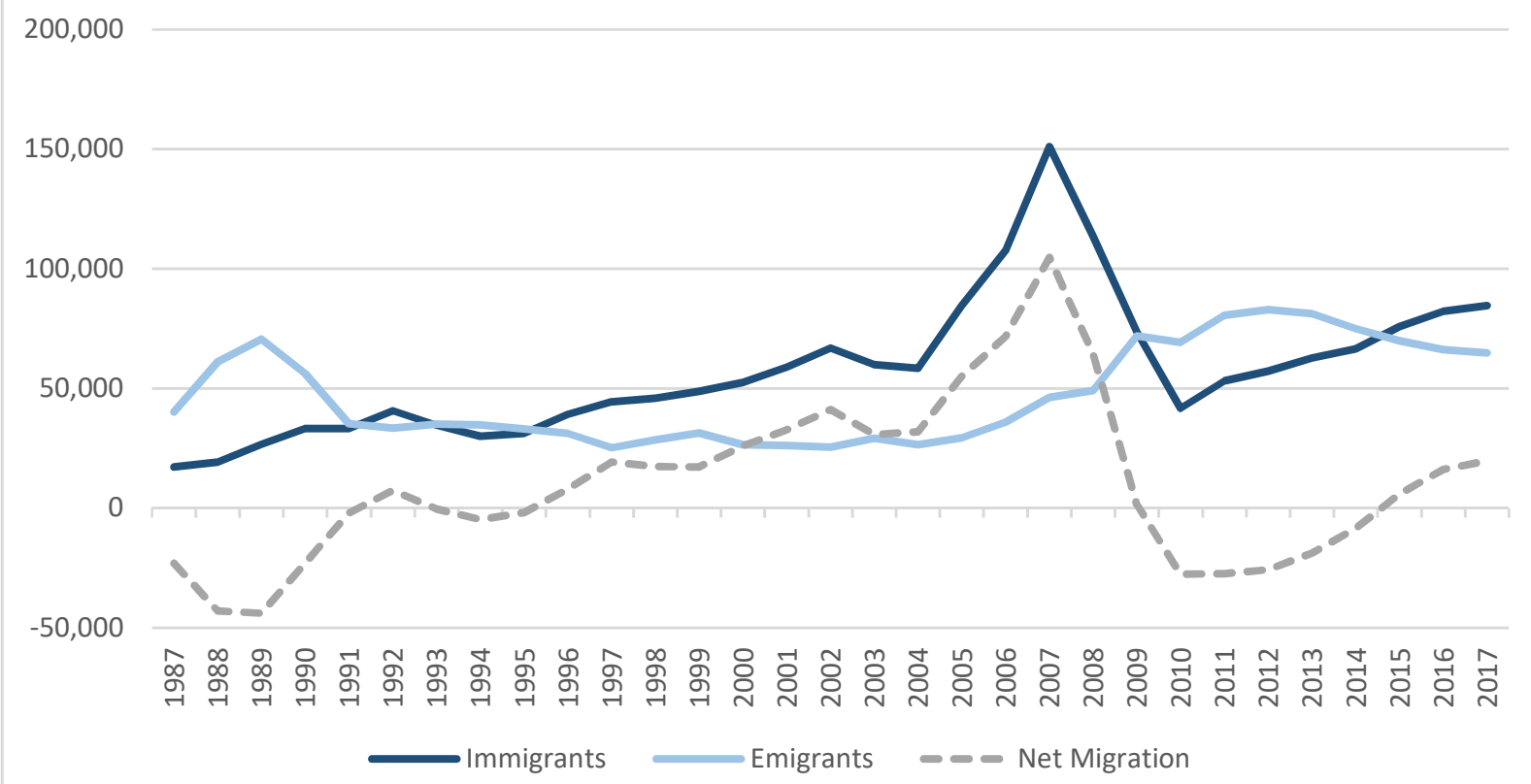

Source: CSO, Population and Migration Estimates (CSO, 2018).

Note: $\quad$ Year to April of reference year.

While Figure 1.1 shows the flow of migrants, it tells us relatively little about the stock, i.e. the number and characteristics of migrants living in Ireland at any given time. We present the number and region of birth (EU/non-EU) of those born outside Ireland in Table 1.1. The figures relate to Census data on country of birth rather than nationality, as this is the classification we use in the analysis of segregation (see below).

The patterns of immigration since the early 2000s have resulted in a significant rise in the proportion of the population born abroad. Recent data show that 17 per cent of the population resident in Ireland is foreign-born, a figure that is surpassed by only a handful of EU countries (McGinnity et al., 2018a). ${ }^{1}$

\subsubsection{Study groups}

The objective of this study is to report on the residential patterns of four broad migrant groups, defined as follows:

- all migrants (born outside of Ireland and the UK)

\footnotetext{
${ }^{1}$ This figure falls to 11.4 per cent foreign-born when those born in the UK are excluded (see Table 1.1). 7 per cent of the foreign-born population were born in Northern Ireland. Over 90 per cent of this group selfidentified as Irish nationals in the 2016 Census.
} 
- migrants born in the EU but outside of Ireland and the UK²

- non-EU migrants

- People with poor language skills, i.e. people who report being able to speak English not well or not at all.

We do not study individual country of birth groups, though we recognise that their residential patterns may differ from what we find for these more broadly defined categories of migrants. This decision is partly due to data constraints - only UK-, Polish- and Lithuanian-born migrants are identified separately in the Small Area Population Statistics (SAPS) data. More importantly, however, research on residential segregation among migrants in Ireland is underdeveloped, so we view this analysis as an early step in contextualising further study on individual country groups.

In addition, the migrant population in Ireland is extremely diverse, with over 200 countries of origin in 2016. Therefore, with the possible exception of UK- or Polishborn migrants, it is not clear which individual groups should be focused on. Preliminary analysis for those born in the UK is presented in an online appendix (available at: www.esri.ie/system/files/publications/BKMNEXT376_Appendix.pdf), and ongoing research is investigating Polish migrants (see also Gilmartin and Mills, 2008).

\begin{tabular}{|c|c|c|c|c|c|c|}
\hline & \multicolumn{2}{|c|}{2006} & \multicolumn{2}{|c|}{2011} & \multicolumn{2}{|c|}{2016} \\
\hline & $N$ & $\%$ & $N$ & $\%$ & $N$ & $\%$ \\
\hline Total population & $4,172,013$ & 100 & $4,525,281$ & 100 & $4,689,921$ & 100 \\
\hline Migrants (exc. UK) & 340,848 & 8.2 & 478,143 & 10.6 & 533,200 & 11.4 \\
\hline EU migrants (exc. UK) & 166,708 & 4.0 & 267,947 & 5.9 & 293,787 & 6.3 \\
\hline Non-EU migrants & 174,140 & 4.2 & 210,196 & 4.6 & 239,413 & 5.1 \\
\hline Poor English & - & - & 89,561 & 2.0 & 86,608 & 1.8 \\
\hline
\end{tabular}

Source: CSO Statbank tables E7050 and C0428. https://www.cso.ie/px/pxeirestat/statire/SelectTable/Omrade0.asp

We adopt country of birth rather than nationality to include those who have been naturalised. One of the success stories of migrant integration in Ireland has been the significant number of those born outside the state that have become Irish citizens in the past decade. Barrett et al. (2017) report that between 2005 and $2015,121,100$ non-Irish nationals acquired Irish citizenship through naturalisation. Naturalised citizens could represent as much as 45 per cent of the population of

2 We henceforth label this group 'EU migrants'. 
non-EEA origin resident at the end of 2017 (McGinnity et al., 2018a). Therefore the inclusion of this group is of substantial interest. ${ }^{3}$

Following Fahey and Fanning (2010), we first look at the total foreign-born population, but exclude the UK group because of the unique history of migration between Ireland and the UK, and because of cross-border migration with Northern Ireland. Previous research (e.g. Barrett et al., 2006) has also shown that the experience of people from the UK living in Ireland differs from that of other EU nationals. In 2016, 277,000 individuals born in the UK were living in Ireland and over 20 per cent of these were born in Northern Ireland.

Our focus is on migrants, as measured by 'country of birth', rather than minority ethnic groups. This is partly because we are interested in the question of migrant integration and the research is situated in a broader investigation of this topic. Furthermore, Ireland's experience of longstanding ethnic diversity is limited to the Traveller community. Because most Irish migrants are White, non-White ethnic minority groups make up a small proportion of the population. For example, in the 2016 Census only 1.4 per cent of the population were classified as Black and 2.1 per cent as Asian. ${ }^{4}$ That said, ethnic segregation in Ireland would be an interesting topic for future research.

The European Economic Area (EEA) is the EU plus Norway, Iceland and Liechtenstein. The proportion of EU/EEA residents who have become Irish citizens is smaller but has risen rapidly in recent years (McGinnity et al., 2018a). 


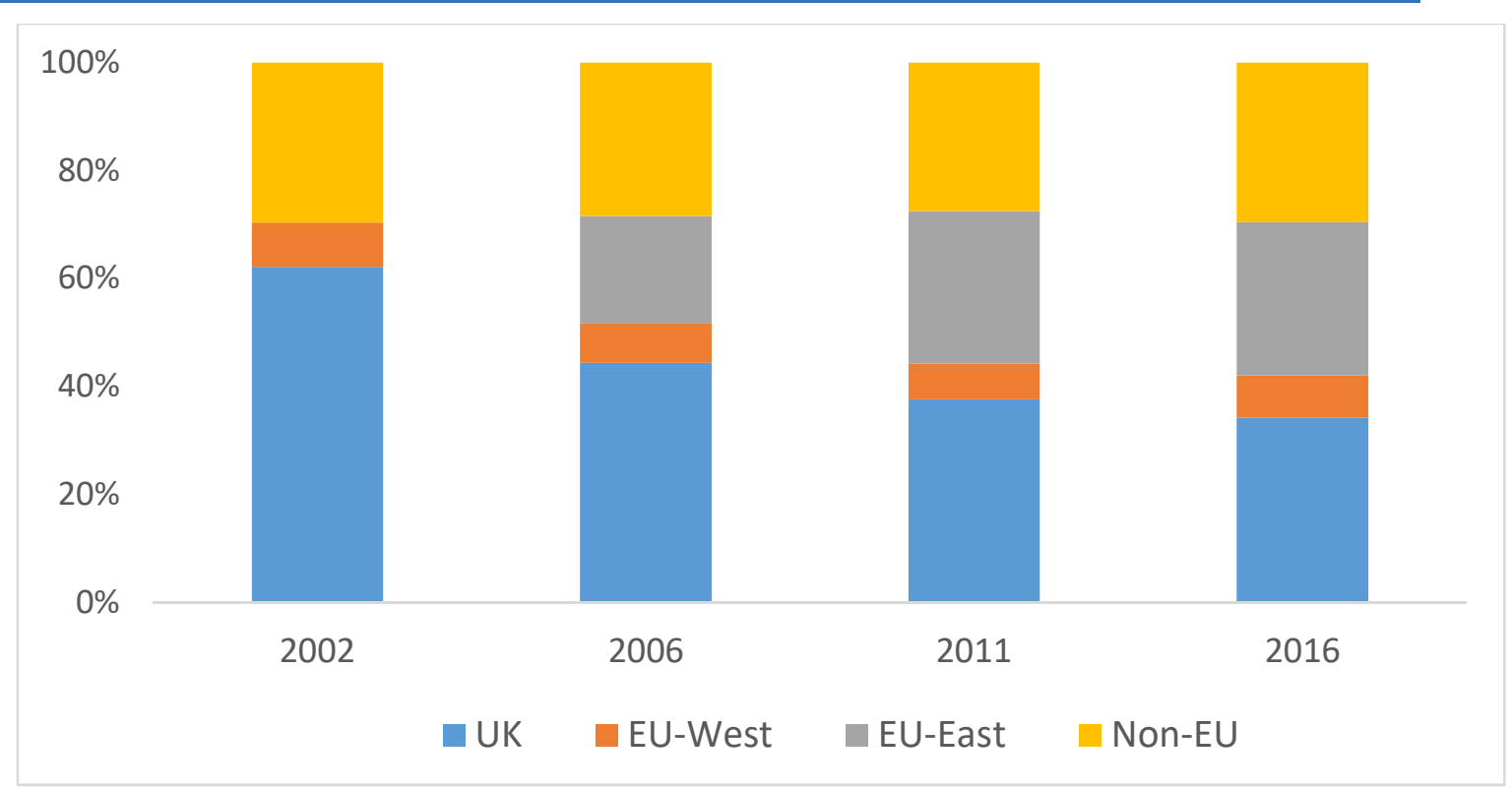

Source: Census of Population. CSO Statbank tables E7050 and C0428.

Note: $\quad$ EU-West is the original EU-15 countries less Ireland and the UK. EU-East refers to the new Member States which acceded in 2004, 2007 and 2013.

Among migrants, we distinguish between residents born inside and outside of the EU. ${ }^{5}$ We divide the population in this way because of the different rights of those from within the EU. These include freedom of movement, the right to work, and entitlements to service and welfare supports on an equal footing with national citizens. The total size of the groups is shown in Table 1.1.

EU migrants consist of those from the original EU Member States, who account for 22 per cent of the group, and those from the newer Member States in the east and south-east of Europe, who account for 78 per cent. Indeed, Figure 1.2 demonstrates the rapid expansion in the relative size of the EU-born group after the 2004 enlargement of the EU. The 2016 Census enumerated just under 294,000 non-UK EU migrants. The biggest groups within this category were Polish$(115,161)$, Lithuanian- $(33,344)$, Romanian- $(28,702)$, Latvian- $(18,991)$ and German-born $(12,964)$. There were also relatively large numbers of French- and Spanish-born residents.

Previous research has shown that EU migrants from the new Member States in Eastern Europe have high employment rates, a lower proportion with third-level qualifications than other non-Irish groups, and lower incomes but similar poverty rates to Irish nationals (McGinnity et al., 2018a). ${ }^{6}$ Migrants from Western Europe

UK migrants are excluded from the EU-born category.

Note that McGinnity et al. (2018a) distinguish Irish and non-Irish nationals, which is also somewhat different from those born abroad and resident in Ireland as used in this report. 
have high employment rates, educational attainment and incomes and very low income poverty/deprivation rates.

The non-EU category of migrants covers a diverse range of countries. The largest non-EU sub-groups in the 2016 Census were people born in the USA $(28,650)$, followed by Indian- $(20,969)$, Nigerian- $(16,569)$ and Brazilian-born $(15,769)$ residents. Previous research has found that non-EU nationals tend to have employment rates similar to Irish nationals, though this varies within the group; a high proportion have third-level qualifications but they also have higher poverty and deprivation rates (McGinnity et al., 2018a).

Finally, we consider people with poor English-language proficiency. Host-country language skills have been shown to be a crucial factor in migrant integration in Ireland (Barrett and McCarthy, 2007) and elsewhere (e.g. Hayfron, 2001). The Census measure of language proficiency is based on self-reports (see Chapter 2 for details on measurement). The residential clustering of individuals with poor language skills has implications for the provision of public services and may have consequences for language skill formation in areas of very high concentration (Beckhusen et al., 2013).

The share of people with poor English-language proficiency fell slightly in 2016 relative to 2011, despite an overall increase in the foreign-born population (see Table 1.1). This may be because of changes in the composition of the immigrant population, or it could be due to ever more foreign-born residents learning English. Information from the 2016 Census on self-assessed language skills indicates that 83 per cent of the 612,000 people who spoke another language at home stated that they could speak English 'well' or 'very well', while 14 per cent stated 'not well' or 'not at all'. Afghans are the nationality with the lowest English-language proficiency, with only 53 per cent speaking English well or very well. They are followed by Chinese (69 per cent), Lithuanian (76 per cent) and Latvian (77 per cent) nationals. The foreign-language speaking groups with the best English include West-European nationals from Sweden, Germany, the Netherlands and France, as well as Indian, Nigerian and Filipino migrants. ${ }^{7}$ This highlights that both EU and non-EU migrants have varied English-language ability.

Of those with poor English-language skills, the largest groupings are Polish (24.6 per cent), Lithuanian (8.5 per cent) and Latvian (4.3 per cent). ${ }^{8}$ 


\subsection{THEORY AND PREVIOUS RESEARCH}

Residential segregation on the basis of minority status such as poverty, unemployment, race, ethnicity or nationality is common across the Western world. However, some cities and groups are much more affected than others, and no single theory can explain this variation. The literature on residential segregation does not lend itself to a comprehensive theoretical review. Here we present our own brief interpretation of plausible explanations, focusing on three sets of arguments: path dependence, rational choice and housing discrimination.

\subsubsection{Path dependence}

Path dependence in the context of residential segregation is the notion that historical economic and social processes have influenced past residential patterns, and this has a strong influence on current settlement patterns. Many US studies on residential segregation focus on race and invoke theories of path dependence. These arguments cannot be easily applied in an Irish context because the American experience of diversity is so radically different to what we have in Ireland.

The American literature highlights processes such as the northward migration of black agricultural workers during the period of industrialisation in the early 20th century (Tolnay, 2003), and the selective migration of White urban residents to the suburbs during the 1940s, termed 'White flight' (Cutler et al., 1999; Frey, 1979). These processes, found in the major metropolitan areas of the United States, mean that American cities are generally more segregated than European cities. However, it has been shown that when the segregation of immigrants is considered independently of racial segregation, American and European cities are much more similar (Musterd, 2005). That said, the only available comparison between Ireland and the US is Vang's (2012) analysis of segregation among African-born immigrants, which shows that Africans in Dublin are generally more successful in integrating with the native population than their counterparts in Boston.

Historical arguments are useful in explaining persistent residential segregation in Northern Ireland, because the Northern Irish religious/ethnic divide has existed there for a period of similar duration to the racial divide in the United States. Doherty and Poole (1997) show that segregation was evident in the very first Census in 1871, and that it has persisted ever since. They also show that periods of inter-group violence (such as the War of Independence and the Troubles) have caused each group to retreat into its historical ethnic heartland.

\subsubsection{Rationalist explanations}

\section{Social network theory and ethnic attraction}

The population of the Republic of Ireland has until relatively recently been very 
homogenous in terms of ethnicity and country of origin. This means that an alternative to path dependence is required in order to form hypotheses on residential segregation. An intuitive explanation views spatial segregation as the result of rational actions on the part of immigrants.

Social network theory, originating in the 1970s but formalised by Massey (1990), argues that migration is a cumulative process. The first migrants to arrive face high costs and high risks. They may lack proficiency in the host country's language, be unfamiliar with the culture, have limited access to housing and the labour market, and be disproportionately subject to discrimination. However, each subsequent migrant moving to the host country faces diminishing costs and risks, thanks to the presence of the first movers. Having a community of migrants to slot into may provide opportunities for jobs and housing, and may increase newcomers' sense of belonging, particularly if they lack proficiency in the local language. Such communities might be seen as 'easy' sources of local know-how or of specialised goods and services (Piekut et al., 2019).

Social network theory has been extended to the field of residential segregation, where it is hypothesised that new migrants will be incentivised to settle in neighbourhoods that are geographically proximate to people of the same national background. This will be particularly prevalent if the immigrant network gives direct assistance in the search process in the housing market. Andersen, in his 2017 study of Danish neighbourhoods, labels this process 'ethnic attraction' and finds that it contributes significantly to the segregation of the non-Danish population.

Note, however, that the strength of the ethnic attraction hypothesis depends on the ethnic and cultural ties between the newcomers and the existing social network. For instance, a Nigerian migrant is unlikely to benefit from the presence of a large Polish community in the host country. Even if the newcomer is from the same country as the social network, ethnic attraction would not occur if they were from different ethnic groups within that country. In fact, we may expect the newcomer to avoid their co-nationals if there is animosity between them. An example of this kind of pattern of migration in Ireland might be ethnically Russian Latvian immigrants, who experience severe discrimination in Latvia (Best, 2013).

Alternatively, a common language between the newcomer and the network might be more important in sustaining the ethnic attraction hypothesis. Chiswick and Miller (2004) find that language has an impact on the geographic concentration of immigrants in the United States - newly arriving immigrants who speak a language other than English take up residence in more ethnically concentrated areas than their counterparts who only speak English in the home. This effect could also be moderated by the ability of the newcomer to speak the host country's language. 
International research suggests that immigrants who do not speak the local language would be most reliant on home-country social networks, and would be least likely to integrate successfully (Chiswick and Miller, 2004; Beckhusen et al., 2013). Again, this expectation is based on the assumption that the immigrants that cluster together come from the same country, or at least from a group of countries that speak the same language. In the case where non-native language speakers are diverse, and speak many different languages, there may be less of an incentive to self-segregate and live in immigrant communities.

\section{Employment and housing}

A separate rationalist argument is that immigrants' place of residence may be determined by the availability of local jobs, public services and, above all, housing. This is the dominant finding in the previous literature on residential segregation in Ireland. Fahey and Fanning (2010) and Vang (2010) have shown that the availability of private rented accommodation is the main driver of the residential segregation of the non-Irish community. Vang's (2010) analysis showed that this effect holds for African, Asian and Eastern-European migrant groups alike. Both papers, which use geocoded Census data, demonstrate that this results in a disproportionate concentration of immigrants in Dublin's western suburbs, in particular around Blanchardstown and Ongar, and, to a lesser extent, in Dublin's city centre.

The concentration of migrants in private rented accommodation is linked to low home ownership among the group, in a context of high rates of home ownership in Ireland. McGinnity et al. (2018a) discuss some of the reasons for this. These include difficulties for migrant mortgage applicants in demonstrating credit and employment history, the temporary nature of some migrants' stay, preferences regarding home ownership, their residence permission, and overall affordability constraints.

O'Boyle and Fanning (2009) focus on Dublin's city centre and the suburbs of Blanchardstown and Ongar, and compare the size of their respective non-Irish populations to their scores on the Haase-Pratschke deprivation index. They find a weak tendency for migrants to concentrate in disadvantaged wards within these areas, but concede that the picture is far from clear.

Morgenroth's (2018) study of the regional economies of Ireland finds a discrepancy between the geographical flow of new migrants to Ireland and their overall stock across the country. While immigrants are likely to 'touch-down' in Dublin or in other major urban centres, they are highly mobile, and many end up living in more rural areas. Morgenroth also shows that there is an ethnic divide in the urban-rural distribution of the minority population. Almost half of people who reported Black 
or Asian ethnicity in the Census lived in Dublin, compared to just a third of nonIrish White people.

\subsubsection{Discrimination}

A seminal theory on housing segregation, initially put forward to explain the persistence of Black ghettos in the United States, is that segregation is a function of the preferences of the majority group (Becker, 1957). It was hypothesised that White residents in American cities had a 'taste' for living near co-ethnics, and for sectioning off black communities in distant, disadvantaged neighbourhoods.

Cutler et al. (1999) consider two mechanisms by which the White community could achieve this. First, they could act collectively to segregate Blacks, a phenomenon that Cutler et al. label 'centralised racism'. This would often be done through legal or legislative channels. Seitles (1998) cites exclusionary zoning and institutionalised racism in the distribution of publicly provided mortgages as major causes perpetuating racial segregation in American housing. A less common but perhaps more disturbing form of centralised racism is the use of organised violence and intimidation against the minority community. Second, Cutler et al. (1999) consider 'decentralised racism' whereby Whites would act on their preferences for ethnically homogenous neighbourhoods at the individual level, by paying a premium for properties in all-White neighbourhoods.

The question of whether there is an empirical association between housing discrimination and residential segregation has not yet been studied in Ireland. However, Grotti et al. (2018) consider the interplay between nationality, ethnicity, discrimination in the housing market and neighbourhood conditions. People identifying as Black or Asian are considerably more likely to report experiencing housing discrimination, but no significant effect is found for White immigrants. ${ }^{9}$ No significant relationships emerge between nationality and neighbourhood deprivation. However, the broad groupings of ethnicity and nationality used in the analysis may conceal more negative outcomes for some smaller groups. A number of studies have highlighted instances of housing discrimination faced by refugees leaving Direct Provision centres (Gouveia, 2013; Ní Raghallaigh et al., 2016).

Discrimination on the basis of race, nationality or ethnicity in accessing housing is outlawed in Ireland under the Equal Status Acts (2000-2015). According to the 2017 Annual Report of the Irish Human Rights and Equality Commission (IHREC), who are responsible for handling queries in this area, 17 per cent of all queries

It should be noted that those looking for accommodation do not always know whether or not they have been discriminated against, which is an issue for all self-reported data. Experimental studies reveal a high level of housing discrimination against ethnic and nationality minority groups in Europe and the US (Rich, 2014). 
relating to this legislation concerned the protected ground of race, ethnicity and nationality (Irish Human Rights and Equality Commission, 2018).

\subsection{POLICY CONTEXT}

While the location of the migrant population is not centrally planned, local and national government policy influences the location decisions of individuals and households. Regional and urban planning policy impacts where new housing is built, while industrial/business policies can influence where new jobs are located. Social and economic policies affect the type of housing supplied (private rental, owner-occupied, social housing) and determine the rules of access to social housing.

\subsubsection{Regional policy}

The recent regional development strategy, the National Planning Framework: Project Ireland 2040, ${ }^{10}$ notes that there has been an over-concentration of growth in the population, jobs and homes in Dublin. It forecasts that there will be an extra one million people in Ireland by 2040 and aims for 75 per cent of that population growth to be outside Dublin, and for half to be outside the cities of Dublin, Cork, Limerick, Galway and Waterford. Since a significant part of the population growth is predicted to come from net migration, achieving these goals will depend on attracting migrants to live outside of Dublin and these urban centres.

Morgenroth (2018) notes that above all else, migrants take up residence in large urban areas where they can find employment. This is particularly the case for those with higher skills, and for migrant couples because the chances of finding two skilled jobs elsewhere is slim. In highlighting the residential mobility of immigrants in Ireland, Morgenroth concludes that there is 'scope to attract international migrants to areas other than Dublin provided there are employment opportunities in these areas, that they provide the right amenities and that the appropriate information is available to migrants to make an informed decision about their residential location' (2018, p. 43). The study also points to the need for further research on spatial patterns of immigration in Ireland.

Policy in relation to refugees and asylum seekers can also influence the concentration of residents of non-EU origin in particular communities, though their overall influence will be modest because of the relatively small size of this group. Refugees who have come to Ireland through the Irish Refugee Resettlement Programme have been located in 29 towns around the country as well as four Dublin local authority areas (Arnold and Quinn, 2016). Direct Provision centres for 
asylum seekers are also located around the country, leading to pockets of diversity in areas that are otherwise more homogenous in terms of nationality and ethnicity. According to a monthly statistics report published by the Reception and Integration Agency (RIA) in April 2016 (the time point at which our data were collected), there were 35 accommodation centres spread around the country, the largest of which was in Mosney, Co. Meath, with an occupancy of 361 people (Reception and Integration Agency, 2016). It is not clear whether refugees who have been granted protection status tend to stay in the area of their centre or move away, for either employment or housing, given that they may face difficulties in securing either (Gouveia, 2013; Ní Raghallaigh et al. 2016).

\subsubsection{Housing policy}

Access to social housing is restricted for both EU and non-EU migrants because of residency and employment eligibility criteria. EEA nationals from outside the UK can only apply for social housing if they are in employment, are registered as unemployed having previously been in employment for at least a year, or are out of work on account of a temporary incapacity. Non-EEA nationals can only qualify if they satisfy this condition and residency rules, which typically require the applicant to have lived in the country for at least five years (Department of the Environment, Community and Local Government, Housing Circular 41/2012).

The migrant population in Ireland is highly over-represented in the private rented sector, and is under-represented in the owner-occupied sector and in social housing (Grotti et al., 2018). ${ }^{11}$ Over three-quarters (76 per cent) of adults from outside the EU, 54 per cent of those from the EU-13, and 86 per cent of those from the new Member States live in private rented accommodation. Therefore, policies that influence the supply (and price) of private rented accommodation are likely to impact the location decisions of the immigrants.

One symptom of the current housing crisis in Ireland is the very sharp rises in rental prices, especially in Dublin (Residential Tenancies Board, 2018). This has resulted in acute problems of housing affordability in this sector (Corrigan et al., 2018).

\subsection{DATA AND METHODOLOGY}

We use the CSO's SAPS to carry out this analysis. The data are free to download from the CSO website and can also be accessed via SAPMAP, the CSO's online interactive map. The data we use relate to the usually resident population enumerated in the Census of population on 10 April 2011 and 24 April 2016. The Irish Census captures data on all those living in Ireland, including people living in private households, student accommodation and Direct Provision centres and the

11 Based on EU SILC data for 2014 and 2015. The EU-13 figure excludes those of UK nationality. 
homeless. The migrant groups that we study refer to the 'usually resident' population by country of birth, as well as people who report having poor Englishlanguage proficiency. An important point to note is that the main text of the Census form was made available in a variety of languages including Polish, Lithuanian, Russian and Chinese, which helps to improve both the quality of the data and response rates.

The SAPS are available at various levels, including 18,641 'small areas', which typically incorporate between 80 and 120 households; 3,409 EDs; 137 Local Electoral Areas (LEAs); and the county level. We produce maps, statistics and models at the ED level. Using small-area data would have made choropleth maps more difficult to interpret, and there is a risk that the top small areas would be dominated by the migrant groups themselves. By using the much larger LEAs we would have lost a lot of detail and missed some patterns. Of the three, the EDs perhaps best capture the concept of the 'neighbourhood' in Ireland.

In any spatial analysis we need to appreciate that the areas (in this case EDs) may not correspond to the communities people live in, and one neighbourhood may span two EDs, for example. In addition, in terms of opportunities for social interaction, individuals may work, go to school, socialise and go shopping in areas other than where they live.

Over half of migrants in Ireland live in Dublin, Cork or Limerick, so the analysis also considers residential patterns in the EDs of these cities in detail, to complement the broad national picture.

Note that because the unit of analysis is the area, rather than the individual, it is not possible with this dataset to provide information about multiple individuallevel characteristics. For instance, it is not possible to report the number of nonEU migrants with third-level education. However, some individual-level nationwide cross-tabulations are available from the CSO via published reports and Statbank, its online database. All analysis was carried out using the statistical package Stata. 


\section{CHAPTER 2}

\section{Maps and descriptive statistics}

\subsection{INTRODUCTION}

This chapter aims to give an overall picture of the distribution of migrants across Ireland. As mentioned in Chapter 1, we focus most of the analysis on foreign-born groups to ensure that the data capture naturalised immigrants.

Previous research has shown that the UK-born population are different to other immigrant groups in terms of integration outcomes. This is partly because a large proportion of them were born in Northern Ireland, and over 90 per cent of this group self-identify as Irish. For that reason, and to save space, we follow Fahey and Fanning (2010) in excluding them from the analysis. Residents are therefore considered foreign-born if they were born outside of Ireland and the UK. Equivalent analysis for the UK-born group can be found in the online appendix (available at: www.esri.ie/system/files/publications/BKMNEXT376_Appendix.pdf). As can be seen, their settlement patterns are very different from other foreignborn groups.

We also consider the residential distribution of people with poor English-language proficiency. Residential concentration and segregation can be viewed as a poor integration outcome, and we might expect people who can't speak English to find it harder to integrate. There is also reason to believe that poor proficiency in the language of the host country could be a direct cause of segregation (Chiswick and Miller, 2004).

The chapter makes two broad contributions. One is that it contains maps showing the residential distribution of four minority groups identified in Chapter 1 :

- all foreign-born (born outside Ireland and the UK)

- EU-born migrants (excluding UK and Ireland)

- non-EU-born migrants

- people who report not being able to speak English well or not being able to speak it at all.

The maps are constructed using geocoded data from the 2016 Census. The unit of analysis is the Electoral Division (ED). There are 3,440 EDs in the country, but 32 are merged by the CSO for confidentiality reasons, resulting in a dataset with 3,409 observations (see Table 2.1). The average ED has 1,376 residents, but this ranges 
from 66 in Dunmoylan West in Limerick to 38,696 in Blanchardstown-Blakestown in West Dublin. Only five EDs have populations in excess of 20,000 and just 47 have populations over 10,000 . In each case, we present the distribution of the groups as percentages of the total population.

The other contribution of this chapter is that it provides basic summary statistics on these distributions. For each group, we report how many EDs register a value of zero. We also show the minimum number of EDs that are required to account for 50 per cent of each group's total population. These basic statistics give an indication of the degree to which the groups are concentrated in small geographical areas. In Chapter 3 we use more complex, formal measures of segregation.

\subsection{THE DISTRIBUTION OF MINORITY GROUPS IN IRELAND}

The following maps were produced using the 'spmap' command in the statistical package Stata. The colours in the legend refer to quintiles. This means that the lightest shade on the map indicates EDs that fall in the first fifth of the variable of interest, the next lightest shade is in the next fifth, and so on.

For example, the lightest shade on the foreign-born map (Figure 2.1) indicates that the ED in question is among the fifth of the 3,409 EDs with the smallest share of the population born outside of Ireland or the UK. Less than 2 per cent of the population of each of these EDs is foreign-born.

\subsubsection{Migrants (born outside Ireland and the UK)}

We first turn our attention to all Census respondents that were born outside of Ireland and the UK. These people numbered 533,200 at the time of the 2016 Census.

Figure 2.1 shows that the foreign-born population in Ireland is largely concentrated in Dublin city and its commuter belt. There are also higher than average values around the cities of Cork, Limerick and Galway. In rural Ireland, the highest concentrations are around coastal Connacht and Munster. The midlands, central Munster and Donegal have relatively low concentrations. There are 36 EDs with no foreign-born residents, and a further 45 divisions with only one foreign-born resident. 


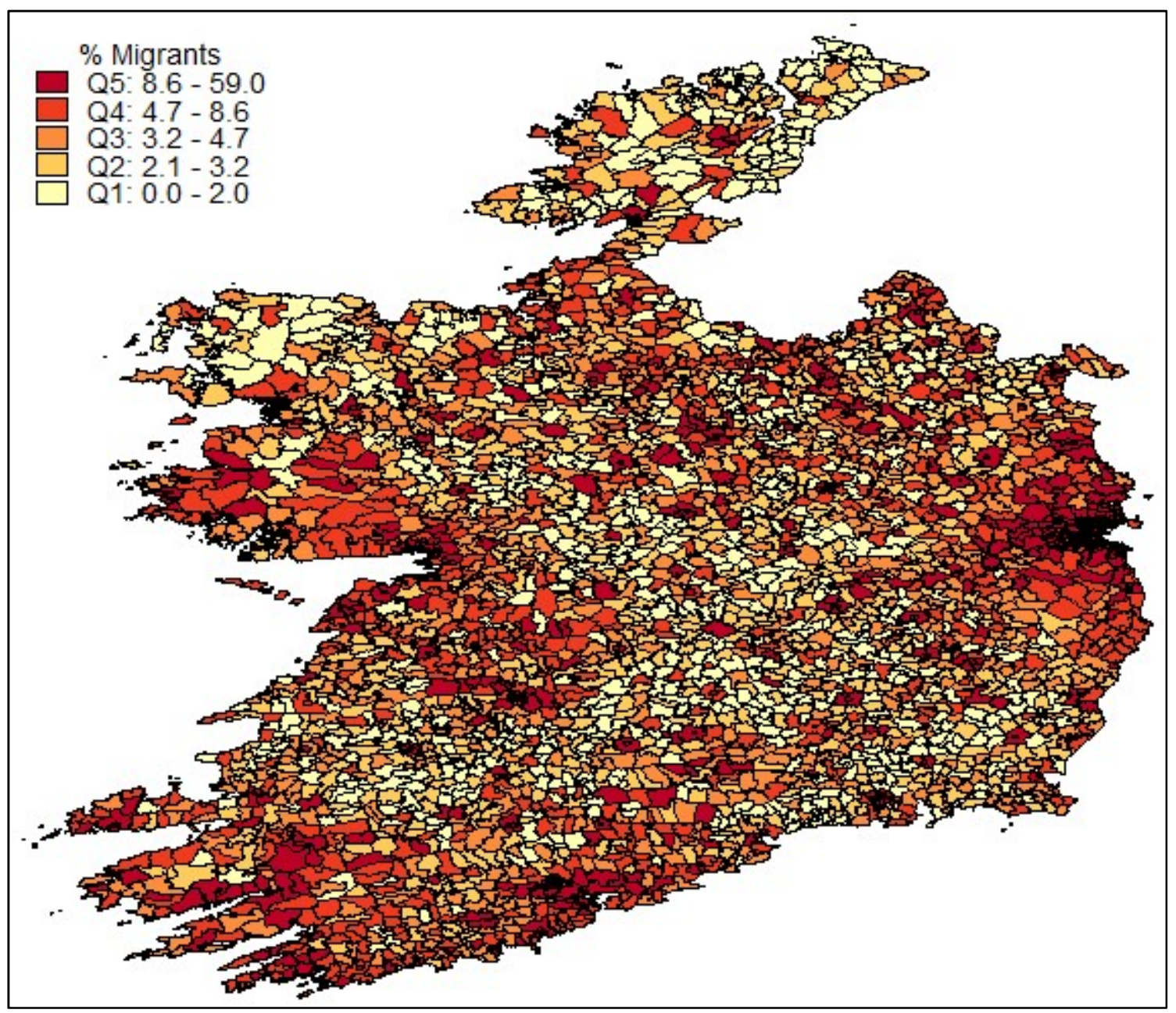

Source: $\quad$ Authors' own analysis, CSO Small Area Population Statistics, Census 2016.

Table 2.1 presents information on the ten EDs with the largest share of the population that is foreign-born. The highest share is in Mountjoy B (the area surrounding Mountjoy Square in Dublin), which is nearly 60 per cent foreign-born. Mountjoy is a relatively large ED, with almost 4,000 residents in total compared to an average of 1,376 . This means that in addition to having the largest share of foreign-born residents, it is among the EDs with the largest absolute numbers of foreign-born residents (ranked 31st). As we might expect from looking at the map above, all ten EDs fall in the four urban areas of Dublin, Waterford, Limerick and Cork. 


\begin{tabular}{|l|l|r|r|}
\hline Electoral Division & County & Non-Irish/UK-born (\%) & Number non-Irish/UK-born \\
\hline Mountjoy B & Dublin & 59.0 & 2299 \\
\hline North City & Dublin & 51.5 & 2480 \\
\hline Dock A & Limerick & 51.1 & 1155 \\
\hline Custom House B & Waterford & 50.2 & 134 \\
\hline Shannon A & Limerick & 49.8 & 441 \\
\hline Shandon A & Cork & 48.1 & 833 \\
\hline Rotunda B & Dublin & 47.7 & 1058 \\
\hline Centre B & Cork & 47.4 & 969 \\
\hline South Gate A & Cork & 47.0 & 974 \\
\hline Market & Limerick & 46.6 & 943 \\
\hline
\end{tabular}

Source: $\quad$ Authors' own analysis, CSO Small Area Population Statistics, Census 2016.

Further analysis shows that the non-Irish population is highly clustered into a relatively small number of EDs. For instance, half of the foreign-born population is concentrated in just 159 of the 3,409 EDs.

\subsubsection{Migrants born in the EU}

We now turn our attention to people born in EU countries other than Ireland and the UK. This is a diverse group, comprising migrants of various ethnic backgrounds and skill levels. As noted in Chapter 1, in the 2016 Census, Poland was by far the most significant country of origin among non-Irish/UK EU-born residents, accounting for almost 40 per cent of the total. A further 27.5 per cent were from the Eastern European nations of Lithuania, Romania and Latvia. Germany, France and Spain were the largest West-European contributors to this group.

Previous research has shown that for the most part, EU migrants tend to integrate more readily than non-EU migrants, perhaps in part because of the legal rights afforded to them (McGinnity et al., 2018a). 


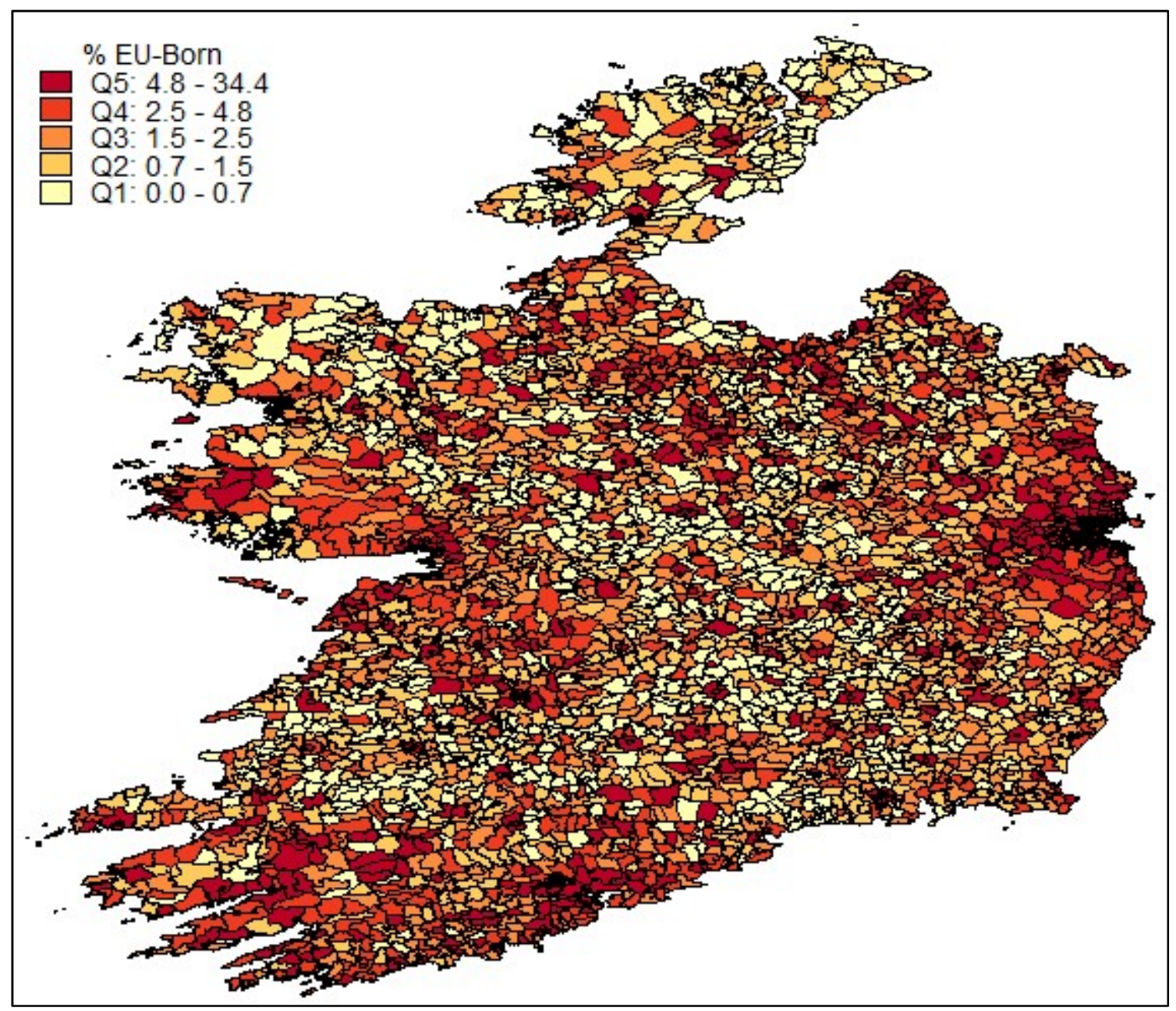

Source: $\quad$ Authors' own analysis, CSO Small Area Population Statistics, Census 2016.

Figure 2.2 shows relatively low concentrations of EU migrants in the midlands, Northern Connacht and Donegal. As with the first map, higher concentrations are visible in Dublin and the surrounding commuter belt, as well as Cork and, to a lesser extent, Limerick city. There are 196 EDs with zero EU migrants and half of this group are situated in just 152 EDs. 


\begin{tabular}{|l|l|r|r|}
\hline Electoral Division & County & EU-born (\%) & Number EU-born \\
\hline Shandon A & Cork & 34.4 & 595 \\
\hline Monaghan Urban & Monaghan & 33.5 & 781 \\
\hline Rosbercon Urban & Wexford & 32.3 & 206 \\
\hline Centre A & Cork & 29.9 & 198 \\
\hline Shandon B & Cork & 28.9 & 359 \\
\hline Centre B & Cork & 28.9 & 591 \\
\hline South Gate A & Cork & 28.0 & 581 \\
\hline St. Patrick's A & Cork & 26.8 & 371 \\
\hline Custom House & Limerick & 26.3 & 188 \\
\hline Mountjoy B & Dublin & 25.3 & 986 \\
\hline
\end{tabular}

Source: $\quad$ Authors' own analysis, CSO Small Area Population Statistics, Census 2016.

The analysis of the top ten areas with EU-born residents (Table 2.2) shows that six are centred on the banks of the river Lee in Cork city. At first sight, it would appear that concentration of this group in Cork is particularly high. However, this is not necessarily the case when we define the cut-off point of our analysis differently. For instance, there are $33 \mathrm{EDs}$ with an EU-born population in excess of 20 per cent of the total. Nine of these are in Cork, but ten are in Dublin, demonstrating that Cork is not as exceptional in this regard as Table 2.2 would suggest.

Two of the top ten centres are outside the main cities, in Monaghan and Wexford, and the remaining two are in Limerick and Dublin. In these ten EDs migrants from the EU make up between a quarter and a third of the population.

\subsubsection{People born outside the European Union}

As mentioned above, people from outside of the European Union tend to exhibit poor integration outcomes, particularly in terms of disposable income and poverty rates (McGinnity et al., 2018a). They are another diverse group, who include students and employees of multinational firms from North America, Australia and New Zealand, as well as economic migrants from Latin America and Sub-Saharan Africa, and refugees or applicants in the international protection system. Unfortunately, it is not possible to separate out these groups with the available data. 


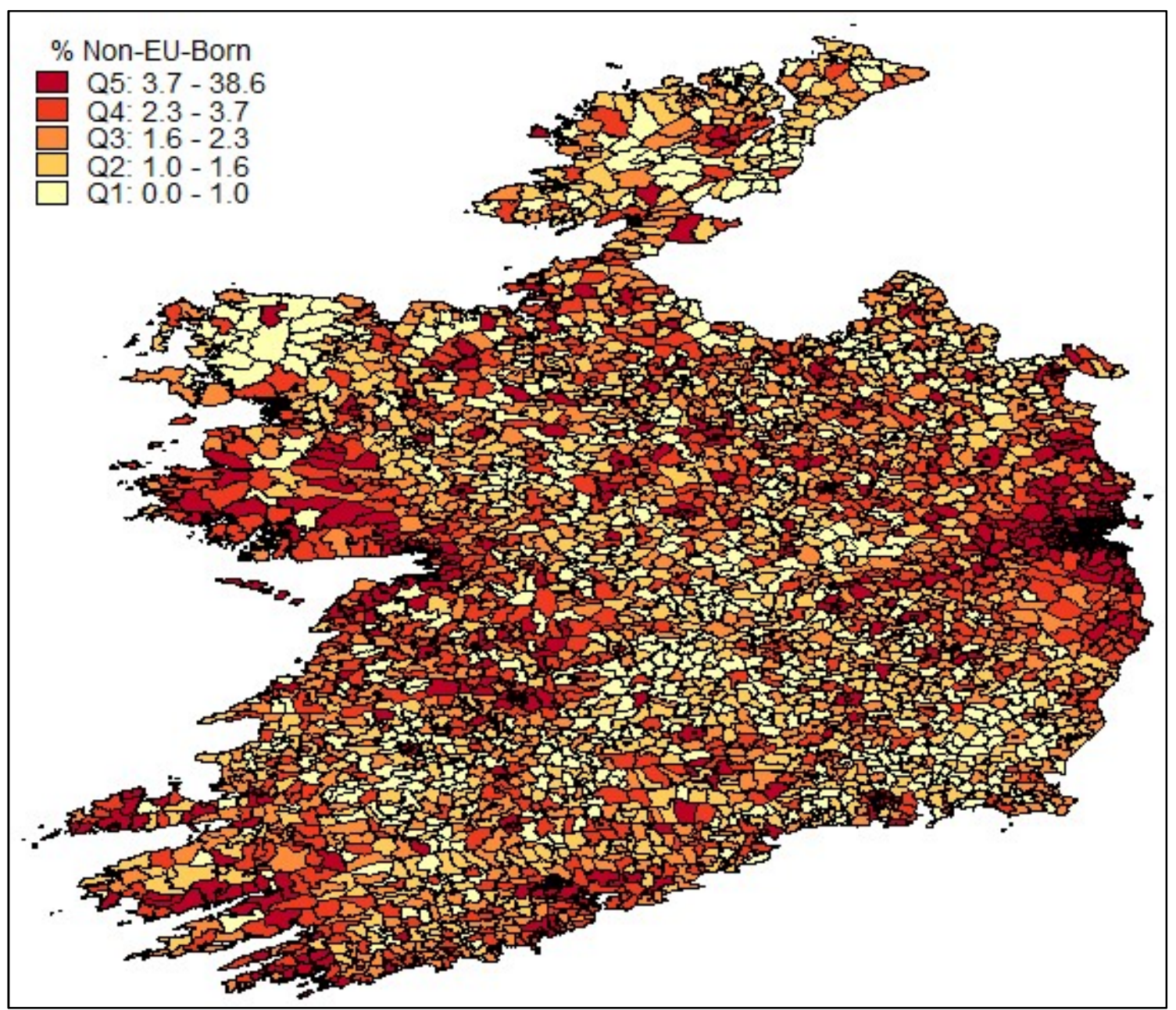

Authors' own analysis, CSO Small Area Population Statistics, Census 2016.

Again, the picture here is almost indistinguishable from those depicting the distributions of other immigrant groups, except that they are perhaps slightly more concentrated in Dublin than in other urban areas (see Figure 2.3). Here the darkest shade of red depicts EDs that are at least 3.7 per cent non-EU (the top quintile). There are 112 EDs with no non-EU-born residents. 


\begin{tabular}{|l|l|r|r|}
\hline Electoral Division & County & Non-EU-born (\%) & Number non-EU-born \\
\hline Custom House B & Waterford & 38.6 & 103 \\
\hline Mountjoy B & Dublin & 33.7 & 1313 \\
\hline North City & Dublin & 31.6 & 1523 \\
\hline Dock A & Limerick & 31.2 & 706 \\
\hline Shannon A & Limerick & 29.2 & 259 \\
\hline Merchants Quay E & Dublin & 26.7 & 602 \\
\hline Shannon B & Limerick & 25.8 & 227 \\
\hline Rotunda B & Dublin & 25.2 & 560 \\
\hline Rotunda A & Dublin & 25.7 & 1289 \\
\hline Inns Quay B & Dublin & 24.8 & 855 \\
\hline
\end{tabular}

Source: $\quad$ Authors' own analysis, CSO Small Area Population Statistics, Census 2016.

In Table 2.3 we see that six of the top ten EDs by non-EU-born population share are in Dublin, and these are once again concentrated around the inner city. The electoral division with the highest proportion of non-EU migrants is Custom House $B$ in Waterford. As with other groups, the centre of Limerick city has a relatively high share of non-EU-born residents. This analysis shows that non-EU migrants are similar to EU migrants in their spatial concentration. Half of their population is located in just 151 EDs.

\subsubsection{People with poor English-language proficiency}

The final group we analyse in this chapter comprises people with poor Englishlanguage proficiency, who self-identify as being able to speak English 'not well' or 'not at all'. In Figure 2.4, the darkest shade represents EDs in which at least 1.4 per cent of the population cannot speak English well or at all. 


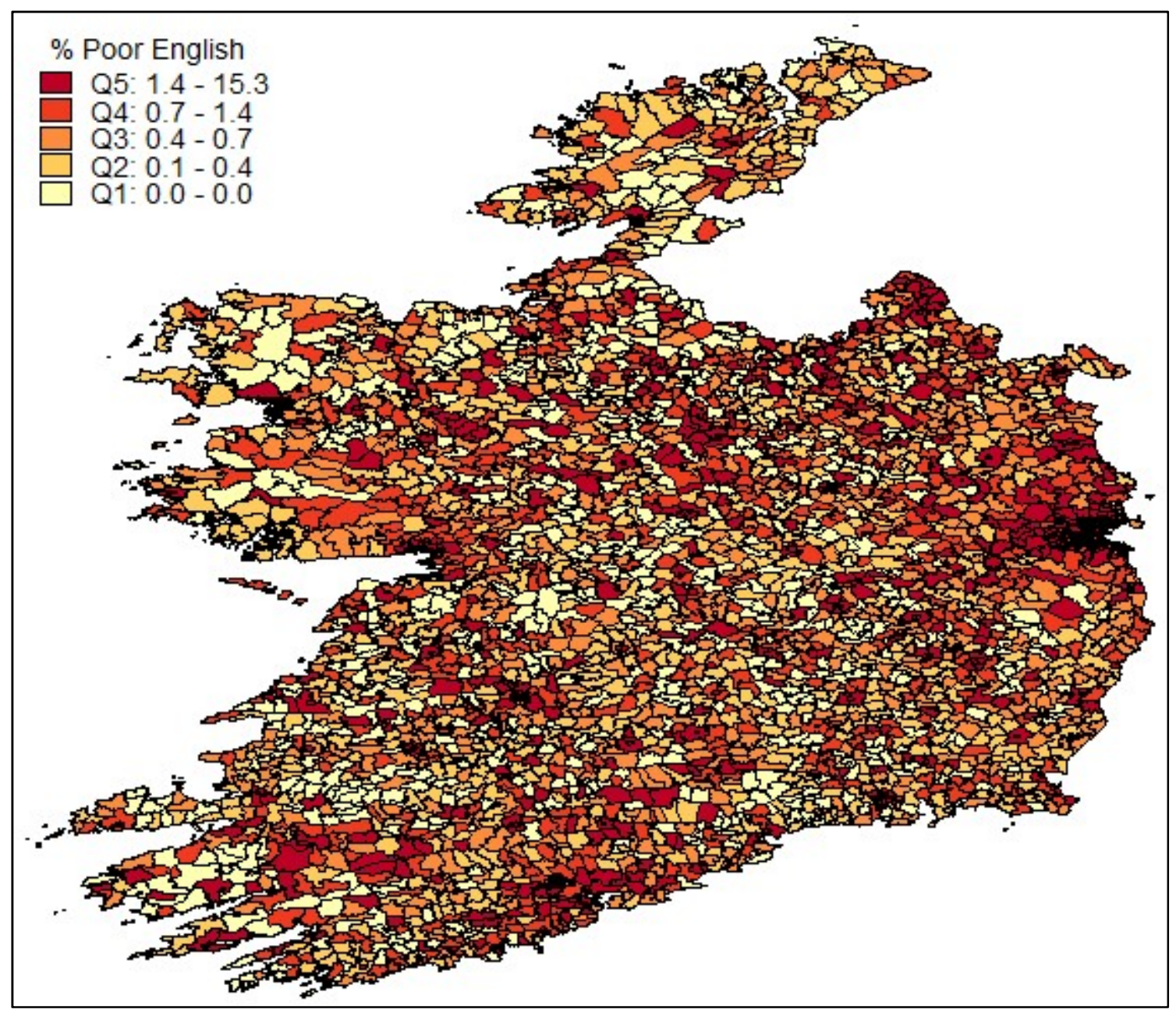

Source: $\quad$ Authors' own analysis, CSO Small Area Population Statistics, Census 2016.

While there is significant concentration of this group around the larger cities, closer analysis shows that people with poor English-language skills are unlike the other immigrant groups in that they also show high concentrations in smaller towns around the country. Table 2.4 shows that only three of the top ten EDs by share of the population with poor English-language skills are in major cities.

Monaghan town has the highest share of the population with poor Englishlanguage proficiency, at $\mathbf{1 5 . 3}$ per cent. This is likely a result of the mushroom picking industry in the area, which employs large numbers of unskilled migrant workers (Mushroom Workers Support Group, 2006). Rosbercon, an ED in the town of New Ross, is fourth, and Ballyhaunis in Co. Mayo is listed fifth, with a non-English speaking population of 335 . This is due to two factors. One is that Ballyhaunis was one of the first towns in Ireland in which diversity flourished. The opening of a meat packaging plant by a Pakistani businessman in the 1970s brought South Asian workers to the area, who were followed by migrants from the Middle East (Fanning, 2018). Second, Ballyhaunis has a Direct Provision centre which in April 
2016 hosted 222 asylum seekers (Reception and Integration Agency, 2016). These features have led some commentators in the media to conclude that Ballyhaunis is Ireland's most diverse town. ${ }^{12}$ Further down the distribution are towns such as Navan (8.9 per cent), Longford (8.2 per cent) and Fermoy (7.5 per cent).

There are 695 EDs in the country that have no non-English speakers. While this appears to be a large number, it is explained by the relatively small number of people with poor English-language proficiency across the country (approximately $86,000)$. Despite being less centralised in urban areas than the other immigrant groups, there is evidence that they are more highly concentrated in a few EDs. It takes only 135 EDs to account for half of the non-English-speaking population.

TABLE 2.4 TEN ELECTORAL DIVISIONS WITH HIGHEST SHARE OF PEOPLE WITH POOR ENGLISHLANGUAGE PROFICIENCY

\begin{tabular}{|c|c|c|c|}
\hline Electoral Division & County & $\begin{array}{c}\text { People with poor } \\
\text { English-language } \\
\text { proficiency (\%) }\end{array}$ & $\begin{array}{c}\text { Number of people with } \\
\text { poor English-language } \\
\text { proficiency }\end{array}$ \\
\hline Monaghan Urban & Monaghan & 15.3 & 356 \\
\hline Market & Limerick & 12.4 & 251 \\
\hline Custom House & Limerick & 11.8 & 84 \\
\hline Rosbercon Urban & Wexford & 11.6 & 74 \\
\hline Ballyhaunis & Mayo & 11.1 & 335 \\
\hline Bandon & Cork & 11.1 & 220 \\
\hline The Glen & Waterford & 10.8 & 71 \\
\hline Roscommon Urban & Roscommon & 10.7 & 181 \\
\hline Ballyjamesduff & Cavan & 10.4 & 334 \\
\hline Mountjoy B & Dublin & 10.2 & 396 \\
\hline
\end{tabular}

Source: $\quad$ Authors' own analysis, CSO Small Area Population Statistics, Census 2016.

While it is difficult to make comparisons across groups at this stage, the analysis here suggests that non-English speakers are less likely than other groups to be situated in urban areas but are more likely to live together in clustered residential areas.

\subsubsection{Summary of basic statistics}

Table 2.5 summarises the analysis so far. Column 3 shows the number of EDs that have no members of the group in question. Not surprisingly, all districts have at least one Irish or UK-born resident. The values in this column are largely determined by group size, with larger groups achieving representation in a greater

12 www.independent.ie/irish-news/the-way-we-live-state-is-not-preparing-for-more-diverse-population-37288175.html www.theguardian.com/news/2017/jul/14/pitching-up-ancient-sports-for-irelands-most-ethnically-diverse-town 
number of EDs. There are only 36 EDs with no migrants. By contrast, non-English speakers, who number less than 90,000, are unrepresented in 695 EDs.

Column 4 shows the number of EDs required to account for half of each group's total population. The more concentrated the group, the fewer EDs it will take to account for half of its numbers. The Irish/UK-born population is itself somewhat unevenly distributed on this count, with half of the population concentrated in just 415 EDs. The three migrant groups (total, EU and non-EU) all register similar values on this measure - between 151 and 159. By contrast, there is evidence that immigrants with poor English are more concentrated. Half of this group resides in just 135 EDs.

However, this table gives only a partial picture of the concentration of minority groups in Ireland. In Chapter 3 we consider more formal measures of spatial segregation.

\section{TABLE 2.5 SUMMARY OF BASIC NATIONWIDE STATISTICS}

\begin{tabular}{|l|r|r|r|} 
& $\begin{array}{c}\text { Number of } \\
\text { residents }\end{array}$ & $\begin{array}{c}\text { No. of EDs with 0 } \\
\text { residents of each } \\
\text { group }\end{array}$ & $\begin{array}{c}\text { No. of EDs required to } \\
\text { account for 50 per cent of } \\
\text { group's total }\end{array}$ \\
\hline Irish/UK born & $4,156,721$ & 0 & 415 \\
\hline Migrants (exc. UK) & 533,200 & 36 & 159 \\
\hline EU migrants (exc. UK) & 293,787 & 196 & 152 \\
\hline Non-EU migrants & 239,413 & 112 & 151 \\
\hline Poor English & 86,608 & 695 & 135 \\
\hline
\end{tabular}

Source: $\quad$ Authors' own analysis, CSO Small Area Population Statistics, Census 2016.

\subsection{THE DISTRIBUTION OF MINORITY GROUPS IN URBAN AREAS}

We now turn our attention to the urban areas where some of these groups appear to be concentrated in greater numbers. The top ten EDs by each group's share are highly concentrated in urban areas. In fact, over three-quarters of the EDs that appear in the top ten for each group are in Dublin, Limerick or Cork. Therefore, we now map the distribution of the groups in those three cities. In the interest of brevity, we focus the analysis on all foreign-born people (excluding UK nationals), people born outside of the EU, and people with poor English-language proficiency as these are likely to have the greatest difficulty in integrating. The equivalent maps for EU migrants can be found in the online appendix.

The aim of these maps is to show the distribution of the groups across urban centres and their surrounding suburbs and commuter belt. Because the three cities vary in size and their commuter belts extend into the countryside to varying degrees, we constrain the maps using two types of administrative boundary, with 
a view to striking a balance between detail and scope.

For Dublin, we consider the entire county. This is a relatively conservative estimate of Dublin's influence, as many commuters to the capital city live in counties Meath, Kildare and Wicklow. For Limerick, we focus on the three Limerick city Local Electoral Areas (LEAs) (North, East and West). This area stretches from just north of Adare in the South-West to Castletroy in the East. It is limited by the border with County Clare across the North. While this is a much smaller area than what we consider for Dublin, we are confident from the preceding nationwide analysis that it contains the most diverse EDs in the region, which are located along the River Shannon in the city centre. Using the county boundary in Cork would mean losing the detail of the diversity in Cork City, because the area is too large. However, focusing on Cork city itself would omit some important suburban areas. As a compromise, we included all EDs contained within Cork City and the neighbouring LEAs of Cobh and Ballincollig-Carrigaline.

Table 2.6 shows each group's share of the total population in each urban area, and the equivalent values for the State as a whole. By this measure Dublin is the most diverse city in terms of country of birth, with 16.6 per cent of the total population born outside of Ireland and the UK. At 2.4 per cent, residents of Limerick are most likely to have poor English-language proficiency. With the exception of non-English speakers in Cork, all immigrant groups are over-represented in all three cities.

TABLE 2.6 EACH GROUP'S SHARE OF EACH CITY'S POPULATION (\%)

\begin{tabular}{|l|r|r|r|r|}
\hline & State & Dublin & Limerick & Cork \\
\hline Irish/UK born & 88.6 & 83.4 & 86.4 & 87.4 \\
\hline Migrants (exc. UK) & 11.4 & 16.6 & 13.5 & 12.6 \\
\hline EU migrants (exc. UK) & 6.3 & 8.1 & 6.9 & 7.3 \\
\hline Non-EU migrants & 5.1 & 8.5 & 6.7 & 5.3 \\
\hline Poor English & 1.8 & 2.2 & 2.4 & 1.6 \\
\hline
\end{tabular}

Source: $\quad$ Authors' own analysis, CSO Small Area Population Statistics, Census 2016.

Rather than using quintiles, we split the maps that follow into eight separate colours. This has the effect of presenting the distribution of these groups across the densely populated urban areas more smoothly. It means that an ED coloured in the lightest shade falls in the bottom eighth in the urban area in terms of the share of its population that the group accounts for. 


\subsubsection{Migrants in Dublin, Limerick and Cork}

Figure 2.5 shows that there are few foreign-born residents living in the affluent South-East of Dublin, with much higher concentrations in the Western and Northern suburbs and in particular in the North inner city. In fact, ten of the top 12 EDs by non-UK foreign-born population in Dublin are located in the North Inner City. The areas surrounding Blanchardstown, Abbotstown, Mulhuddart and Dublin Airport are also diverse, with over 35 per cent of the population foreign-born. The division of Tallaght-Springfield in the South-West has a large foreign-born population of 3,662, making up nearly 30 per cent of the ED's total population. The main exceptions to the homogeneity of the South-Eastern suburbs are CabinteelyLoughlinstown (27.6 per cent) and Dundrum-Balally (27.5 per cent).

\section{FIGURE 2.5 SHARE OF ELECTORAL DIVISION FOREIGN-BORN (NON-IRISH/UK), DUBLIN 2016}

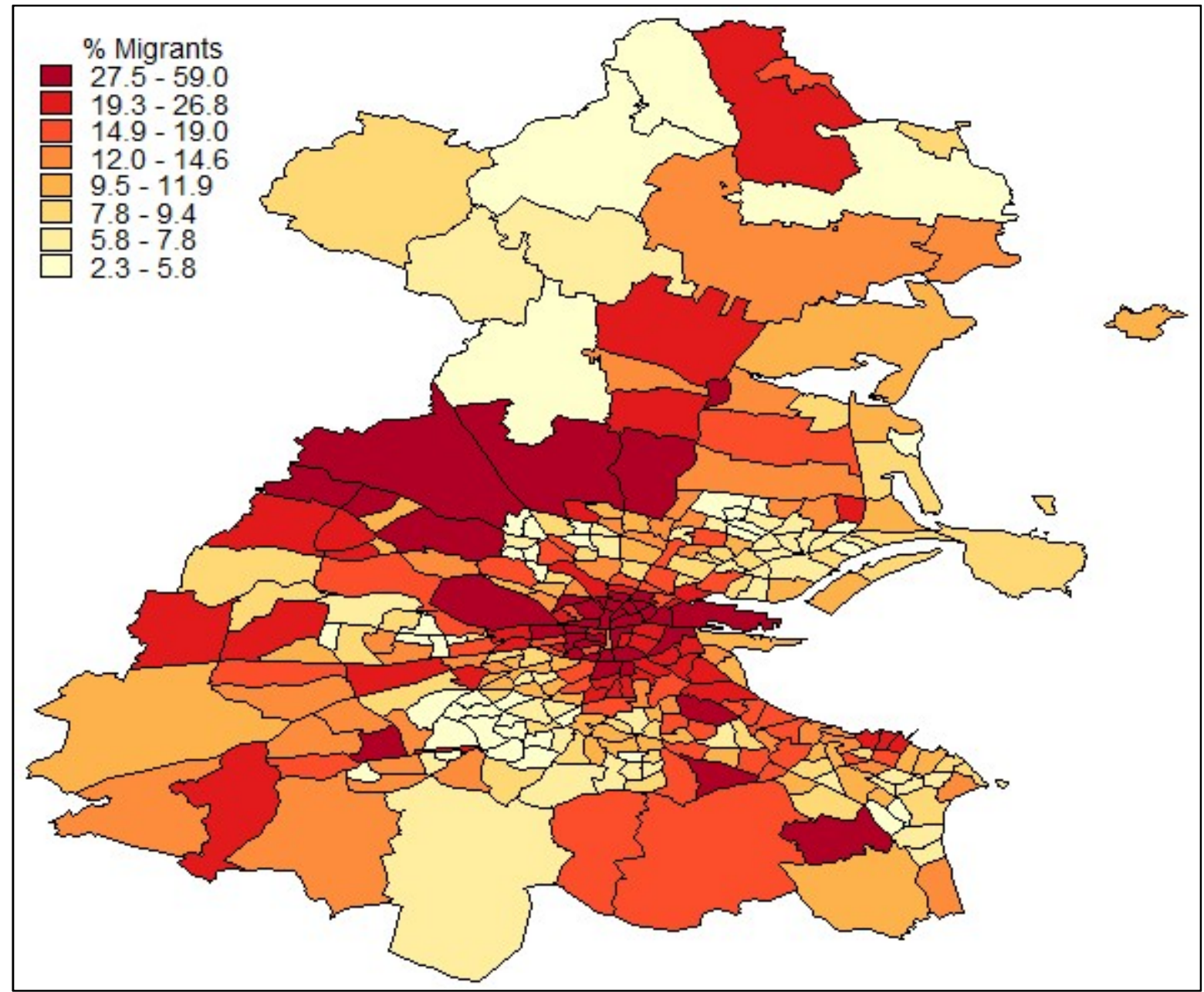


In Limerick (Figure 2.6), we see that the foreign-born population is heavily concentrated in the city centre. As in Dublin, the top EDs by migrant population share are tightly concentrated in this area. These proportions range from the ED of John's $C$ in ninth place, with 25 per cent, to Dock $A$, which is 51 per cent nonIrish/UK born. Outside of the city centre, Ballycummin (20 per cent) and Ballysimon (14.3 per cent) also have large migrant populations.

\section{FIGURE 2.6 SHARE OF ELECTORAL DIVISION FOREIGN-BORN (NON-IRISH/UK), LIMERICK 2016}

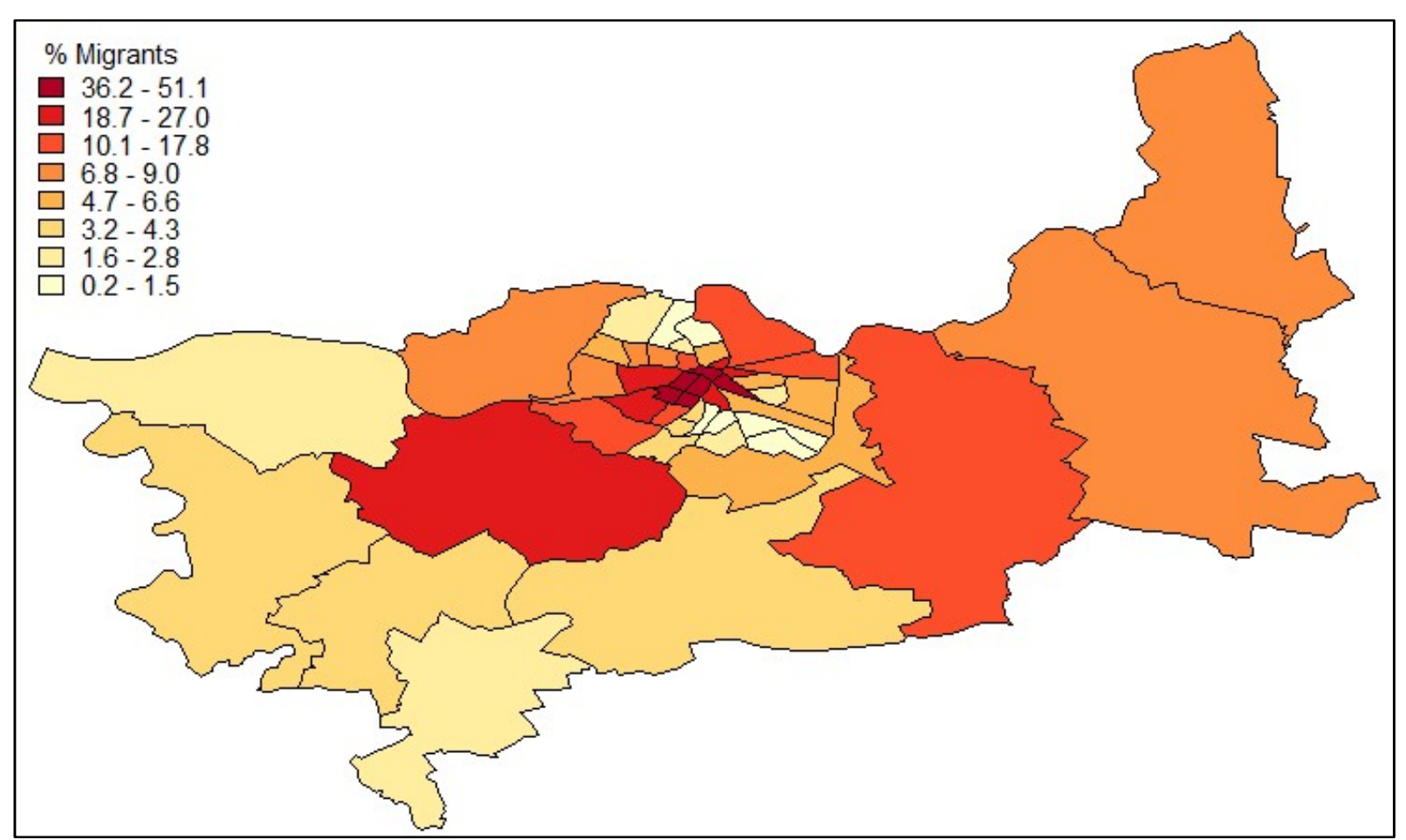

Source: $\quad$ Authors' own analysis, CSO Small Area Population Statistics, Census 2016. 
The same picture emerges for Cork (Figure 2.7). There is a strong clustering of foreign-born residents in the centre of Cork city. Six EDs in this urban area have foreign-born populations in excess of 40 per cent. The only ED outside of the city centre in the top 20 of this set is Inishkenny to the South-West (in 20th place) which is 22 per cent foreign-born. Carrigtohill, a geographically large ED to the east of the city, is just under 17 per cent foreign-born.

FIGURE 2.7 SHARE OF ELECTORAL DIVISION FOREIGN-BORN (NON-IRISH/UK), CORK 2016

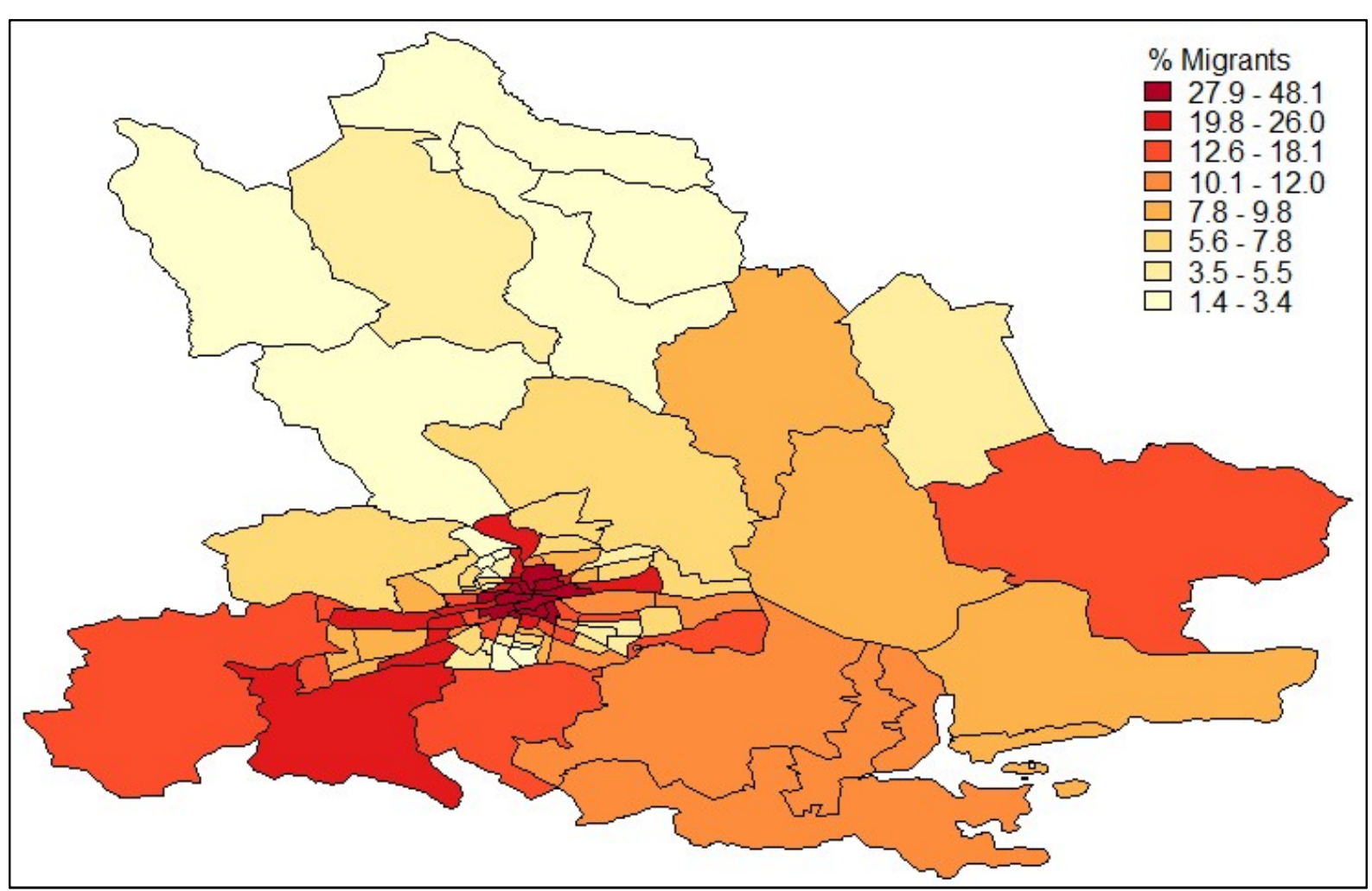

Source: $\quad$ Authors' own analysis, CSO Small Area Population Statistics, Census 2016. 


\subsubsection{People born outside the EU in Dublin, Limerick and Cork}

Across all three urban areas, the distributions of people born outside of the EU closely resemble the patterns for all migrant residents. This is not surprising, given that one is a subset of the other, but it does show that the residential location of EU and non-EU nationals are very similar. The highest concentrations of this group are in Dublin's North Inner City (Figure 2.8). However, the ED of ClonskeaghBelfield in Dublin city's southern suburbs also has a high concentration of non-EU residents, at 23.7 per cent. This is the location of the University College Dublin Belfield campus, which suggests that a large share of this group are foreign students.

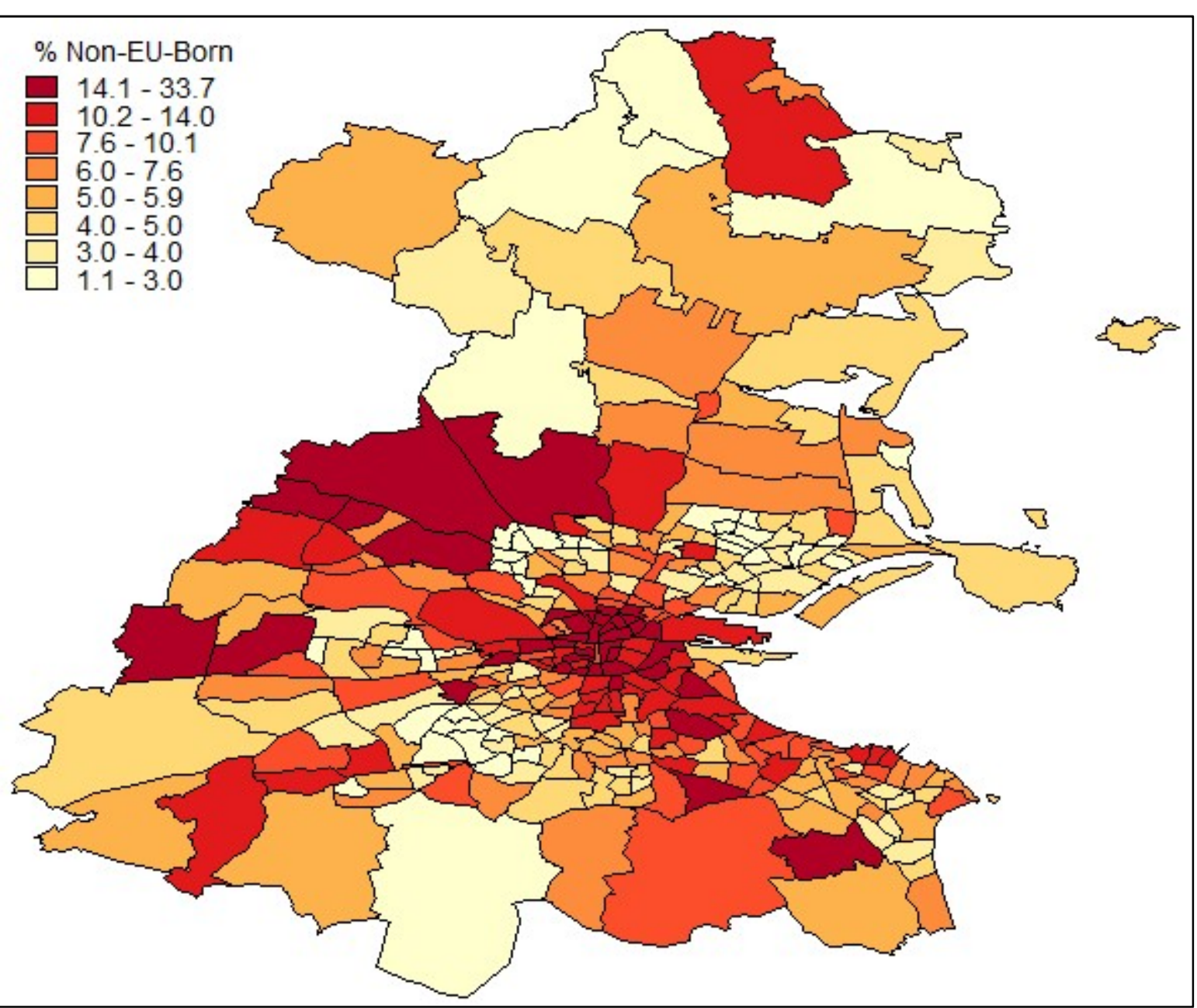


Limerick city is represented by three EDs in the nationwide top ten EDs by non-EU population in Table 2.3. All three of these, Dock A, Shannon A and Shannon B, have concentrations in excess of 25 per cent. The city centre EDs of Market and Abbey $C$ also have high concentrations, at 23.4 and 18 per cent respectively (Figure 2.9).

\section{FIGURE 2.9 SHARE OF ELECTORAL DIVISION BORN OUTSIDE EU, LIMERICK 2016}

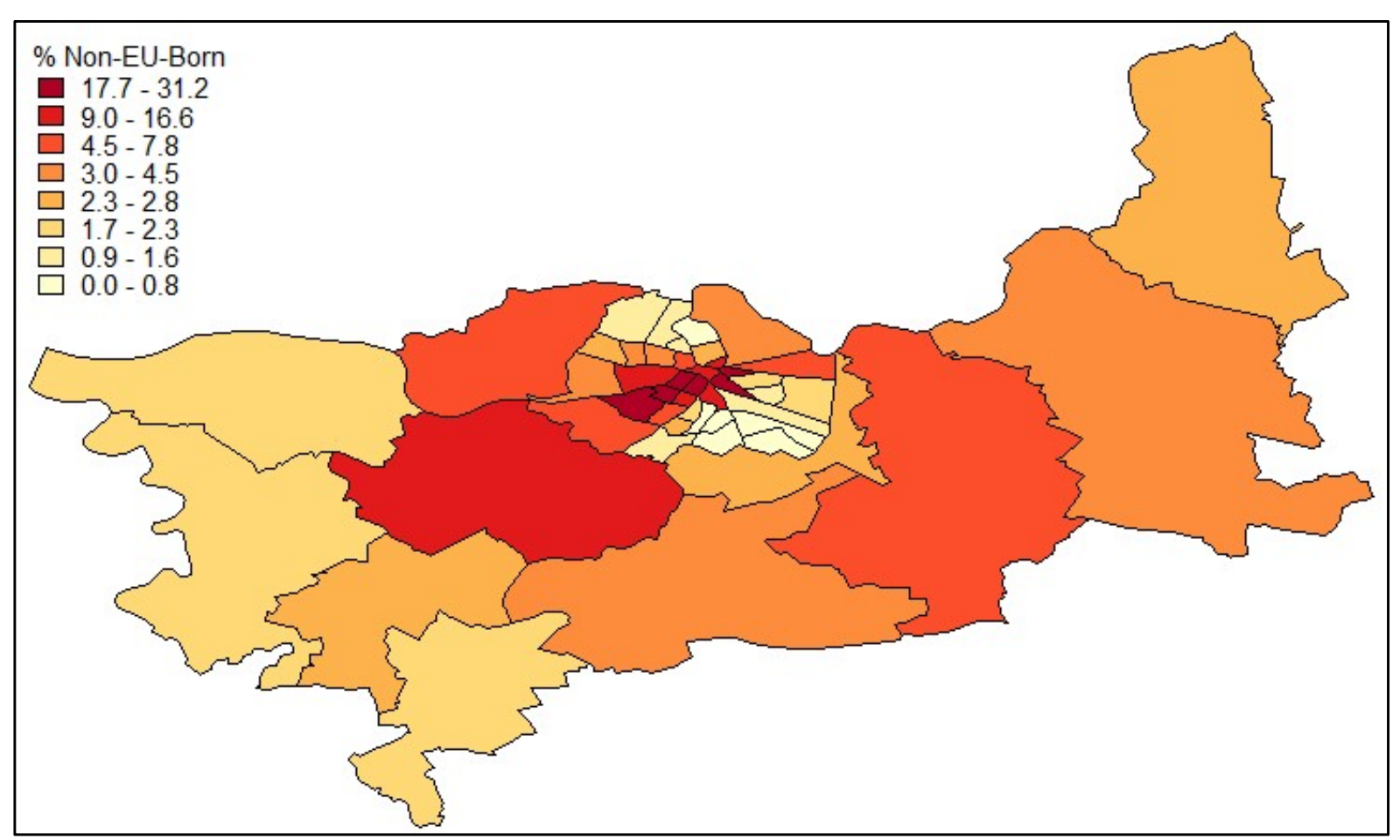

Source: $\quad$ Authors' own analysis, CSO Small Area Population Statistics, Census 2016. 
None of the EDs listed in Table 2.3 (the nationwide analysis of EDs with the highest share born outside the EU) is in Cork city. The highest shares in Cork are in St Patrick's A and B divisions, where 19.1 and 21.3 per cent of the population are registered as non-EU-born in the Census (Figure 2.10).

\section{FIGURE 2.10 SHARE OF ELECTORAL DIVISION BORN OUTSIDE EU, CORK 2016}

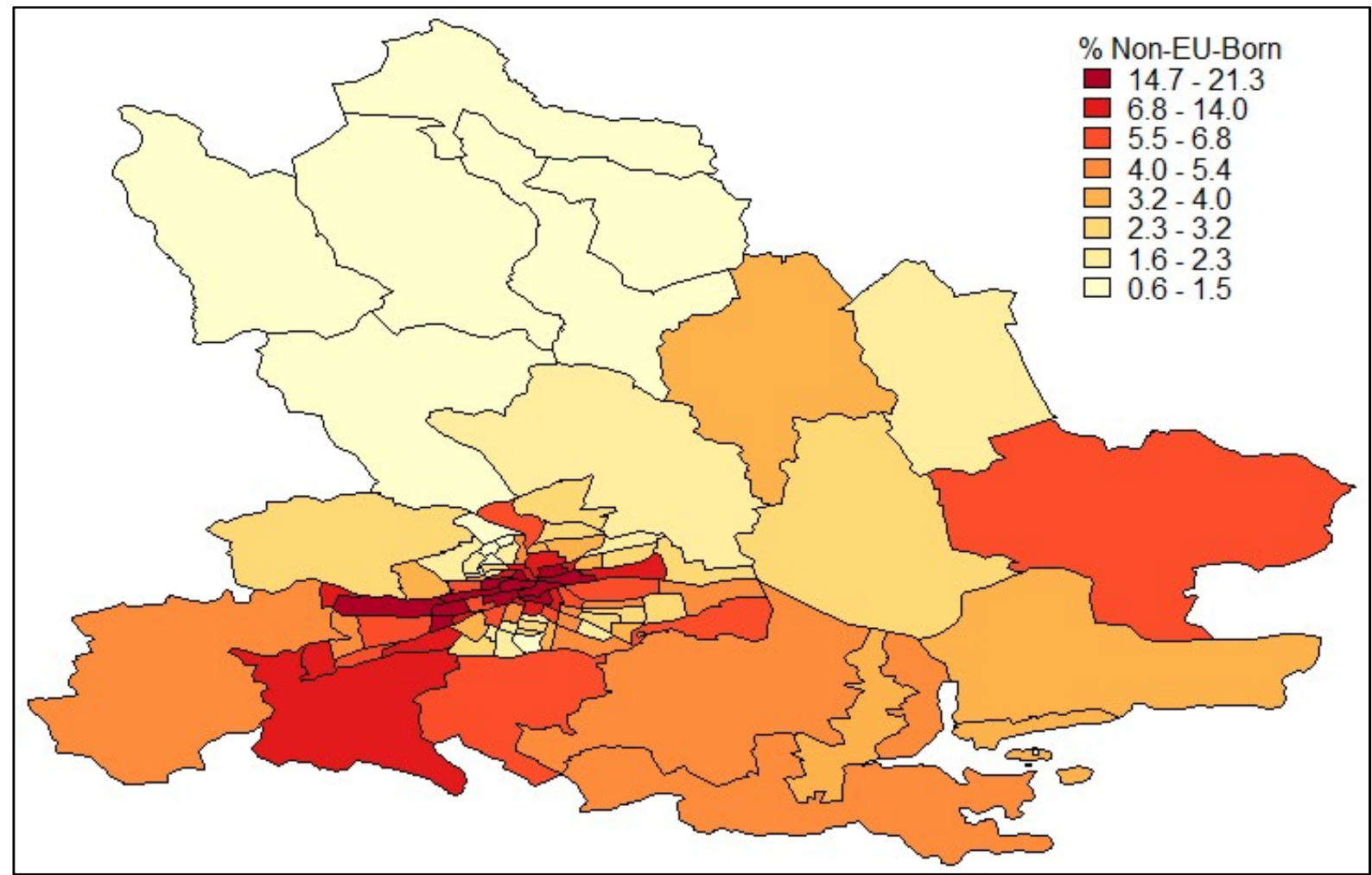




\subsubsection{People with poor English-language proficiency in Dublin, Limerick and Cork}

We find people with poor English-language proficiency to be distributed across all three cities in a similar way to the total foreign-born group. In Dublin they are concentrated in the North Inner City and the suburbs to the north and west (Figure 2.11). Mountjoy $B$ has the largest share of this group, at 10.2 per cent. Five of the top ten EDs in Dublin are also in the top ten when ranked by total migrant share of population. However, Blanchardstown-Mulhuddart and Tallaght-Springfield also have large shares of people with poor English, at 6.9 per cent and 6.4 per cent respectively.

\section{FIGURE 2.11 SHARE OF ELECTORAL DIVISION WITH POOR ENGLISH-LANGUAGE PROFICIENCY, DUBLIN 2016}

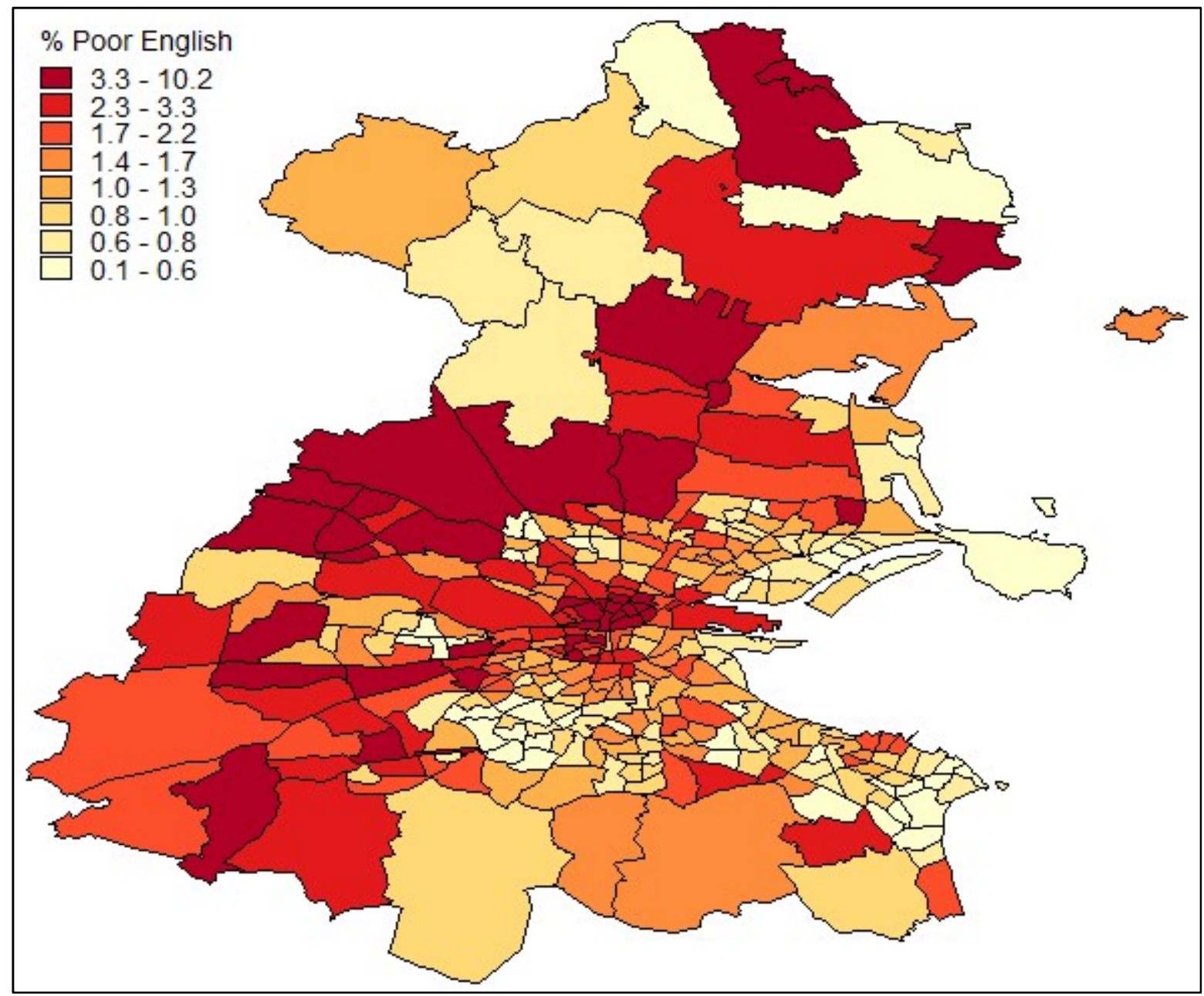


The overlap between the concentration of foreign-born immigrants and people with poor English is even stronger in Limerick. We find that nine of the ten EDs with the highest proportions of this group are also in the top ten in the non-Irish/UKborn variable. All ten are in Limerick's city centre (Figure 2.12). The highest proportion is in Market, where over 12 per cent of census respondents could not speak English well or at all.

\section{FIGURE 2.12 SHARE OF ELECTORAL DIVISION WITH POOR ENGLISH-LANGUAGE PROFICIENCY, LIMERICK 2016}

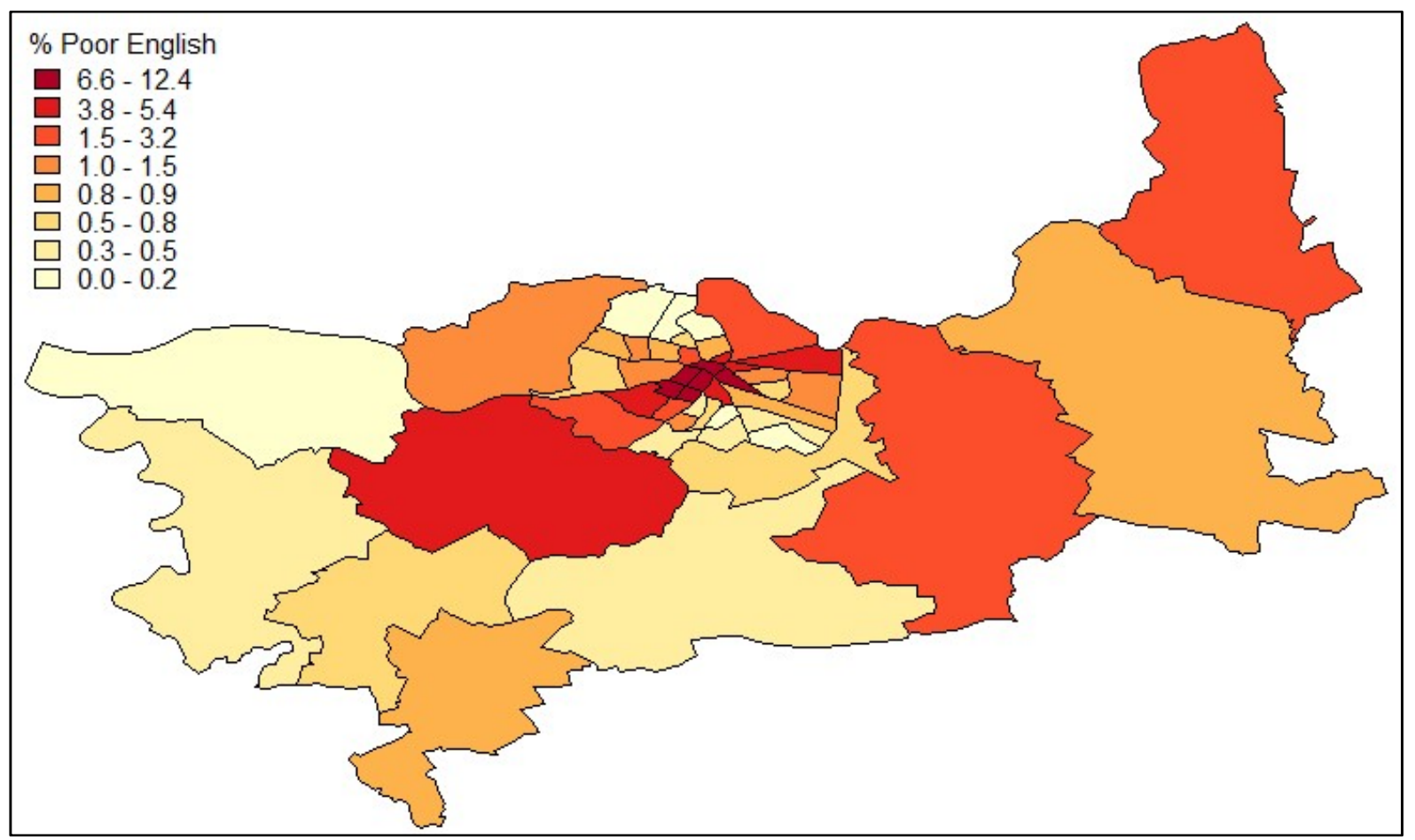

Source: $\quad$ Authors' own analysis, CSO Small Area Population Statistics, Census 2016. 
In Cork, the residential patterns of people with poor English-language proficiency are similar to the patterns we find for other groups. In Figure 2.13 the darkest shade represents EDs in which between 2.8 and 5.6 per cent of residents do not speak English well or at all. However, 11.6 per cent of the population of Bandon, which is $30 \mathrm{~km}$ south-west of Cork city and is therefore beyond the bounds of this map, lack English-language skills (see Table 2.4).

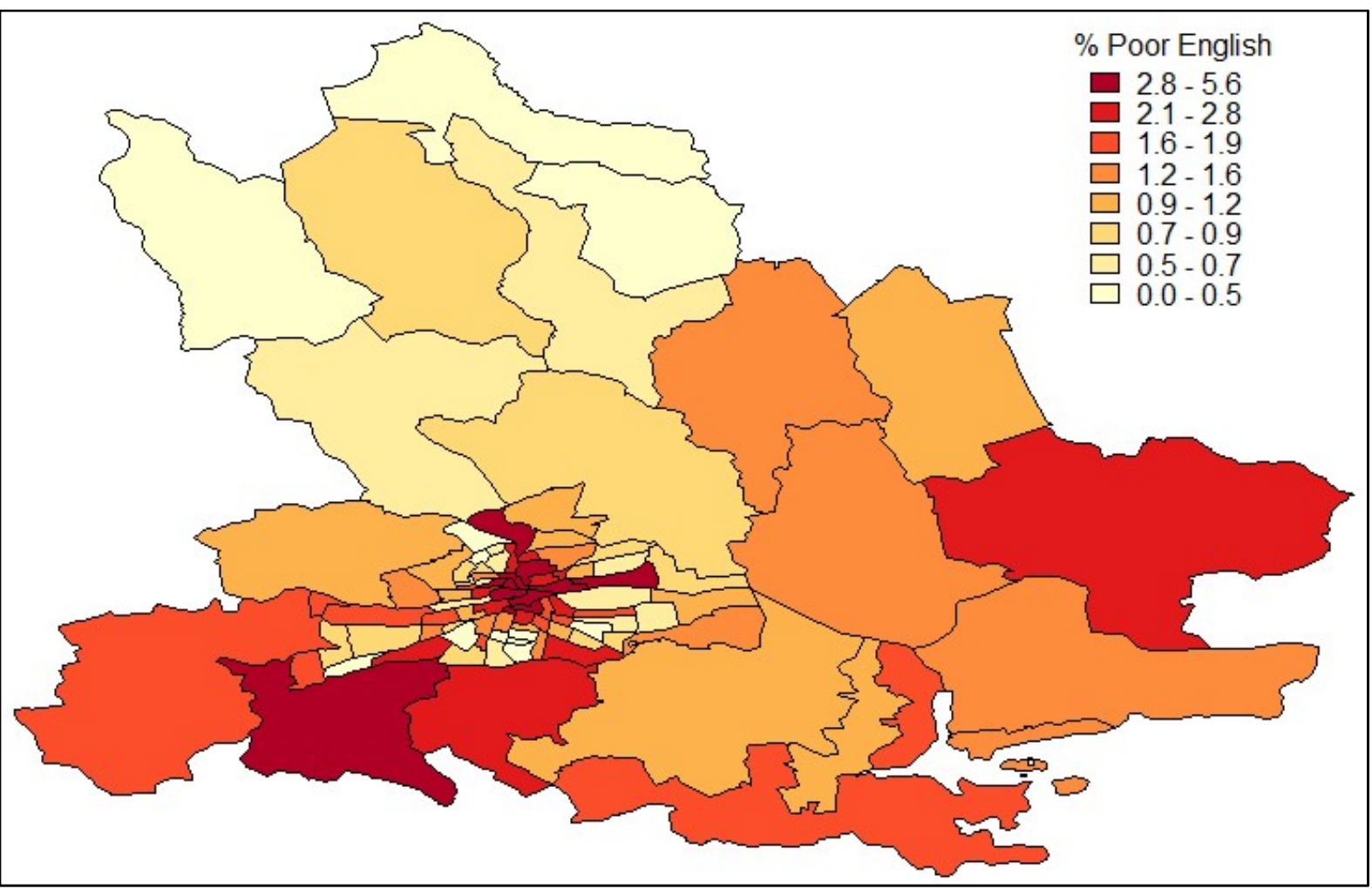

Source: $\quad$ Authors' own analysis, CSO Small Area Population Statistics, Census 2016.

\subsection{SUMMARY}

This analysis has presented distributions of various immigrant groups across the country and in three major urban centres. The patterns are similar for all three foreign-born groups, with high concentrations in Dublin's North Inner City as well as Limerick and Cork's city centres. A somewhat different pattern emerges for people with poor English-language proficiency. They appear to be less centralised in urban areas, but nonetheless seem to be more highly concentrated than the other immigrant groups. In the following chapters we consider more formal measures of residential segregation and examine the relationships between minority concentration and some socio-economic and demographic covariates. 



\section{CHAPTER 3}

\section{Spatial segregation and diversity}

This chapter seeks to quantify the spatial segregation of the migrant population of Ireland. While segregation seems to be a relatively simple concept - the degree of separation of different groups - measuring it is challenging (Harris and Johnston, 2018; Piekut et al., 2019). Massey and Denton (1988) outline five components of segregation: the evenness of the distribution of the group in question, their exposure to other groups, the extent to which they are concentrated in tight geographical areas, the degree to which they are centralised in urban areas, and the extent to which ethnic neighbourhoods are clustered together. Components of segregation such as uneven population distributions, spatial concentrations, spatial clustering and/or one group's isolation from others may be correlated, but are not interchangeable (Harris and Johnston, 2018). For example, a migrant group may be distributed unevenly without being isolated from other population groups. This would occur if the group was small and highly concentrated in a few streets but formed such a small proportion of those neighbourhoods' populations that most of its members' neighbours would not be fellow group members. Concentration of groups can lead to spatial clustering, where neighbourhoods with high concentrations are found close to each other, yet groups can also be concentrated in neighbourhoods or areas that are distant to each other (Yao et al., 2018).

Many researchers and policymakers are interested in not just residential patterns at a given time point, but how patterns change over time: an issue we explore later in this chapter. In a similar vein, many are interested not just in the degree of separation but in whether migrants or ethnic minorities live in socially disadvantaged areas (Piekut et al., 2019). This is investigated in Chapter 4.

This chapter uses two formal measures of segregation, which focus on the evenness of the distribution (the dissimilarity index) and the exposure of minorities to other groups (the isolation index). These measures were chosen for two reasons. First, they capture two important dimensions of segregation that are well established in the field, thus allowing for international comparisons. Second, they are relatively easy to interpret. The latter point is important. As Harris and Johnston (2018) point out, many of the latest methods in this field are sophisticated and statistically complex, and are therefore difficult to convey to a more general audience. In the conclusion (Chapter 5), we discuss how recent methodological developments in the literature address some limits of these measures and the potential some of the new methods offer for future research in Ireland. 


\subsection{DISSIMILARITY INDEX}

Perhaps the most commonly used measure of spatial segregation in housing studies and urban geography is the dissimilarity index $(D)$. This score has two advantages: one is that it is relatively easy to interpret. It is simply the proportion of the minority group that would have to relocate to achieve an even distribution across all EDs (Iceland et al., 2002). That means that larger scores indicate more segregated communities. It is calculated as follows:

$$
D=\frac{1}{2} \sum_{i=1}^{n}\left|\frac{w_{i}}{W_{T}}-\frac{x_{i}}{X_{T}}\right|
$$

where $n$ is the number of spatial units (in this case EDs), $w_{i}$ is the number of Irishborn residents in district $i, W_{T}$ is the number of Irish-born residents in the city/country, $x_{i}$ is the number of foreign-born residents in district $i$ and $X_{T}$ is the number of foreign-born residents in the city/country.

The second advantage is that because it is so widely used, comparisons can easily be drawn with other cities around the world, particularly in Western Europe and North America, where much of this scholarship has been focused.

\begin{tabular}{|l|r|r|r|r|}
\hline & State & Dublin & Limerick & Cork \\
\hline Migrants (exc. UK) & 32.7 & 28.4 & 35.7 & 27.7 \\
\hline EU migrants (exc. UK) & 34.9 & 30.1 & 34.9 & 28.0 \\
\hline Non-EU migrants & 33.8 & 28.8 & 37.0 & 29.0 \\
\hline Poor English & 37.4 & 32.4 & 42.3 & 26.4 \\
\hline
\end{tabular}

Source: $\quad$ Authors' own analysis, CSO Small Area Population Statistics, Census 2016.

Note: The dissimilarity index is the proportion of the minority group that would have to relocate to achieve an even distribution across all EDs (Iceland et al., 2002). In this case, the index is calculated relative to the Irish-born population.

Table 3.1 shows that 33 per cent of the total migrant population would need to relocate to another ED in order to achieve an even distribution across the entire country. Within, the three cities, between 28 and 37 per cent would have to move to achieve evenness. Across the state as a whole, we find that 34 per cent of nonEU migrants and 35 per cent of EU migrants would have to move to achieve evenness, but it is as high as 37 per cent for the non-EU-born in Limerick.

Consistent with the findings of Chapter 2, this formal measure of segregation shows that people with poor English-language skills register a relatively high value, particularly in Limerick, where 42 per cent would have to relocate to achieve evenness. 
There is much greater variation across cities than over time. Table 3A.1 in the appendix to this chapter shows $D$ for Ireland and the three cities in 2011. While there is a reduction between 2011 and 2016 for most groups/cities, the changes are typically one or two points. One exception is Limerick, which experienced a 5.5 point intercensal increase in the dissimilarity index for people with poor Englishlanguage proficiency (see Table 3A.2 in the appendix to this chapter).

Table 3.2 situates the dissimilarity index scores for Dublin, Limerick and Cork in an international context. The left-hand panel presents dissimilarity index scores for a number of individual country of origin groups living in Western European cities. The right-hand panel considers groups that are defined more broadly, such as ethnic groups and immigrants from multiple countries/regions, and this includes the dissimilarity index scores for Irish cities produced in the current report.

We might expect dissimilarity index scores to be higher when we define the migrant groups narrowly, because members of groups defined by a single country of origin are likely to be more similar to one another in various ways, such as their socio-demographic, cultural and linguistic characteristics. This is indeed what we find cross-nationally, where segregation is worse among groups defined by a single country of origin, with an average score of 43.3 compared to 34.9 for the righthand side of the table. This may mean that 'ethnic attraction' is playing a role, as immigrants self-segregate into social networks that form on the basis of national identities. Alternatively, it may be that some groups integrate better than others, and that smaller groups who suffer poor integration outcomes are 'washed out' by immigrant groups that integrate more successfully.

With the exception of people with poor English-language skills in Limerick, the minority groups living in Ireland that we study here appear in a cross-national context to be spread quite evenly within each of the three cities. 


\begin{tabular}{|c|c|c|c|c|c|}
\hline City & Group & $D$ & City & Group & $D$ \\
\hline Birmingham & Bangladeshi & 79 & Antwerp & N. Africans, Bosnians & 70 \\
\hline London & Bangladeshi & 75 & Large US cities & Blacks & 59 \\
\hline Birmingham & Bangladeshi & 68 & Bristol & Black Caribbean & 57 \\
\hline Birmingham & Pakistani & 66 & Large US cities & Hispanics & 48 \\
\hline London & Bangladeshi & 63 & Manchester & Black Caribbean & 48 \\
\hline Manchester & Bangladeshi & 63 & London & Black Caribbean & 45 \\
\hline Brussels & Moroccan & 59 & The Hague & Minorities & 43 \\
\hline Stockholm & Iranian & 58 & Birmingham & Black Caribbean & 43 \\
\hline France & Turkish & 55 & Limerick & Poor English & 42 \\
\hline Manchester & Pakistani & 54 & Large US cities & Asians & 41 \\
\hline London & Pakistani & 49 & Bradford & Black Caribbean & 40 \\
\hline The Hague & Moroccan & 46 & Oldham & Black Caribbean & 39 \\
\hline Rotterdam & Moroccan & 44 & Limerick & Non-EU migrants & 37 \\
\hline Rotterdam & Turkish & 44 & Birmingham & Black Africans & 36 \\
\hline Amsterdam & Turkish & 42 & Limerick & Migrants ${ }^{*}$ & 36 \\
\hline Amsterdam & Moroccan & 41 & Limerick & EU migrants* & 35 \\
\hline France & Algerian & 40 & Dublin & Poor English & 32 \\
\hline Amsterdam & Moroccan & 40 & Dublin & EU migrants* & 30 \\
\hline Rotterdam & Moroccan & 40 & Vienna & Foreigners & 30 \\
\hline Amsterdam & Surinamese & 34 & Leicester & Black Caribbean & 30 \\
\hline Turin & Chinese & 32 & Oslo & Third World immigrants & 29 \\
\hline Düsseldorf & Turkish & 30 & Cork & Non-EU migrants & 29 \\
\hline Rotterdam & Surinamese & 26 & Dublin & Non-EU migrants & 29 \\
\hline Frankfurt & American & 23 & Dublin & Migrants* & 28 \\
\hline Paris & Algerian & 23 & Cork & EU migrants* & 28 \\
\hline Amsterdam & Surinamese & 23 & Turin & Africans & 28 \\
\hline Turin & Romanian & 22 & Cork & Migrants* & 28 \\
\hline Rotterdam & Surinamese & 21 & Cork & Poor English & 26 \\
\hline Milan & Filipino & 20 & Lille & Foreigners & 25 \\
\hline \multirow[t]{4}{*}{ Frankfurt } & Turkish & 19 & Milan & $\begin{array}{l}\text { West Europeans/N. } \\
\text { Americans }\end{array}$ & 2 \\
\hline & & & Milan & Foreigners & 20 \\
\hline & & & Rome & Africans & 18 \\
\hline & & & Munich & Foreigners & 12 \\
\hline
\end{tabular}

Source: Data provided by Dan Lichter (Cornell University) and Mimmo Parisi (Mississippi State University). Irish data from authors' own analysis, CSO Small Area Population Statistics, Census 2016.

Note: $\quad$ *Excluding UK migrants. The dissimilarity index is the proportion of the minority group that would have to relocate to achieve an even distribution across all EDs (Iceland et al., 2002).

A limitation of the dissimilarity index is that it is sensitive to both unit size and the size of the minority population. Where these are small they can lead to a high segregation score even when individuals are randomly distributed (Allen et al., 2015). As the analysis in this report is carried out at the level of EDs, which have an average population of 1,376 , the unit size is not problematic in this case. The higher 
scores for the group with poor English-language proficiency may in part be due to the smaller size of this minority group (1.8 per cent of the population). ${ }^{13}$

\subsection{ISOLATION INDEX}

Another commonly used measure of segregation is the isolation index, which is the extent to which the average minority group member shares his or her district with other minority members. It is calculated as follows:

$$
I=\sum_{i=1}^{n}\left[\left(\frac{x_{i}}{X}\right)\left(\frac{x_{i}}{t_{i}}\right)\right]
$$

where $n$ is the number of spatial units (in this case EDs), $x_{i}$ is the number of foreignborn residents in district $i, X$ is the total number of foreign residents in the country/city, and $t_{i}$ is the total number of people in district $i$.

Substantively, an isolation index for foreign-born residents of 0.3 would mean that the average foreign-born resident lives in a district with a population that is 30 per cent foreign-born. High values on the isolation index therefore mean that minority groups are segregated because their people would be unlikely to encounter Irishborn people in the residential environment. Unlike the dissimilarity index, the isolation index is not weighted by group size, meaning that larger groups will be much more likely to have high values.

To grasp the intuition, consider a hypothetical example from the United States. A member of a large minority group, such as a Hispanic American, would have a relatively high probability of interacting with other Hispanics only, even if they weren't living in highly segregated areas. However, a member of a much smaller minority, such as a Pacific Islander, would have to face extraordinary levels of segregation to have little or no interaction with non-Pacific islanders.

The influence of group size on the isolation index is in some ways a weakness, because comparisons cannot be easily made between groups. However, its strength is that it is more indicative of the 'lived' experience of segregation. This is because small groups have an improved chance of living in diverse communities. In the aforementioned example, it is not unreasonable to say that the Pacific Islander would have a greater chance of living in a mixed neighbourhood, even if that is only because their own ethnic group is not large enough to sustain an ethnic enclave. ${ }^{14}$ 


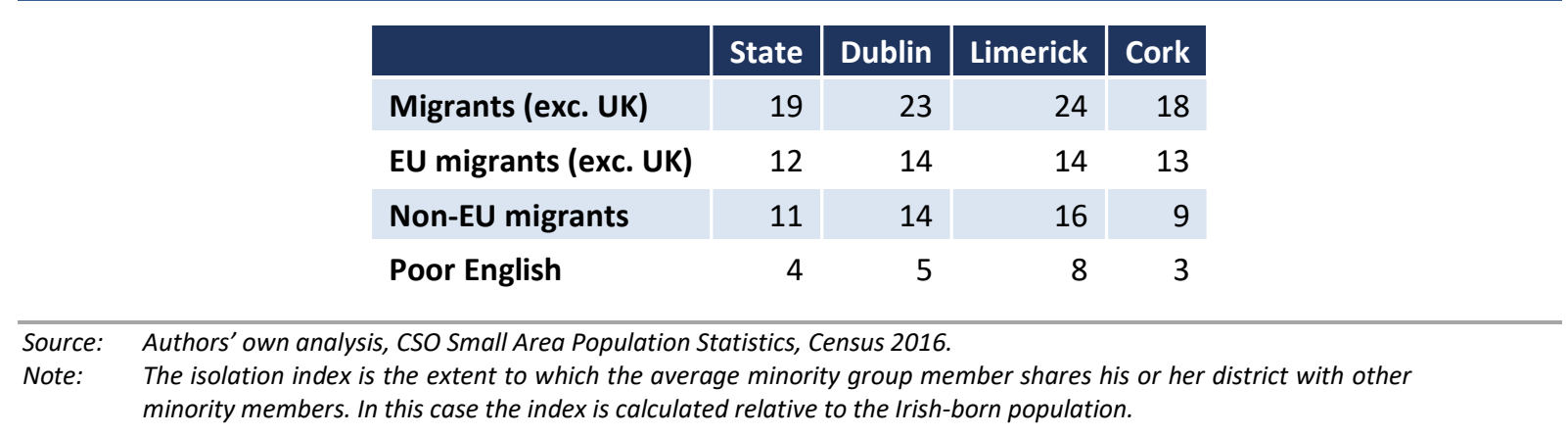

As expected, the results from the analysis of the isolation index are heavily influenced by group size (Table 3.3). The overall foreign-born group has the highest probability of living in a neighbourhood dominated by fellow group members, while the equivalent values for the very small group of people with poor Englishlanguage proficiency are much smaller. The other, intermediate-sized groups (EUand non-EU-born) fall in between.

Comparing across regions, we see that the cities are generally more segregated than the state as a whole. Within groups, Cork is slightly less segregated and Limerick and Dublin are slightly more segregated. The typical non-English speaker in Limerick lives in an ED in which 8 per cent of the population are fellow nonEnglish speakers. This is high when we consider that only 1.8 per cent of the population of Ireland does not speak English well or at all. This finding is consistent with the high value for non-English speakers in the dissimilarity index for Limerick above (42).

\subsection{CHANGE IN IMMIGRANT CONCENTRATION OVER TIME}

We now consider whether immigrant groups became more or less concentrated over the 2011-2016 intercensal period. From a socio-economic perspective, this is an interesting period in Ireland, which was characterised by recovery from deep recession and a return to net inward migration.

Perhaps the most intuitive method to evaluate change over this period is to simply compare dissimilarity and isolation indices for each group in 2011 and 2016. However, this is problematic because the time period is so short, meaning that there is a great deal of residential stability. While these indices do change from 2011 to 2016, the differences are typically quite small (see Table 3A.2 in the appendix to this chapter). Instead, we consider the change over time in the proportion of migrants at the ED level and see whether the increase is greater in areas with higher initial levels (showing increased concentration) or with lower initial levels (showing desegregation). 
To do this, we constructed change over time variables for each group's share of the ED's population. We then split all 3,409 EDs into quintiles (fifths) by 2011 group share. The bottom quintile is the 20 per cent of EDs with the smallest minority group shares, the second quintile is the next 20 per cent, and so on. We then compare average over-time change across these quintiles. If the groups were becoming more segregated, we would expect to see the biggest increase in the top quintiles, and the smallest increases (or perhaps even a decrease) in the bottom quintiles. If they were becoming less segregated we would see the largest increases accruing to the bottom quintiles.

Figure 3.1 shows the breakdown of change in the share of foreign-born residents (non-Irish/UK) by 2011 quintile. No clear pattern emerges. EDs in the top quintile by foreign-born population in 2011 had by 2016 experienced an increase in the share of foreign-born population of 0.76 percentage points. However, a relatively large increase ( 0.66 percentage points) also accrued to the quintile with the fewest foreign-born residents in 2011. Much smaller increases were registered in the middle three quintiles.

FIGURE 3.1 PERCENTAGE POINT CHANGE IN SHARE OF POPULATION COMPRISING MIGRANTS BY 2011 QUINTILE, 2011-2016

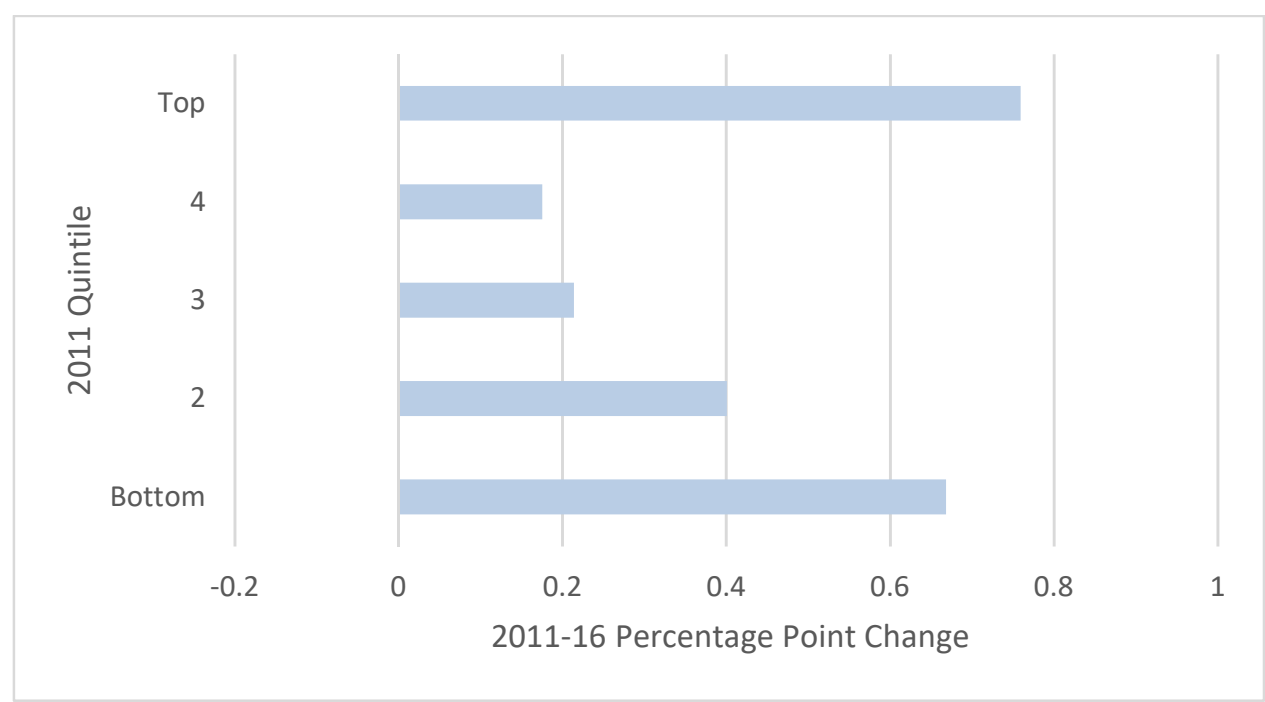

Source: $\quad$ Authors' own analysis, CSO Small Area Population Statistics, Census 2011 and 2016.

Note: $\quad$ Foreign-born population increased from an average of 5.72 per cent across all EDs in 2011 to 6.17 per cent in 2016. 
By contrast, in Figure 3.2 we see a clear trend towards a decrease in segregation among EU migrants. Very little of the increase in the EU-born population that occurred over the 2011-16 period took place in the top two quintiles by 2011 group share. In the EDs with the fewest EU migrants relative to their population in 2011 there was a substantial increase of 0.47 per cent. This amounts to a trebling of the average EU-born population share in the bottom quintile, which was 0.23 per cent in 2011 and 0.76 in 2016.

FIGURE 3.2 PERCENTAGE POINT CHANGE IN SHARE OF POPULATION COMPRISING EU MIGRANTS BY 2011 QUINTILE, 2011-2016

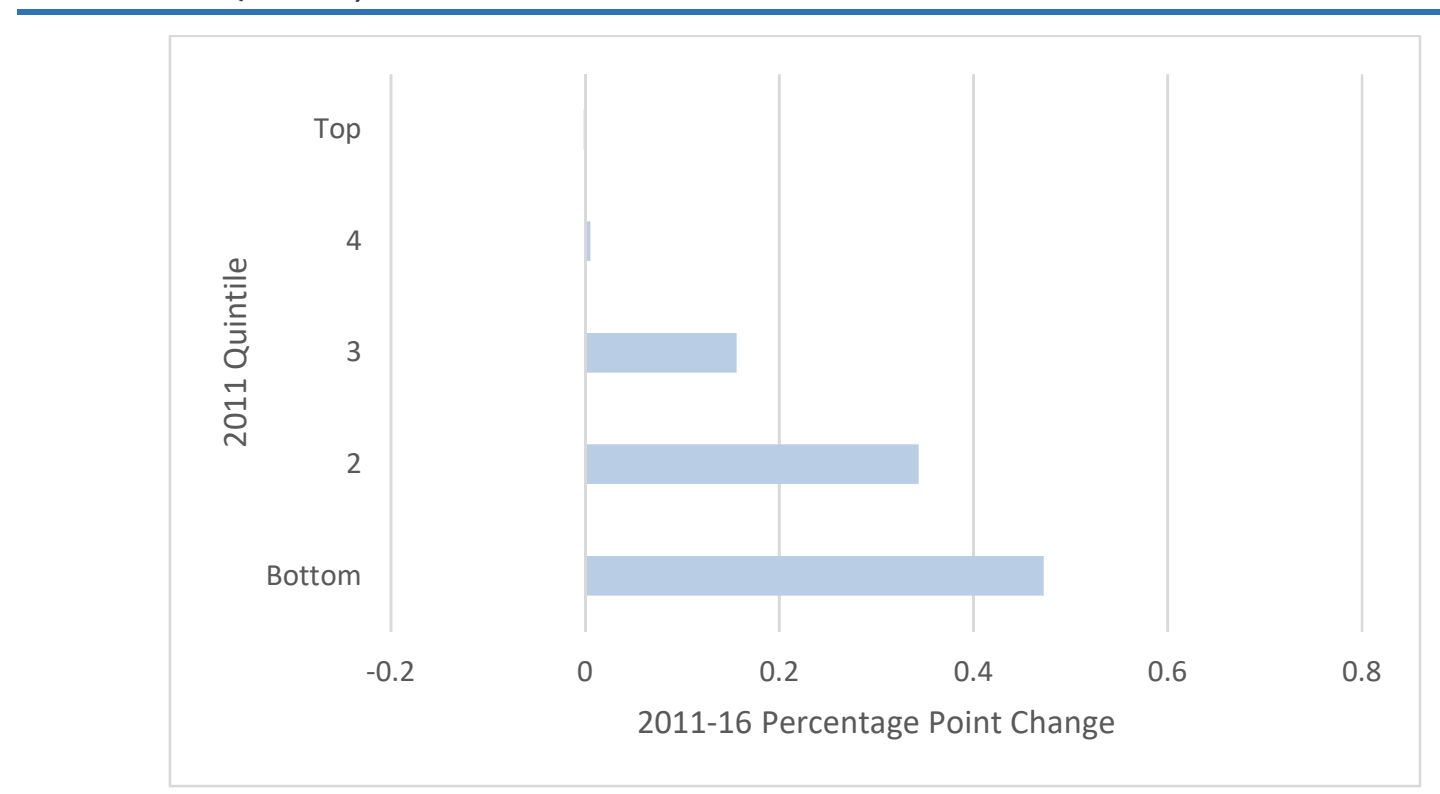

Source: $\quad$ Authors' own analysis, CSO Small Area Population Statistics, Census 2011 and 2016.

Note: $\quad$ Population born in the EU increased from an average of 3.09 per cent across all EDs in 2011 to 3.28 per cent in 2016. 
For the non-EU migrant group there is no clear pattern of change over time (see

Figure 3.3). Here the largest increases are at both the top and bottom of the 2011 distribution. For instance, the EDs with the highest shares of non-EU-born residents in 2011 experienced an average increase of half a percentage point (rising from 7 to 7.5 per cent), while the lowest quintile saw an increase of 0.4 percentage points (rising from 0.48 per cent to 0.88 per cent). The increase in the second quintile, of 0.26 percentage points, was similar to the average across all EDs.

FIGURE 3.3 PERCENTAGE POINT CHANGE IN SHARE OF POPULATION COMPRISING NON-EU MIGRANTS BY 2011 QUINTILE, 2011-2016

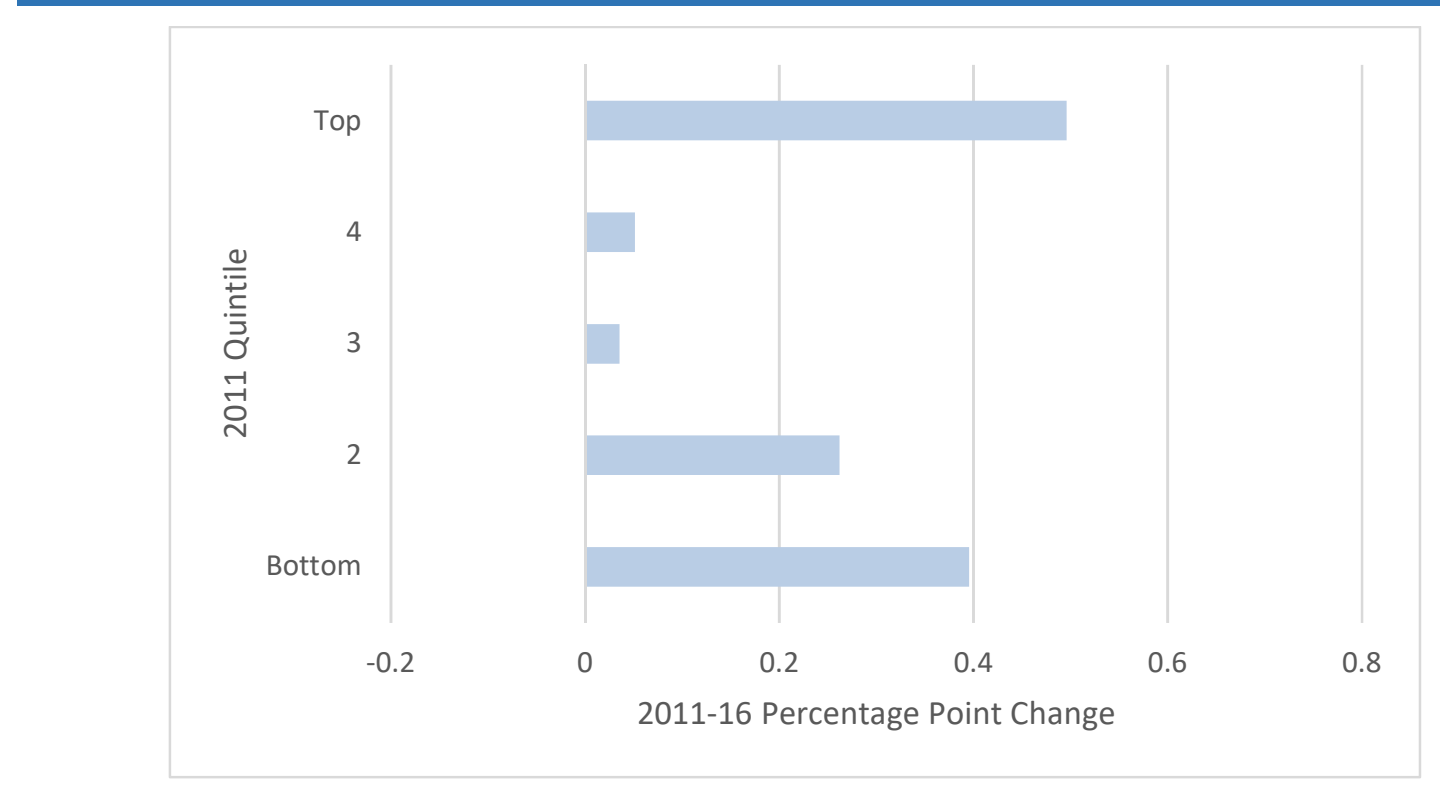

Source: $\quad$ Authors' own analysis, CSO Small Area Population Statistics, Census 2011 and 2016.

Note: $\quad$ Population born outside the EU increased from an average of 2.64 per cent across all EDs in 2011 to 2.89 per cent in 2016. 
Finally, much like the EU-born population, Figure 3.4 shows a clear trend towards desegregation of the population with poor English-language proficiency. While the overall size of this group declined very slightly (by 0.06 percentage points) between 2011 and 2016, the decrease was more marked (a further 0.45 percentage points) in the top quintile. By contrast, there were substantial increases in the bottom two quintiles.

It is important to keep in mind that unlike the country of birth variables, this measure of language ability is not permanent. So the people that report not being able to speak English in 2011 may not be the same people who report it in 2016. In fact, we would expect people's English to improve the longer they stay in Ireland.

FIGURE 3.4 PERCENTAGE POINT CHANGE IN SHARE OF POPULATION COMPRISING PEOPLE WITH POOR ENGLISH-LANGUAGE PROFICIENCY BY 2011 QUINTILE, 2011-2016

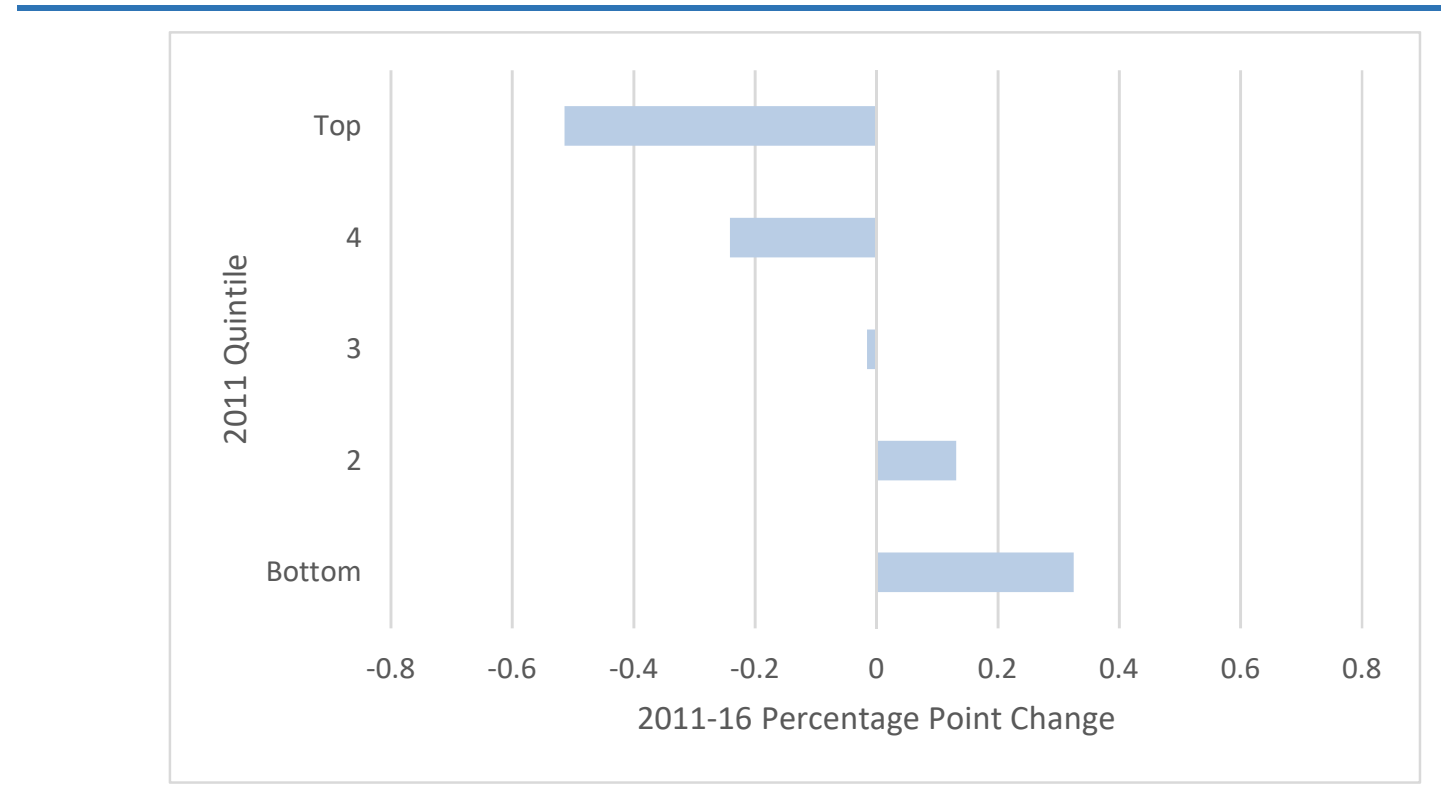

Source: $\quad$ Authors' own analysis, CSO Small Area Population Statistics, Census 2011 and 2016.

Note: $\quad$ Population with poor English-language proficiency decreased from an average of 1.01 per cent across all EDs in 2011 to 0.95 per cent in 2016.

\subsection{SUMMARY}

This chapter has shown that while there is some variation between groups in the extent to which they are segregated from the Irish-born population, levels of segregation in Ireland are typical of West-European nations. In line with the results from Chapter 2, the formal measures we use here show that segregation is somewhat greater among people with poor English-language proficiency, especially in Limerick. The analysis of cross-national data shows that defining groups by single countries of origin tends to yield higher scores on the dissimilarity index. With the data available to us, we cannot rule out that some narrowly defined groups experience much greater residential segregation, though it is also known that for small minorities the segregation indices are prone to greater error. 
When we use a measure of interaction known as the isolation index, the values are largely determined by group size, with larger groups showing higher scores. NonUK migrants as a whole have a relatively high propensity to share their neighbourhood with other foreign-born residents. Finally, the chapter shows that while there is a good deal of stability over time in migrant residential settlement, there is some evidence of movement away from segregation among the EU born group and migrants with poor English-language proficiency.

CHAPTER 3 APPENDIX

TABLE 3A.1 DISSIMILARITY INDICES FOR MINORITY GROUPS IN IRELAND, 2011

\begin{tabular}{|l|r|r|r|r|}
\hline & State & Dublin & Limerick & Cork \\
\hline Migrants (exc. UK) & 33.6 & 30.2 & 37.7 & 26.6 \\
\hline EU migrants (exc. UK) & 36.5 & 32.1 & 38.5 & 28.2 \\
\hline Non-EU migrants & 34.1 & 31.2 & 37.3 & 26.8 \\
\hline Poor English & 38.5 & 33.8 & 36.8 & 28.2 \\
\hline
\end{tabular}

Source: $\quad$ Authors' own analysis, CSO Small Area Population Statistics, Census 2011.

Note: The dissimilarity index is the proportion of the minority group that would have to relocate to achieve an even distribution across all EDs (Iceland et al., 2002). In this case, the index is calculated relative to the Irish-born population.

TABLE 3A.2 CHANGE IN DISSIMILARITY INDICES FOR MINORITY GROUPS IN IRELAND, 2011-16

\begin{tabular}{|l|r|r|r|r|}
\hline & State & Dublin & Limerick & Cork \\
\hline Migrants (exc. UK) & -0.9 & -1.9 & -1.9 & 1.1 \\
\hline EU migrants (exc. UK) & -1.6 & -2.0 & -3.6 & -0.2 \\
\hline Non-EU migrants & -0.2 & -2.3 & -0.4 & 2.3 \\
\hline Poor English & -1.1 & -1.4 & 5.5 & -1.7 \\
\hline
\end{tabular}

Source: $\quad$ Authors' own analysis, CSO Small Area Population Statistics, Census 2011 and 2016.

Note: $\quad$ The dissimilarity index is the proportion of the minority group that would have to relocate to achieve an even distribution across all EDs (Iceland et al., 2002). In this case, the index is calculated relative to the Irish-born population. 



\section{Characteristics of areas with high immigrant concentrations}

While residential patterns are important in their own right, it is particularly useful to know if patterns of concentration are linked to area-level characteristics in any systematic way (Piekut et al., 2019). If the areas in which migrants live in high concentrations are disadvantaged, this has implications for equality and wellbeing. It has been argued that neighbourhood characteristics can have impacts over and above individual factors on diverse outcomes such as child development and health and wellbeing (Morenoff, 2003; Riva et al., 2007; Russell et al., 2016; Sellstrom and Bremberg, 2006). We present a series of bivariate correlation coefficients showing the relationship between group share and the characteristics of EDs. We also present results from negative binomial regressions which show the association of each variable with the group's size while controlling for other factors.

The area characteristics we look at concern both deprivation/affluence and housing. Deprivation is important in this instance because, from an integration perspective, a concentration of immigrants in one geographic area is much more problematic if the area is disadvantaged. We look at housing because it has been identified in the literature as critical in explaining the distribution of the migrant population in Ireland (Fahey and Fanning, 2010; Vang, 2010).

We follow various authors in employing the Haase-Pratschke (HP) deprivation index as a measure of deprivation/affluence. The index, which was developed for Pobal, is centred near zero (-1.1) across EDs, and 99.5 per cent of EDs have a value between -20 (most deprived) and +20 (most affluent). ${ }^{15}$ The HP measure is constructed using Census data, and is based on demographic factors, the social class composition of the area, and its labour market characteristics. ${ }^{16}$

We then focus on three key variables which are used in constructing the overall deprivation index. These are: the share of the ED's population that have completed tertiary education, the share of the population that are unemployed and the share of the population that are living in a household headed by an unskilled or semiskilled worker. Note that for some of these variables higher values indicate

15 At ED level the scores range from a minimum of -31.9 to +22.5 . Eight of the ten most affluent EDs are in Dublin. Across the small areas (SAs) the HP score is centred on zero and ranged from -39 to +40 in 2016.

16 The HP index score is derived from ten area-based indicators: age dependency ratio, population change in past five years, percentage of population with primary education only, percentage of population with third-level education, percentage of households headed by professional/managerial worker, percentage of households headed by semiskilled or unskilled manual worker, percentage of households with children aged under 15 years and headed by a single parent, persons per room, male unemployment rate and female unemployment rate. These are combined using confirmatory factor analysis to establish weights (Haase and Pratschke, 2017). 
advantage (HP index, share of ED with tertiary education), but for others higher values indicate disadvantage (share unemployed and share living in a household headed by an unskilled or semi-skilled worker).

In terms of housing, we are interested in both the dominant form of tenure in the area and the age of the housing stock. We therefore consider two variables that capture the share of the housing stock that is rented from local authorities (LAs) and the share rented from private landlords. Finally, we include a variable for the share of residential properties that were built after the year 2001. Approximately three-quarters of the residential properties in the ED of Dublin Airport and its neighbouring ED of Dubber were built in this period. There are also high shares of recently built properties in Kilbarry (75 per cent) and Gracedieu (71 per cent) in Waterford. We include the proportion of new housing as a potential indicator of housing supply.

Table 4.1 displays descriptive statistics for these variables in 2016. The three housing variables have minimum values of zero. Two EDs have no new housing, 40 have no private rented accommodation and 433 have no local authority housing.

\begin{tabular}{|l|r|r|l|}
\hline & Mean & Min & Max \\
\hline HP index & -1.1 & -31.9 & 22.5 \\
\hline \% Third level & 30.9 & 2.4 & 81.3 \\
\hline \% Unemployed & 7.1 & 0.7 & 31.7 \\
\hline \% Semi-skilled/unskilled & 18.3 & 2.2 & 55.4 \\
\hline \% New housing & 27.1 & 0 & 75.2 \\
\hline \% Private rent & 11.7 & 0 & 87.3 \\
\hline \% LA rent & 5.5 & 0 & 66.4 \\
\hline
\end{tabular}

Source: $\quad$ Authors' own analysis, CSO Small Area Population Statistics, Census 2016.

\subsection{CORRELATIONS}

Table 4.2 shows a series of bivariate correlations between the groups' shares in the EDs and the covariate of interest. Correlation coefficients range from 1 to -1 . A score of 1 means that there is a perfect positive relationship between the two variables, meaning that one increases in step with the other. A score of -1 indicates that there is a perfect negative relationship, meaning that one decreases as the other increases, and a score of zero means that there is no association between the two variables. Because the data we use cover the universe of cases (rather than a sample), we do not give an indication of statistical significance. 
TABLE 4.2 CORRELATIONS, 2016

\begin{tabular}{|c|c|c|c|c|c|c|c|}
\hline & $\begin{array}{c}\text { HP } \\
\text { index }\end{array}$ & $\begin{array}{l}\% \text { Third } \\
\text { level }\end{array}$ & $\begin{array}{c}\% \\
\text { Unemployed }\end{array}$ & $\begin{array}{l}\text { \% Semi- } \\
\text { skilled/ } \\
\text { Unskilled }\end{array}$ & $\begin{array}{l}\% \text { New } \\
\text { housing }\end{array}$ & $\begin{array}{l}\text { \% Private } \\
\text { rent }\end{array}$ & $\begin{array}{l}\% \text { LA } \\
\text { Rent }\end{array}$ \\
\hline $\begin{array}{l}\text { Migrants (exc. } \\
\text { UK) }\end{array}$ & 0.24 & 0.43 & 0.29 & 0.08 & -0.03 & 0.90 & 0.36 \\
\hline $\begin{array}{l}\text { EU migrants } \\
\text { (exc. UK) }\end{array}$ & 0.17 & 0.32 & 0.30 & 0.14 & 0.04 & 0.83 & 0.36 \\
\hline $\begin{array}{l}\text { Non-EU } \\
\text { migrants }\end{array}$ & 0.29 & 0.50 & 0.22 & -0.01 & -0.11 & 0.83 & 0.29 \\
\hline Poor English & 0.01 & 0.13 & 0.38 & 0.23 & 0.06 & 0.69 & 0.37 \\
\hline $\begin{array}{ll}\text { Source: } & \text { Authors'c } \\
\text { Note: } & \text { Correlatio } \\
& \text { positive re }\end{array}$ & $\begin{array}{l}\text { alysis, CS } \\
\text { ficients ra } \\
\text { ship. }\end{array}$ & $\begin{array}{l}\text { mall Area Pop } \\
\text { e from }-1 \text { to } 1\end{array}$ & $\begin{array}{l}\text { ation Statistics, } \mathrm{Ce} \\
\text { vith }-1 \text { indicating }\end{array}$ & $\begin{array}{l}\text { sus } 2016 . \\
\text { perfect negati }\end{array}$ & lationship, & ting a perfect & \\
\hline
\end{tabular}

The correlation coefficients show that with the exception of people with poor English-language proficiency, these groups are more likely to reside in more affluent areas, as measured by the HP index. This is particularly the case for nonEU immigrants. A large part of that association appears to be due to the educational profile of the areas in which immigrants live. However, it may also be due to the age structure of these neighbourhoods, because a low ratio of children and elderly people to the working-age population (age dependency ratio) yields a higher score on the HP index.

By contrast, the findings on employment and social class are inconsistent with the HP index. All four groups, and in particular people with poor English-language proficiency, tend to live in areas with higher unemployment rates. With the exception of non-EU migrants, they are also more likely to live in areas with high concentrations of people in semi-skilled or unskilled occupations.

Turning to the housing variables, the strongest association is between private rented accommodation and group share, particularly for the total foreign-born group. This relationship is displayed in Figure 4.1. 


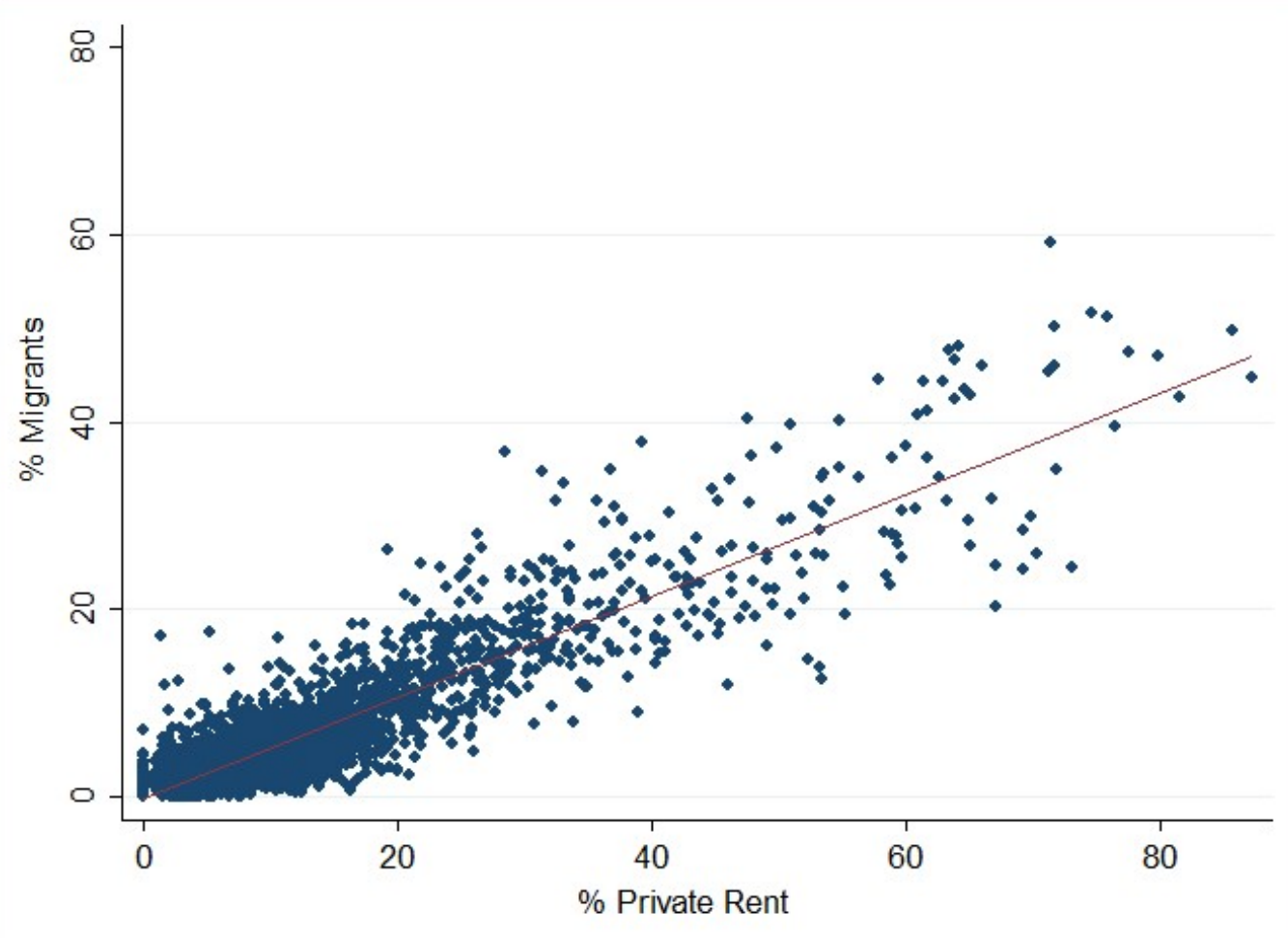

Source: $\quad$ Authors' own analysis, CSO Small Area Population Statistics, Census 2016.

\subsection{MODELS}

\subsubsection{Estimation}

We now turn to investigating the relationship between these covariates and the group shares in a multivariate framework. We employ negative binomial regression models. This is a specification designed to model count variables, such as the number of migrants in a spatial unit. ${ }^{17}$ We present the results of these models as semi-elasticities. They therefore represent the percentage increase in the outcome variable (in this case number of migrants in the ED) associated with a one-unit increase in the explanatory variable, holding other explanatory variables constant and including a control for the size of the ED. ${ }^{18}$

We estimate two models for each group. We first look at the effect of the HP index alone and then at the other six variables. Including the HP index with the measures of education, unemployment and social class would be problematic because these

17 A negative binomial regression is used instead of a Poisson regression when the dependent variable is over-dispersed - i.e. when the variance is greater than the mean.

18 We account for the total population of the ED by including the log of the total population as an 'offset' variable (Anderson, 2018). 
variables feed in to the construction of the index, meaning that they would operate both in isolation and through the index.

In the chapter appendix we present results from the equivalent models restricted to EDs in the cities of Dublin, Limerick and Cork. This incorporates 466 EDs which are home to 50 per cent of the migrant population. City location affects both the concentration of migrants (they are more concentrated in the three cities) and the distribution of some of the independent variables of interest. For instance, Appendix Table A4.1 shows that tertiary education is considerably higher in the three main cities than elsewhere. This means that some of the association between tertiary education and the size of the migrant population may be related to residence in the three cities. ${ }^{19}$

We present the results graphically to allow for easy comparison between groups and across independent variables. Again, because we are using Census data rather than a sample, we do not comment on the statistical significance of the estimates.

\subsubsection{Results}

\section{All migrants}

Figure 4.2 presents the results from the two models for the entire foreign-born population (excluding UK). As in the correlations shown above, the HP index has a positive association with the size of the migrant population, meaning that the migrant population tends to be concentrated in relatively affluent areas. According to this model, a one-unit increase in the HP index is associated with a 3.2 per cent increase in the size of the migrant population.

Private rented accommodation has the strongest association with the size of the migrant population. Accounting for other variables, a 1 percentage point increase in the proportion of housing that is rented on the private market is associated with a 4.7 per cent increase in the migrant population. This is borne out at the top of the distribution - seven of the top ten districts by migrant share (shown in Table 2.1) are in the 20 districts with the highest proportions of private rented accommodation. There is also a relatively strong relationship between local authority housing and the migrant population, demonstrating that migrants tend to live in areas characterised by low rates of home ownership. Finally, migrants tend to live in areas with above-average prevalence of third-level education.

However, when we run this model in Dublin, Limerick and Cork only (see chapter appendix), we find that some of these relationships change. The association with

19 As an additional robustness test, we ran the full models with a control for population density. The same pattern of results for the disadvantage and housing variables is reproduced, which means that the findings are not driven by urban-rural location. 
tertiary education disappears within the cities (see Appendix Figure A4.1). We also find that within cities, migrants are more likely to live in areas with high unemployment, but are less likely to live in areas characterised by high levels of unskilled or semi-skilled occupations. A one percentage point increase in the prevalence of these occupations reduces the number of migrants by almost 2 per cent. While restricting the analysis to the cities makes little difference to the private rented accommodation variable, it eliminates the effect of local authority housing. This is because there is a much higher concentration of local authority housing in urban areas, where migrants tend to reside in greater numbers.

FIGURE 4.2 ASSOCIATIONS BETWEEN AREA CHARACTERISTICS AND MIGRANT (EXCLUDING UK-BORN) POPULATION - NEGATIVE BINOMIAL REGRESSIONS

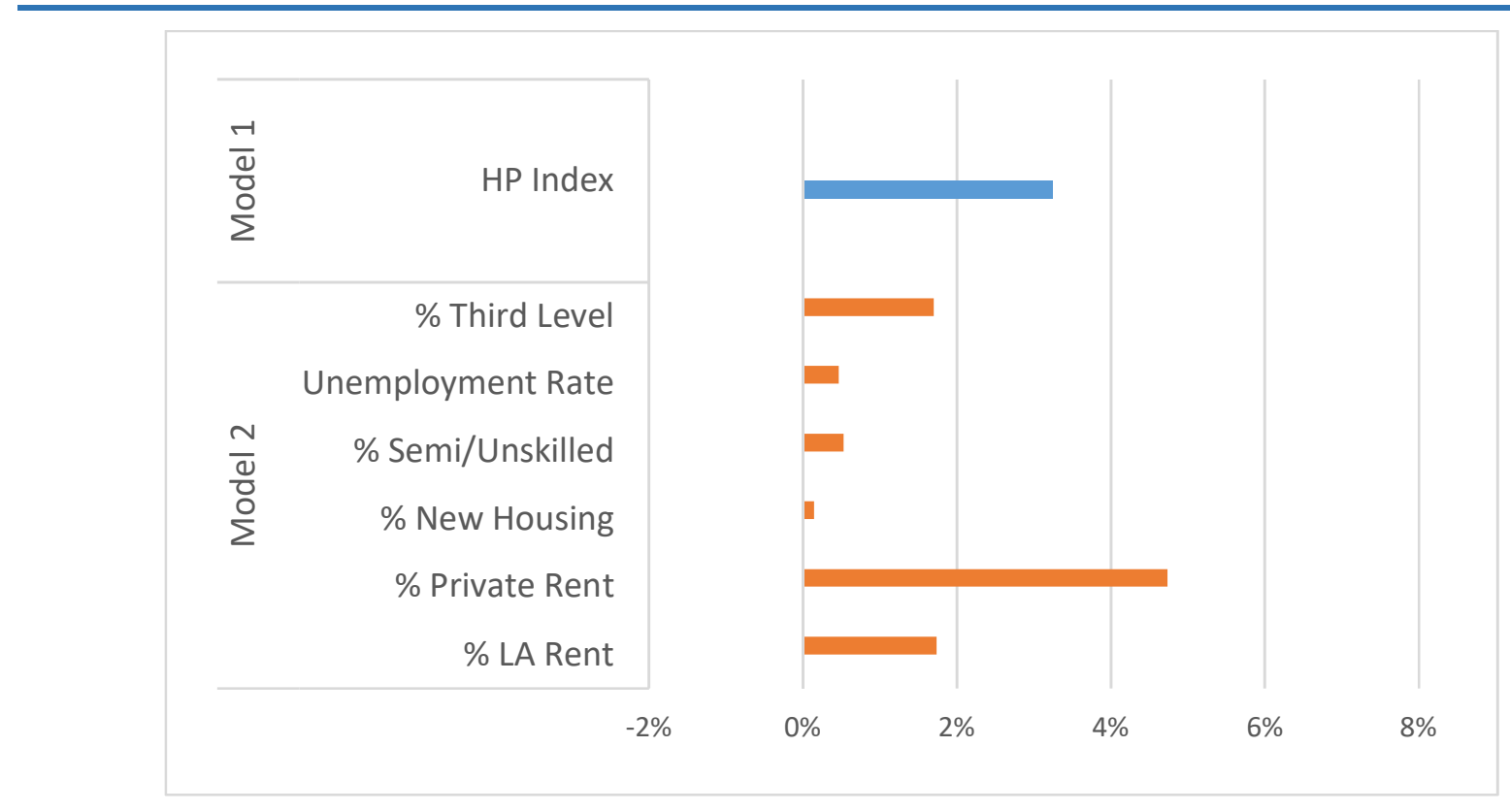

Source: $\quad$ Authors' own analysis, CSO Small Area Population Statistics, Census 2016.

\section{EU migrants}

The magnitude of the effects is somewhat different for EU migrants (see Figure 4.3). We find that this sub-group of the migrant population is more likely to live in affluent areas, but the relationship is weaker than that found for all migrants.

The association between private rented accommodation and size of the EU-born population is even stronger than in the case of the total migrant population. The model shows that when we account for other factors, a 1 percentage point increase in private rented accommodation is associated with a 6.1 per cent increase in the size of the EU migrant population. Centre A in Cork city is the ED with the fourth highest share of EU-born residents (29.9 per cent), and is also the ED with the highest share of private rented accommodation in the country (87.3 per cent). Like for the total migrant population, there is also a relatively strong 
relationship between the share of LA housing in the district and the EU-born population. ${ }^{20}$

While the correlations suggested that the proportion of EU-born was positively associated with unemployment, this is not the case when other area characteristics are controlled for. In the model the relationship is negative, meaning that the EU migrant population is concentrated in areas with below-average unemployment when other characteristics are taken into account. Figure 4.3 also shows that the EU-born population have a weak tendency to live in areas with higher educational profiles.

However, when we look at the cities only (see chapter appendix), we find that some of the effects shown in Figure 4.3 reverse. Within cities, EU migrants are more likely to live in areas characterised by below-average rates of tertiary education and slightly above-average unemployment. There is also a relatively strong association between new housing and the size of the EU-born population. A 1 percentage point increase in the share of houses that are newly built (since 2001 ) is associated with a 1 per cent increase in the number of EU migrants.

FIGURE 4.3 ASSOCIATIONS BETWEEN AREA CHARACTERISTICS AND EU-BORN POPULATION - NEGATIVE BINOMIAL REGRESSIONS

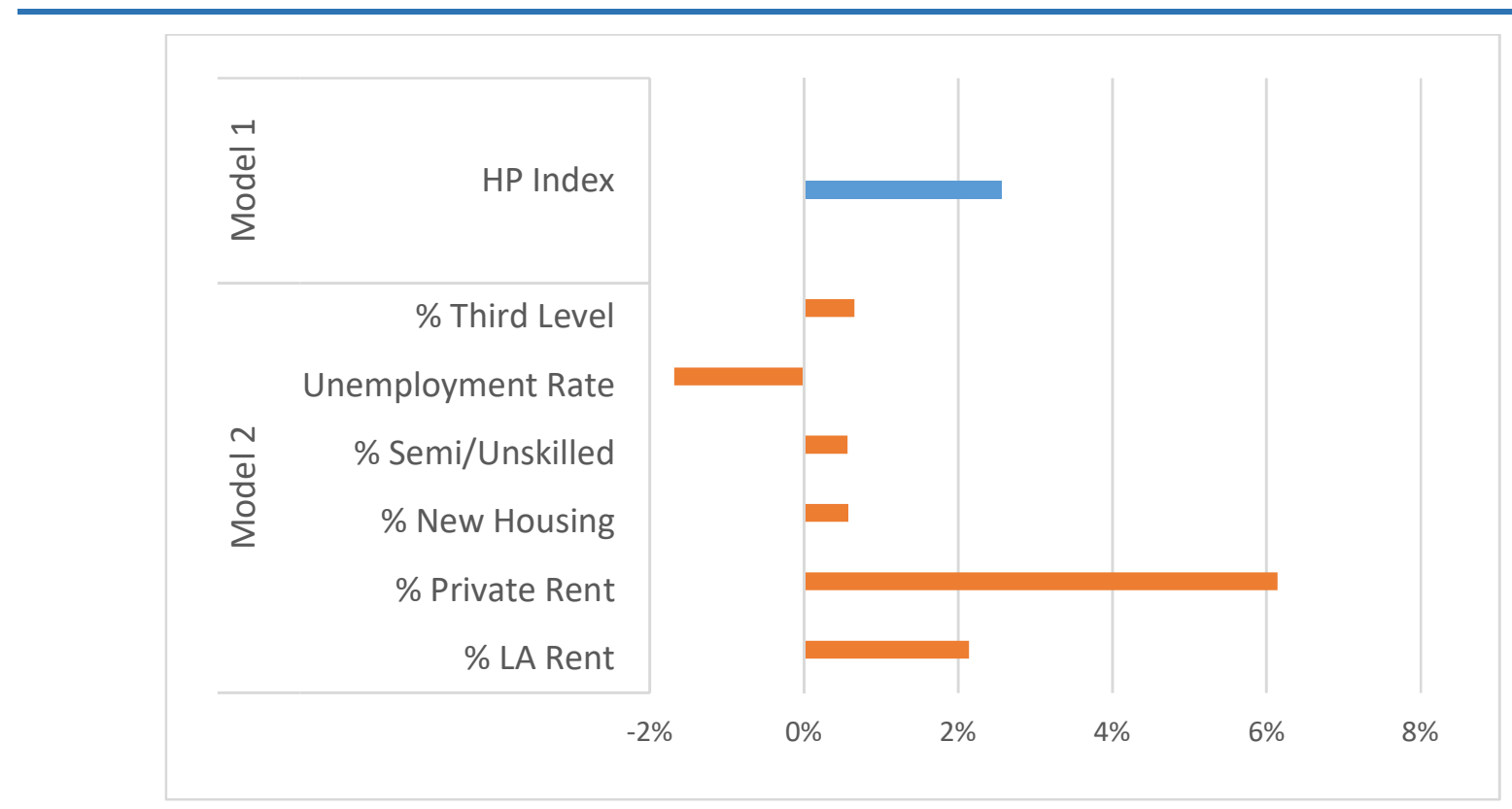

Source: $\quad$ Authors' own analysis, CSO Small Area Population Statistics, Census 2016.

Note: $\quad$ Excludes UK-born.

20 Note however that this finding is reversed when we restrict the analysis to Dublin, Limerick and Cork (see chapter appendix). 


\section{Non-EU migrants}

The results for non-EU migrants are shown in Figure 4.4. Here we find stronger associations with both the prevalence of tertiary education in the ED and the unemployment rate. A 1 percentage point increase in the prevalence of unemployed people and people with third-level education brings about increases in the size of the non-EU migrant population of just over 2.5 per cent when we control for other variables. The ED of Custom House B in Waterford has both the highest unemployment rate (31.7 per cent) and the highest share of non-EU-born residents (38.6 per cent). Overall, however, the non-EU population tends to live in affluent areas as measured by the HP index. For instance, the top ten areas by share of non-EU residents have an average HP index score of 5, and the top 100 have an average HP index score of 5.6, both of which are somewhat above the national average score of -1.1 .

These findings suggest that the age profile of the EDs may be mediating the relationship between the educational and employment profile of the areas and the size of the population born outside of the EU. Young people in Ireland are both more likely to be unemployed and more likely to be highly educated (Kelly et al., 2016). However, as a robustness check we added a variable for the percentage of the population made up of young adults (aged 15 to 35). This made no significant difference to the effects of area-level education and unemployment.

That said, restricting the analysis to the three main cities causes the education effect to weaken substantially. Another difference that emerges in the urban models in Figure A4.3 is that the non-EU population are found to be concentrated in areas with a low prevalence of low or semi-skilled workers. A 1 percentage point increase in this measure is associated with a 2.9 per cent decrease in the size of the non-EU population within cities, controlling for other factors. 
FIGURE 4.4 ASSOCIATIONS BETWEEN AREA CHARACTERISTICS AND NON-EU-BORN POPULATION NEGATIVE BINOMIAL REGRESSIONS

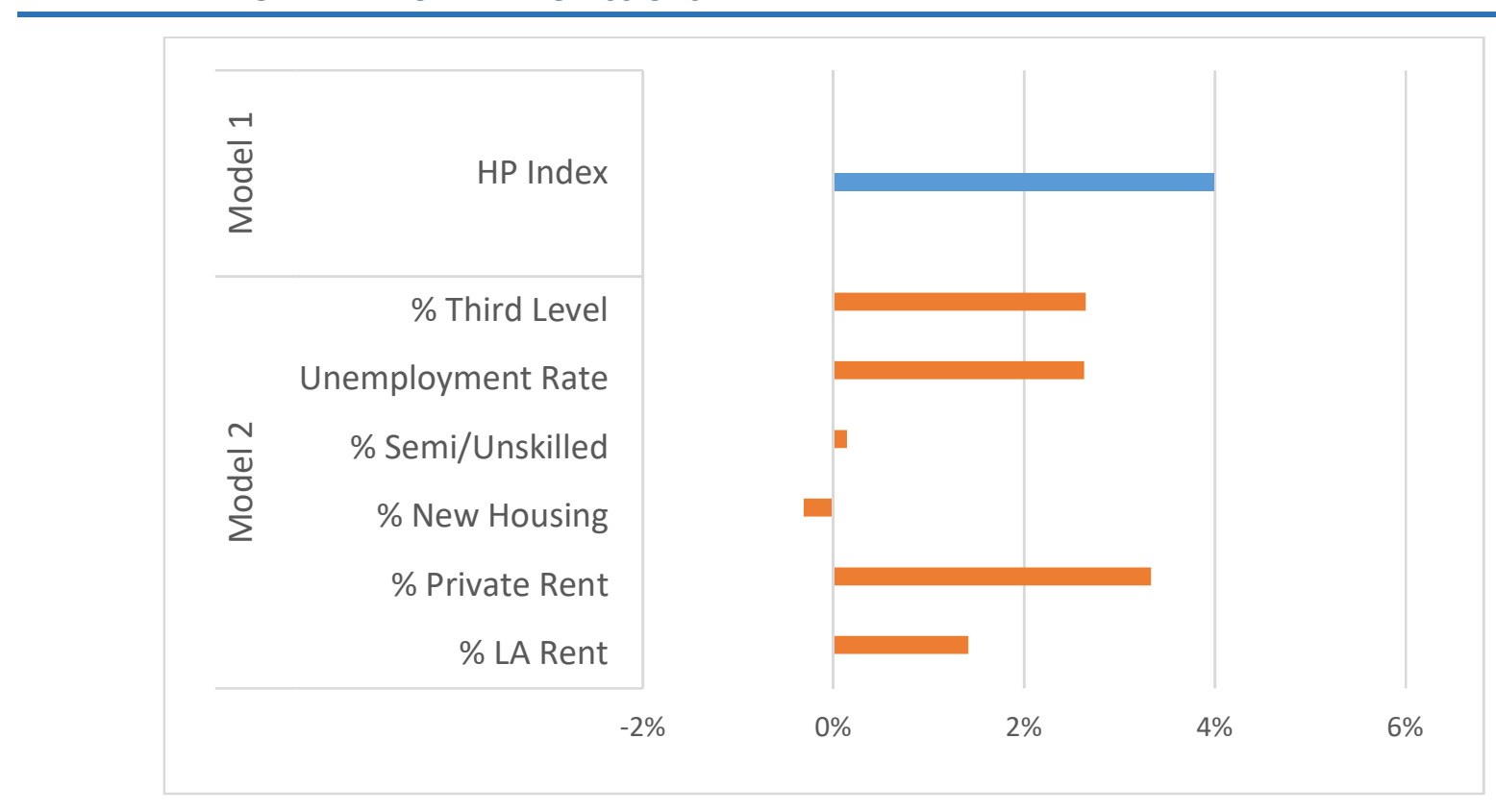

Source: $\quad$ Authors' own analysis, CSO Small Area Population Statistics, Census 2016.

\section{Poor English-language proficiency}

Unlike the other groups, we find that the HP index has no substantial association with the number of people with poor English-language proficiency (see Figure 4.5). The finding that they tend to live in less advantaged areas than other migrants is borne out by model 2. Unlike the other groups studied here, the association between tertiary education and the concentration of non-English speakers is negative. A 1 percentage point increase in area-level tertiary education is associated with a 1 per cent reduction in the number of people with poor Englishlanguage proficiency.

As with the other groups, private rented accommodation has a very strong, positive association with this group's residential concentrations. LA housing has a weaker but still substantial association.

When we consider only the EDs in the three cities, we find evidence that people with poor English-language proficiency are concentrated in areas of high unemployment. A 1 percentage point increase in the unemployment rate is associated with a 5 per cent increase in the size of the population with poor English within these urban areas. Furthermore, the positive effect of local authority housing is reversed when we consider the 466 urban EDs only. 
FIGURE 4.5 ASSOCIATIONS BETWEEN AREA CHARACTERISTICS AND POPULATION WITH POOR ENGLISHLANGUAGE PROFICIENCY - NEGATIVE BINOMIAL REGRESSIONS

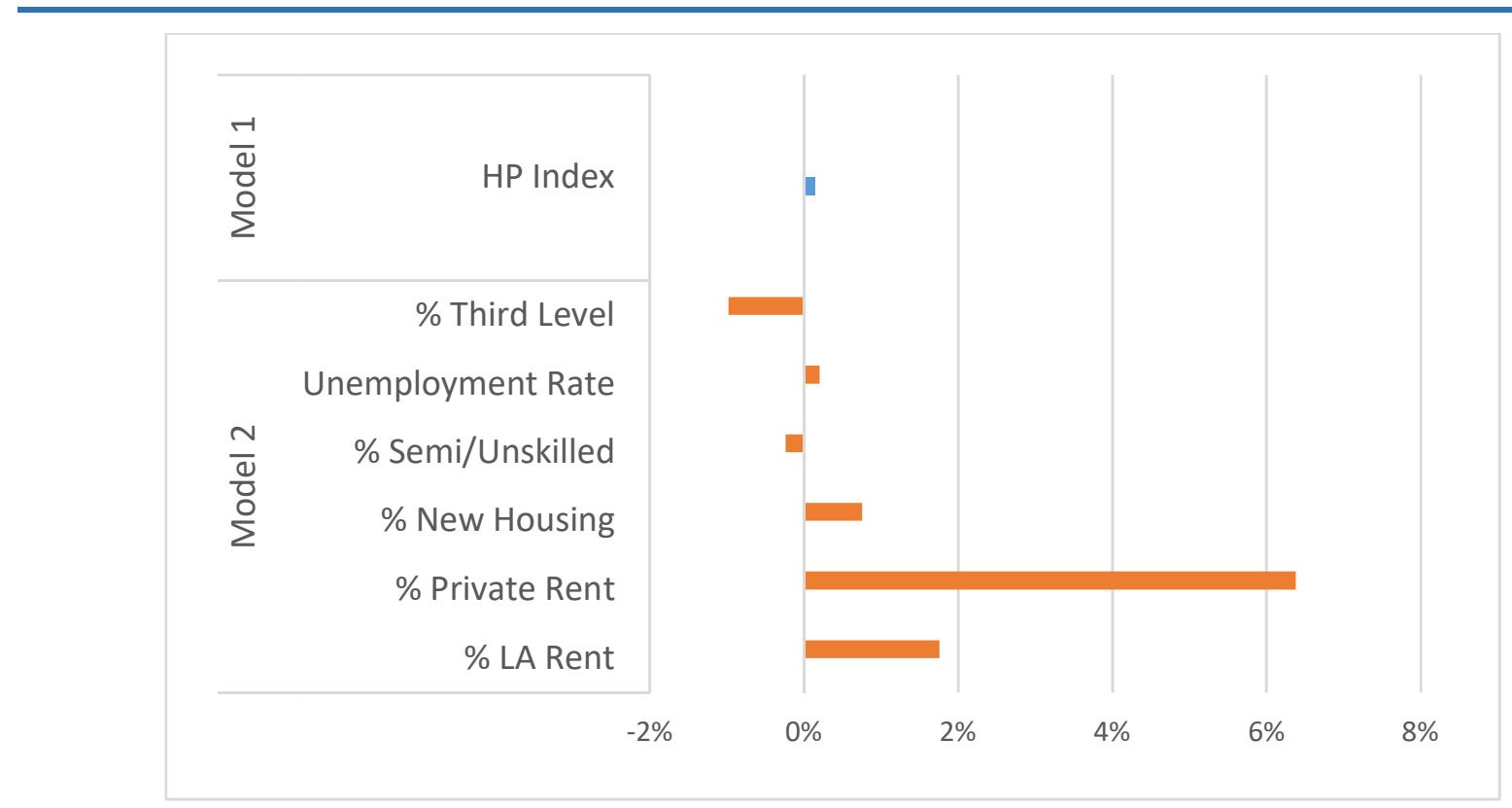

\subsection{SUMMARY}

Consistent with Fahey and Fanning's (2010) analysis of migrants' residential patterns in Dublin, this analysis shows that the availability of private rented accommodation is the area-level factor with the greatest association with migrant residential concentration in Ireland. The results also show that despite having relatively high levels of unemployment, the EDs with high levels of migrant concentrations tend to be affluent, and have high levels of acquisition of tertiary education.

However, some of these effects do not persist within the three main cities. The exception to the pattern of area affluence is people with poor English-language proficiency, who live in areas with average levels of affluence/deprivation and low tertiary education. Looking within the three major cities, we also find that people from this group, along with non-EU migrants, are more likely to live in areas with high unemployment rates. 


\section{CHAPTER 4 APPENDIX}

TABLE A4.1 MEAN VALUES OF INDEPENDENT VARIABLES BY RESIDENCE IN DUBLIN/CORK/ LIMERICK OR ELSEWHERE

\begin{tabular}{|l|r|r|}
\hline HP index & $\begin{array}{c}\text { Dublin/Cork/ } \\
\text { Limerick }\end{array}$ & Elsewhere \\
\hline \% Third level & 2.3 & -1.7 \\
\hline \% Unemployed & 41.4 & 29.2 \\
\hline \% Semi-skilled/Unskilled & 7.8 & 7.0 \\
\hline \% New housing & 17.1 & 18.4 \\
\hline \% Private rent & 16.1 & 28.8 \\
\hline \% LA rent & 25.0 & 9.6 \\
\hline
\end{tabular}

Source: $\quad$ Authors' own analysis, CSO Small Area Population Statistics, Census 2016.

Note: $\quad$ Refers to the 466 EDs in Dublin, Limerick and Cork that are described in Chapter 3.

FIGURE A4.1 ASSOCIATIONS BETWEEN AREA CHARACTERISTICS AND MIGRANT (EXCLUDING UK-BORN) POPULATION IN DUBLIN, LIMERICK AND CORK - NEGATIVE BINOMIAL REGRESSIONS

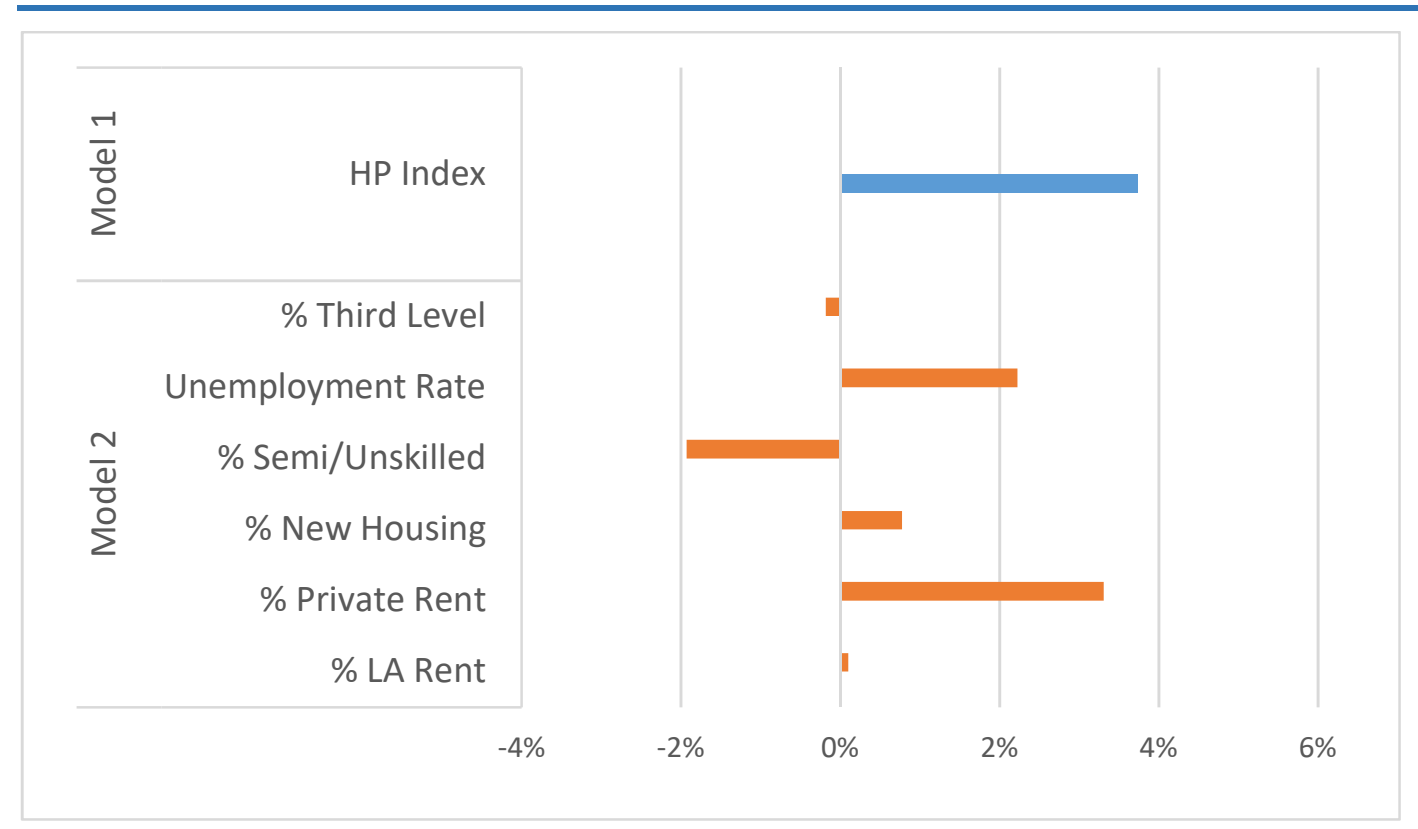

Source: $\quad$ Authors' own analysis, CSO Small Area Population Statistics, Census 2016.

Note: If we run these models with both the HP index and the other socio-economic variables, we find evidence that the independent variables are collinear. 
FIGURE A4.2 ASSOCIATIONS BETWEEN AREA CHARACTERISTICS AND EU-BORN POPULATION IN DUBLIN, LIMERICK AND CORK - NEGATIVE BINOMIAL REGRESSIONS

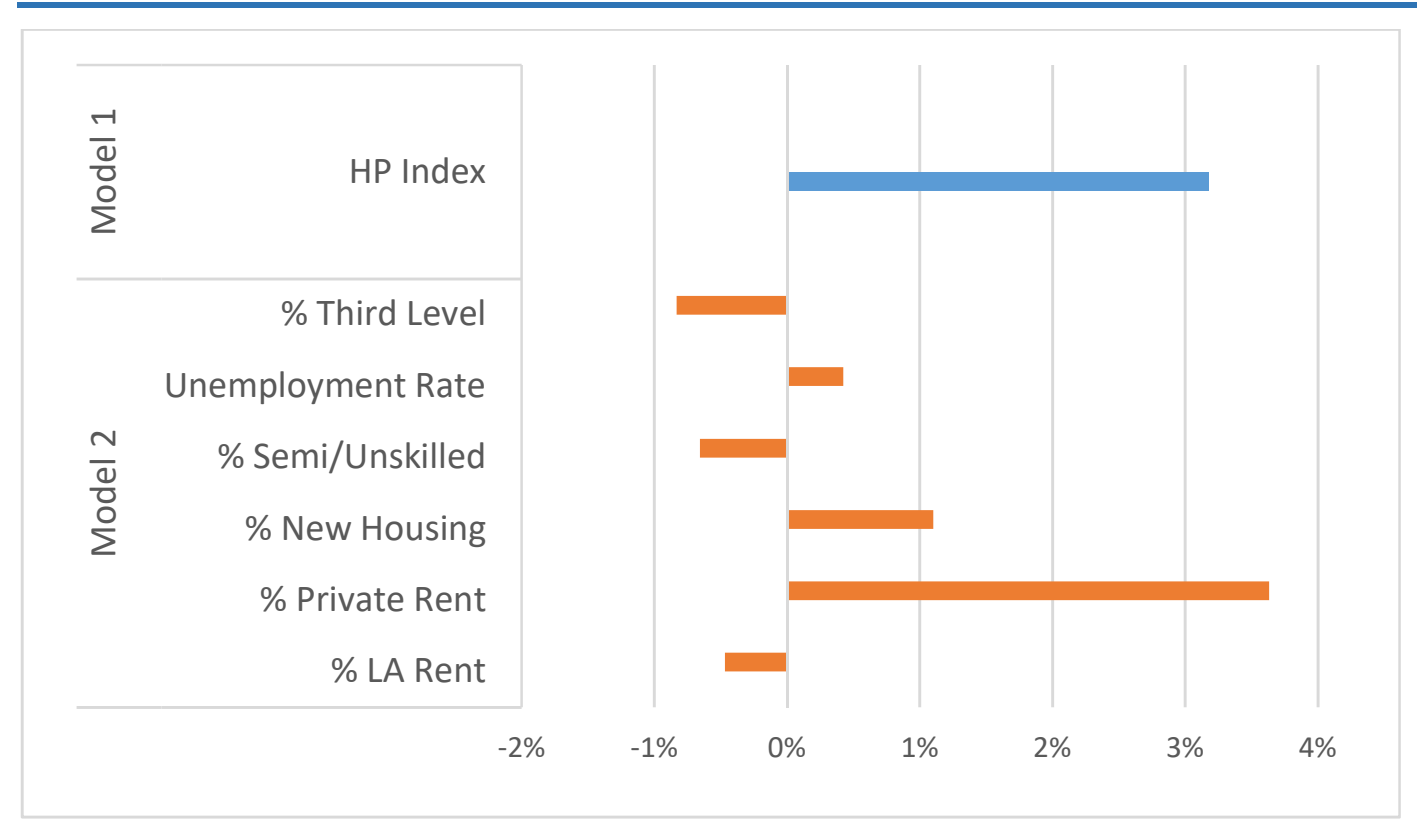

Source: $\quad$ Authors' own analysis, CSO Small Area Population Statistics, Census 2016.

Note: Excludes UK-born. If we run these models with both the deprivation index and the other socio-economic variables, we find evidence that the independent variables are collinear.

FIGURE A4.3 ASSOCIATIONS BETWEEN AREA CHARACTERISTICS AND NON-EU-BORN POPULATION IN DUBLIN, LIMERICK AND CORK - NEGATIVE BINOMIAL REGRESSIONS

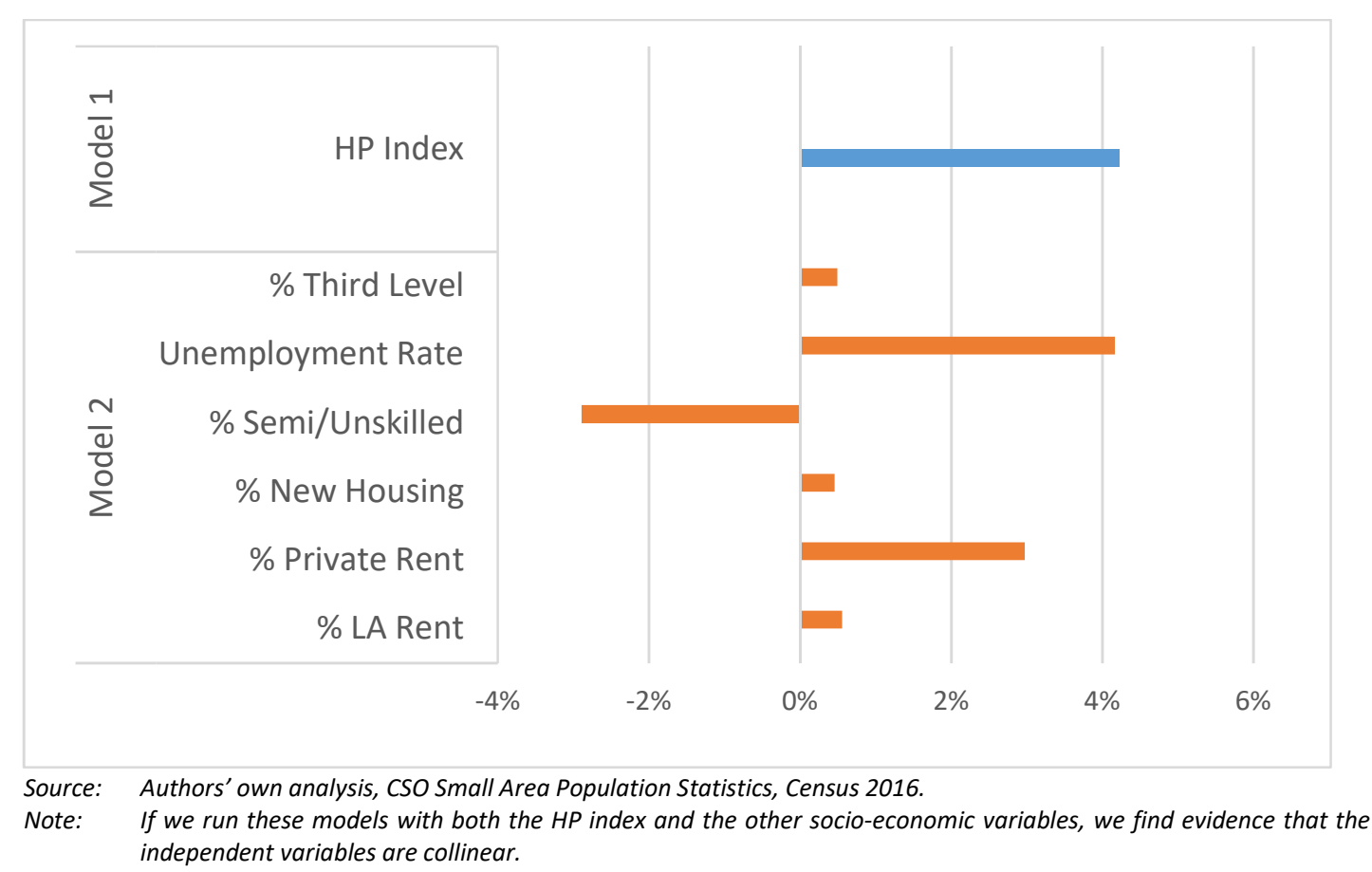


FIGURE A4.4 ASSOCIATIONS BETWEEN AREA CHARACTERISTICS AND POPULATION WITH POOR ENGLISHLANGUAGE PROFICIENCY IN DUBLIN, LIMERICK AND CORK - NEGATIVE BINOMIAL REGRESSIONS

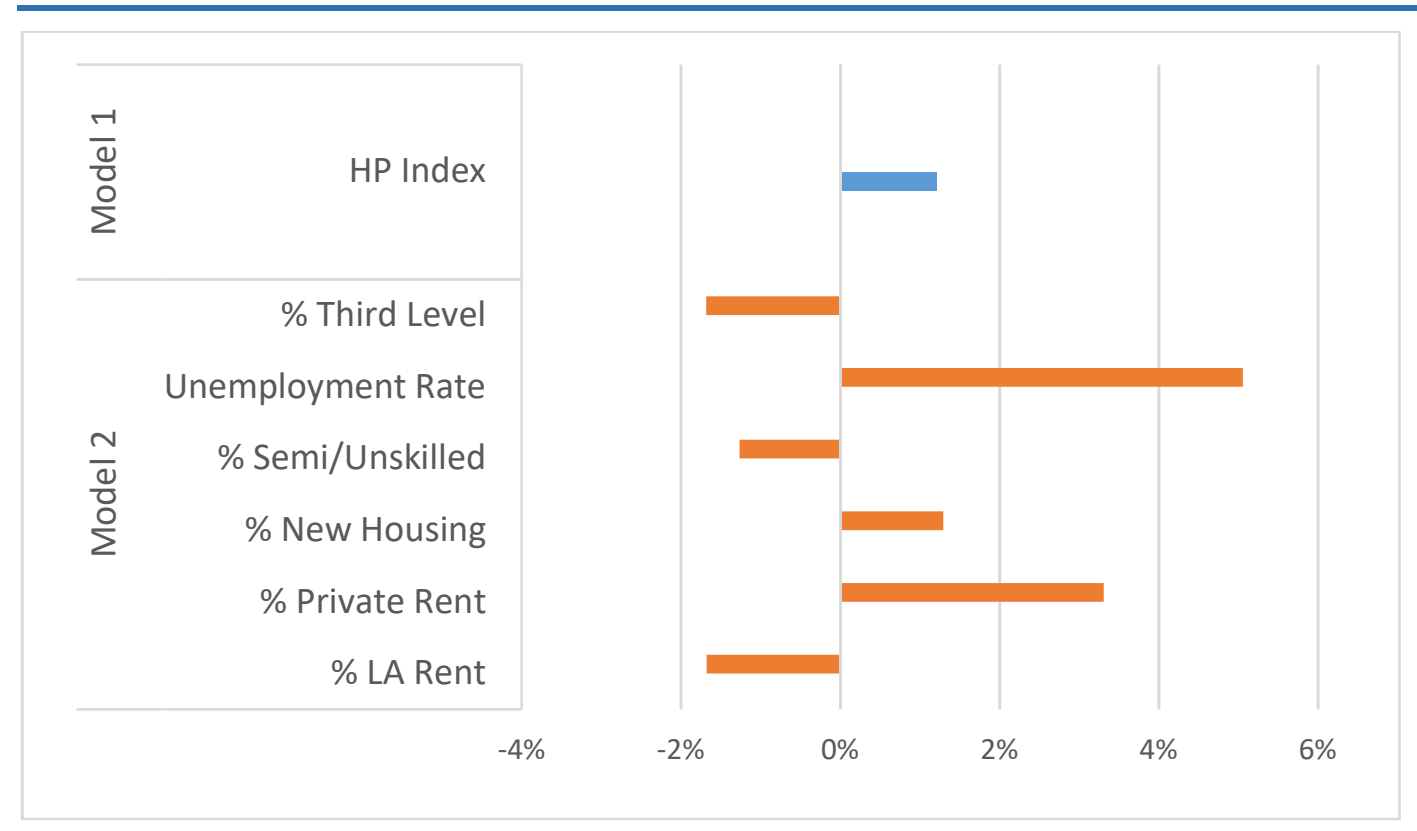

Source: $\quad$ Authors' own analysis, CSO Small Area Population Statistics, Census 2016.

Note: If we run these models with both the HP index and the other socio-economic variables, we find evidence that the independent variables are collinear. 



\section{CHAPTER 5}

\section{Summary and conclusions}

This report set out to use geocoded Census data to investigate residential outcomes among the migrant population in Ireland. It considers the entire non-UK foreign-born population, EU migrants, non-EU migrants and people with poor English-language proficiency. The analysis is carried out at the Electoral Division (ED) level.

The international literature and theoretical approaches reviewed in Chapter 1 highlight that there can be both positive and negative reasons for the residential clustering of migrants. Proximity to migrant networks can provide support and information. However, high levels of residential segregation may be a signal of poor integration and disadvantage, especially if the areas in which migrants are clustered are themselves deprived.

On the whole, we find little evidence that highly segregated communities or disadvantaged ethnic enclaves are being formed. This conclusion rests on a number of key findings.

\subsection{INTEGRATED COMMUNITIES}

First, while the foreign-born population is centralised in cities to a greater extent than the Irish population, our formal measures of dissimilarity show that levels of segregation in Irish cities are near or below average in a cross-national perspective.

Second, there is no discernible trend towards greater residential segregation. In fact, analysing change between the 2011 and 2016 Censuses shows clear evidence of desegregation among EU-born residents.

Finally, far from living in ghettos, immigrants in Ireland appear to be concentrated in affluent areas with above-average educational profiles. This is supported by recent individual-level research on immigrants in Ireland, which shows that many non-Irish nationals outperform natives in education and the labour market (McGinnity et al., 2018a).

\subsection{AREAS OF CONCERN}

That said, there are some areas of concern. In general, we find that people with poor English-language proficiency are less advantaged in terms of these outcomes. While they are less centralised in urban areas than the migrant groups that are defined by country of birth, they are more concentrated in relatively few areas. 
Half of Ireland's population with poor English-language skills can be found in just 135 of its 3,409 EDs. The typical resident of Limerick with poor English-language proficiency lives in a neighbourhood in which 8 per cent of the population cannot speak English well or at all.

Furthermore, unlike the EU and non-EU migrant groups, the size of the population with poor English-language proficiency in an area is not associated with affluence. In fact, this group is more likely to reside in areas with average levels of affluence/deprivation and low tertiary educational attainment. The findings therefore suggest that future research on individual-level integration outcomes is warranted among this group.

Particularly within the cities of Dublin, Limerick and Cork, immigrants from outside the EU and people with poor English-language proficiency show a tendency to reside in areas of above-average unemployment (holding other area characteristics constant). This finding is consistent with higher than average unemployment among non-EU migrants found at the individual level (see discussion in Chapter 1). While the correlation at the area level cannot be seen as causal, there is nevertheless the risk that neighbourhoods and social networks characterised by high unemployment can increase the prevalence of various negative outcomes. Evidence on this has been found in relation to depressive symptoms (Wight et al., 2012), crime (Andresen, 2012), lower school performance (Goux and Maurin, 2007), and higher mortality (van Lenthe et al., 2005).

Furthermore, while the number of EDs with a high concentration of migrants is small, where they occur, highly diverse communities may create challenges for the provision of services. For example, the provision of language supports is crucial in communities where migrants with poor English proficiency are clustered.

\subsection{WHERE MIGRANTS LIVE}

The distribution of the populations described in Chapter 2 shows the attraction of cities for migrants. The highest concentrations of all four groups examined are clustered in the cities, where there is a larger supply of jobs and housing. Dublin, Limerick and Cork all have a higher share of migrants than the average for the State, and exactly half of the foreign-born population is resident in these three cities alone.

Apart from the general pull of cities, our models show that the location of migrants appears to be most strongly associated with the supply of private-rental housing, and this pattern persists within the three largest cities. 


\subsection{LIMITATIONS AND AVENUES FOR FURTHER RESEARCH}

This report has sought to provide a high-level overview of residential patterns among the migrant population; however, this has not allowed for detailed analysis of experiences within groups. Although the possible depth of research is limited by the Small Area Population Statistics (SAPS) data and the fact that only three individual country-of-birth groups can be identified (UK, Poland and Lithuania), more detailed analysis could be pursued. For instance, Polish-born residents are a large group that are identified in the data (Gilmartin and Mills, 2008). Ongoing research is investigating residential patterns of this group. Research on narrower groups with shared cultural and linguistic characteristics would allow a more robust test of some of the theories put forward in the literature such as social network theory.

The present project has focused on migrants, as measured through a 'country of birth' variable rather than ethnicity. Due to the relatively recent nature of immigration to Ireland, there is an absence of long-established ethnic minority groups in Ireland, with the exception of the Traveller Community. This means that there is relatively limited variation in the ethnic/cultural background variable in the Census for further spatial analysis. For instance, less than 1.5 per cent of the population are of Black ethnicity and only 2.1 per cent are Asian. That said, replicating the analysis with the ethnic/cultural background Census variable, at least within urban areas, would be a valuable exercise because it would assess residential segregation among groups that have been shown to be disadvantaged in recent research, in particular Black people and the Traveller community (McGinnity et al., 2018b; Watson et al., 2017). From a migrant integration perspective, this may become increasingly important in future censuses, as ever more people from diverse backgrounds begin to record Irish nationality and Irish country of birth.

Future research could also begin to explore the association between migrant residency patterns and rental prices. The Residential Tenancy Board produces nationwide rental price data for 137 Local Electoral Areas, which could be used to investigate housing affordability in areas with high migrant concentrations.

Although we find no strong relationship between immigrant concentration and disadvantage, evidence of high concentration may emerge in some very small geographical areas. This possibility could be investigated if a similar analysis was carried out at the small-area level. However, the disadvantage of this approach is that the socio-economic characteristics of the areas with the highest group concentrations would be determined by the presence of the group, rather than by exogenous factors, a point noted in Chapter 1. 
While the indices of segregation used in the current study are the most widely used in the literature and provide a good initial overview of residential segregation, a number of methodological developments/innovations could be applied in future research to address some of the limits of conventional indices. A key limitation of many segregation indices is that they are 'aspatial': neither the dissimilarity index nor the isolation index accounts for the composition of proximate or even adjacent EDs.

One direction for future research would be to employ more complex, spatial measures of segregation which would evaluate to what extent neighbourhoods with high migrant concentrations are located near or next to each other. Options include a spatial dissimilarity index, a general spatial exposure/isolation index and a spatial clustering index (Reardon and O'Sullivan, 2004; Yao et al., 2018). While these are more complex measures, they could give an additional sense of spatial clustering in Ireland.

Work by Maguire et al. (2016) reflects a growing awareness in recent years of how important the spatial interface between different groups can be. It is not only the overall degree of spatial separation that matters but also the nature of transitions between residential communities. Dean et al. (2018), for example, have argued that sharp spatial transitions ('social frontiers') between two groups rather than gradual blending of residents across neighbourhood boundaries may indicate an aversion to living near members of the other group. This in turn may be indicative of social tensions and potential conflict. This method would be interesting to apply to selected groups in Dublin, for example, though it poses some formidable methodological challenges.

Other recent developments allow researchers to quantify the uncertainty surrounding segregation measures such as the dissimilarity index using Bayesian hierarchical modelling (see Lee et al., 2015), though once again computation is complex and these measures are not widespread. Manley et al. (2018) apply a multilevel approach to multi-ethnic segregation in Auckland, New Zealand. This allows them to investigate segregation in smaller neighbourhoods and larger areas at the same time, to circumvent the problem that most segregation indices are sensitive to the level or area chosen. As well as being computationally difficult, their models use data from many individual country of origin groups, which is not currently possible in Ireland.

A trend in advancing segregation measurement is to move from place-based approaches using spatially aggregated data to an individual or people-based approach using individual-level data. This is important because a key limitation of conventional segregation indices is that people may work, shop and socialise 
outside their local neighbourhood. There has also been some recent progress in developing measures of 'activity spaces', i.e. all locations within which an individual has contact as a result of their day-to-day activities (Yao et al., 2018). Challenges remain here in terms of effectively collecting detailed individual data on locations, but also as to how to 'weight' the locations in terms of how long the individual spends there.

\subsection{POLICY IMPLICATIONS}

Under 'continuing challenges and risks' the Migrant Integration Strategy mentions segregation and 'ghettoization' of specific migrant groups, with the potential for social exclusion and economic disadvantage. In terms of segregation, at least for the groups studied, the evidence suggests that spatial segregation in Ireland is relatively low. That said, as noted in the further research discussion above, the immigrant population is highly mobile, so residential patterns may change over time.

Segregation is most likely to lead to additional social exclusion and economic disadvantage if the areas where immigrants live are disadvantaged: it is possible to have highly segregated communities living in comparatively affluent, or certainly not disadvantaged, communities. The evidence from Chapter 4 suggests that migrants as a whole tend to live in rather affluent areas in Ireland, and in particular in EDs with advantaged educational profiles. However, this is not the case for immigrants with poor English-language proficiency. Instead, this group tend to live in areas where the HP index is close to zero (the midway point on the scale) and are less likely to live in areas with an above-average proportion of third-level graduates.

The clearest finding from Chapter 4 is that the migrant population tends to live in areas with higher concentrations of private rented accommodation. This is likely driven in part by low levels of home ownership among the foreign-born population itself (see Chapter 1). McGinnity et al. (2018a) identify a number of likely factors contributing to low home ownership among immigrants. For example, the residency, income and savings requirements to secure credit for a home loan might be difficult for immigrants to meet. Immigrants may have different preferences regarding owning a home versus renting; some may view their stay as temporary and may not want a long-term commitment such as buying a house. From a housing policy perspective, this suggests that greater dispersal of new housing developments for the rental market, at least across cities, suburban areas and towns, would help to diversify Irish social life.

Of course, the location of housing must also be linked to the location of jobs and services; people want to live close to where they work and study. The new National 
Planning Framework sets out a plan to achieve more balanced regional development. It proposes that 75 per cent of the growth should occur outside Dublin and its suburbs. The plan envisages a strong role for the development of cities outside of Dublin, which requires a considerable increase in the housing supply in these 'second tier' cities (Morgenroth, 2018). A NESC report also highlights the need to develop employment policies that are responsive to the needs of local communities and employment sectors in order to better integrate households experiencing labour market difficulties (NESC, 2014).

However, in a dysfunctional housing market with steeply rising rents, especially in the Dublin area, reliance on the rental sector by immigrants may be problematic in terms of social inclusion. Issues of affordability and security of tenure are particularly salient for groups highly dependent on this market. The high level of competition between tenants due to lack of housing supply could lead to increased discrimination against minority groups by landlords (Grotti et al., 2018). This suggests that regulation and monitoring may be necessary in the private rented sector, in addition to measures to tackle supply, affordability and security of tenure (Grotti et al., 2018).

Although this report has not found particularly high levels of residential segregation among the foreign-born population, it has shown that there are some areas with high concentrations of migrants. Policymakers could conceivably use this finding to better target service provision to migrant communities. The descriptive analysis in Chapter 2 could be particularly useful in this regard. Further local-level information about the experience of residents in these areas in accessing services, jobs and housing is needed to establish whether current policies are meeting community needs. Information on the spatial distribution of different migrant groups could also be used to mobilise political representation and participation in decision-making for these groups.

Finally, this report underscores the value of supplying high-quality, easily accessible data. The SAPS data could be even more useful if other public datasets were geocoded, allowing researchers to map important and policy relevant social phenomena. A recent example of this kind of exercise is the Dublin Housing Observatory's Mapping Viewer (https://airomaps.geohive.ie/dho/), which allows researchers and members of the public to overlay housing data from the Rental Tenancies Board, the Property Price Register and the Census in a single interactive map. 


\section{REFERENCES}

Allen, R., S. Burgess, R. Davidson, and F. Windmeijer (2015). 'More reliable inference for the dissimilarity index of segregation', Econometrics Journal, Vol. 18, No. 1, pp. 4066.

Andersen, H.S. (2017). 'Selective moving behaviour in ethnic neighbourhoods: white flight, white avoidance, ethnic attraction or ethnic retention?', Housing Studies, Vol. 32, No. 3, pp. 296-318.

Anderson, C.J. (2018). Poisson regression of counts and rates, Champaign: Department of Educational Psychology, University of Illinois, available at: https://bit.ly/2CHPNIZ

Andresen, M.A. (2012). 'Unemployment and crime: a neighborhood level panel data approach', Social Science Research, Vol. 41, No. 6, pp. 1615-1628.

Arnold, S. and E. Quinn (2016). Resettlement of refugees and private sponsorship in Ireland, Dublin: European Migration Network/The Economic and Social Research Institute.

Barrett, A., A. Bergin, and D. Duffy (2006). 'The labour market characteristics and labour market impacts of immigrants in Ireland', The Economic and Social Review, Vol. 37, No. 1, pp. 1-26.

Barrett, A. and Y. McCarthy (2007). 'Immigrants in a booming economy: analysing their earnings and welfare dependence', Labour, Vol. 21, No. 4, pp. 789-808.

Barrett, A., F. McGinnity and E. Quinn (2017). Monitoring report on integration 2016, Dublin: The Economic and Social Research Institute and Department of Justice and Equality.

Becker, G. (1957). The economics of discrimination, Chicago: University of Chicago Press.

Beckhusen, J., R.J.G.M. Florax, T. de Graaff, J. Poot, and B. Waldorf (2013). 'Living and working in ethnic enclaves: English language proficiency of immigrants in US metropolitan areas', Papers in Regional Science, Vol. 92, No. 2, pp. 305-329.

Best, M. (2013). 'The ethnic Russian minority: a problematic issue in the Baltic States', Germanic \& Slavic Studies in Review, Vol. 2, No. 1, pp. 33-41.

Central Statistics Office (2018). Population and Migration Estimates, Cork: CSO, available at: https://www.cso.ie/en/methods/population/populationandmigrationestimates/

Chiswick, B.R. and P.W. Miller (2004). 'Where immigrants settle in the United States', Journal of Comparative Policy Analysis: Research and Practice, Vol. 6, No. 2, pp. 185-197.

Corrigan, E., D. Foley, K. McQuinn, C. O’Toole, and R. Slaymaker (2018). 'Exploring affordability in the Irish housing market', Technical Working Paper, Dublin: Department of Housing, Planning and Local Government and The Economic and Social Research Institute.

Cutler, D.M., E.L. Glaeser, and J.L. Vigdor (1999). 'The rise and decline of the American ghetto', Journal of Political Economy, Vol. 107, No. 3, pp. 455-506. 
Dean, N., G. Dong, A. Piekut, and G. Pryce (2018). 'Frontiers in residential segregation: understanding neighbourhood boundaries and their impacts', Tijdschrift voor Economische en Sociale Geografie, available at: https://doi.org/10.1111/tesg.12316

Department of Justice and Equality (2017). The Migrant Integration Strategy - a blueprint for the future, Dublin: Department of Justice and Equality, available at: www.justice.ie/en/JELR/Pages/Migrant_Integration_Strategy__A_Blueprint_for_the_Future

Doherty, P. and M.A. Poole (1997). 'Ethnic residential segregation in Belfast, Northern Ireland, 1971-1991', Geographical Review, Vol. 87, No. 4, pp. 520-536.

Fahey, T. and B. Fanning (2010). 'Immigration and socio-spatial segregation in Dublin, 1996-2006', Urban Studies, Vol. 47, No. 8, pp. 1625-1642.

Fanning, B. (2018). Migration and the making of Ireland, Dublin: UCD Press.

Frey, W.H. (1979). 'Central city white flight: racial and nonracial causes', American Sociological Review, Vol. 44, No. 3, pp. 425-448.

Gilmartin, M. and G. Mills (2008). 'Mapping migrants in Ireland: the limits of cartography', Translocations: Migration and Social Change, Vol. 4, No. 1, pp. 21-34.

Gouveia, D. (2013). Refugee integration capacity evaluation in Europe, Geneva: UNHCR.

Goux, D. and E. Maurin (2007). 'Close neighbours matter: neighbourhood effects on early performance at school', Economic Journal, Vol. 117, pp. 1193-1215.

Grotti, R., H. Russell, É. Fahey, and B. Maître (2018). Discrimination and inequality in housing in Ireland, Dublin: The Economic and Social Research Institute and Irish Human Rights and Equality Commission.

Haase, T. and J. Pratschke (2017). The 2016 Pobal HP Deprivation Index for Small Areas (SA), available at: https://www.pobal.ie/app/uploads/2018/06/The-2016-Pobal-HPDeprivation-Index-Introduction-07.pdf

Harris, R. and R. Johnston (2018). 'Measuring and modelling segregation - new concepts, new methods and new data', Environment and Planning B: Urban Analytics and City Science, Vol. 45, No. 6, pp. 999-1002.

Hayfron, J.E. (2001). 'Language training, language proficiency and earnings of immigrants in Norway', Applied Economics, Vol. 33, pp. 1971-1979.

Iceland, J., D.H. Weinbert, and E. Steinmetz (2002). Racial and ethnic residential segregation in the United States: 1980-2000, U.S. Census Bureau, Series CENSR-3, Washington, DC: U.S. Government Printing Office.

Irish Human Rights and Equality Commission (2018). Irish Human Rights and Equality Commission annual report 2017, Dublin: Irish Human Rights and Equality Commission.

Kelly, E., G. Kingston, H. Russell, and F. McGinnity (2016). 'The equality impact of the employment crisis', Journal of the Statistical and Social Inquiry Society of Ireland, Vol. 44, pp. 71-85. 
Lee, D., J. Minton, and G. Pryce (2015). 'Bayesian inference for the dissimilarity index in the presence of spatial autocorrelation', Spatial Statistics, Vol. 11, pp. 81-85.

Maguire, A., D. French, and D. O'Reilly (2016). 'Residential segregation, dividing walls and mental health: a population-based record linkage study', Journal of Epidemiology and Community Health, Vol. 70, No. 9, pp. 845-854.

Manley, D., R. Johnston, and K. Jones (2018). 'Decomposing multi-level ethnic segregation in Auckland, New Zealand, 2001-2013: segregation intensity for multiple groups at multiple scales', Tijdschrift voor Economische en Sociale Geografie, available at: https://onlinelibrary.wiley.com/doi/full/10.1111/tesg.12314

Marcuse, P. (2005). 'Enclaves yes, ghettos no: segregation and the state', in D.P. Varady (ed.), Desegregating the city: ghettos, enclaves and inequality, Albany, NY: SUNY Press.

Massey, D. (1990). 'Social structure, household strategies, and the cumulative causation of migration', Population Index, Vol. 56, No. 1, pp. 3-26.

Massey, D. and N. Denton (1988). 'The dimensions of residential segregation', Social Forces, Vol. 67, No. 2, pp. 281-315.

Massey, D. and B.P. Mullen (1984). 'Processes of Hispanic and Black spatial assimilation', American Journal of Sociology, Vol. 89, No. 4, pp. 836-873.

McGinnity, F., É. Fahey, E. Quinn, S. Arnold, B. Maitre, and P. O'Connell (2018a). Monitoring report on integration 2018, Dublin: The Economic and Social Research Institute and Department of Justice and Equality.

McGinnity, F., R. Grotti, S. Groarke, and S. Coughlan (2018b). Ethnicity and nationality in the Irish labour market, Dublin: The Economic and Social Research Institute and Irish Human Rights and Equality Commission.

McGinnity, F., R. Grotti, H. Russell, and É. Fahey (2018c). Attitudes to diversity in Ireland, Dublin: The Economic and Social Research Institute and Irish Human Rights and Equality Commission.

Morenoff, J.D. (2003). 'Neighborhood mechanisms and the spatial dynamics of birth weight', American Journal of Sociology, Vol. 108, No. 5, pp. 976-1017.

Morgenroth, E. (2018). Prospects for Irish regions and counties: scenarios and implications, Research Series No. 70, Dublin: The Economic and Social Research Institute.

Mushroom Workers Support Group, The (2006). Harvesting justice: mushroom workers call for change, Dublin: Migrant Rights Centre Ireland.

Musterd, S. (2005). 'Social and ethnic segregation in Europe: levels, causes and effects', Journal of Urban Affairs, Vol. 27, No. 3, pp. 331-348.

NESC (2014). Jobless households: an exploration of the issues, NESC Council Report No. 137, Dublin: NESC.

Ní Raghallaigh, M., M. Foreman, and M. Feeley (2016) Transition: from Direct Provision to life in the community, Dublin: Irish Refugee Council. 
O'Boyle, N. and B. Fanning (2009). 'Immigration, integration and risks of social exclusion: the social policy case for disaggregated data in the Republic of Ireland', Irish Geography, Vol. 42, No. 2, pp. 145-164.

Pettigrew, T.F. and L.R. Tropp (2011). When groups meet: the dynamics of intergroup conflict. New York: Psychology Press.

Piekut, A., G. Pryce, and W. Van Gent (2019). 'Segregation in the twenty first century: processes, complexities and future directions', Tijdschrift voor Economische en Sociale Geografie, available at: https://onlinelibrary.wiley.com/doi/full/10.1111/tesg.12355

Reardon, S.F. and D. O'Sullivan (2004). 'Measures of spatial segregation', Sociological Methodology, Vol. 34, No. 1, pp. 121-162.

Reception and Integration Agency (2016). Reception and Integration Agency monthly statistics report, April 2016, Dublin: RIA, available at: www.ria.gov.ie/en/RIA/Pages/Monthly_Reports

Residential Tenancies Board (2018). Rent Index 2018: Quarter 3, Dublin: Residential Tenancies Board and The Economic and Social Research Institute.

Rich, J. (2014). What do field experiments of discrimination in markets tell us? A meta analysis of studies conducted since 2000, Discussion Paper No. 8584, Bonn: IZA.

Riva, M., L. Gauvin, and T.A. Barnett (2007). 'Toward the next generation of research into small area effects on health: a synthesis of multilevel investigations published since July 1998', Journal of Epidemiology and Community Health, Vol. 61, No. 10, pp. 853-861.

Russell, H., O. Kenny, and F. McGinnity (2016). Childcare, early education and socioemotional outcomes at age 5: evidence from the Growing Up in Ireland Survey, Dublin: The Economic and Social Research Institute and Pobal.

Seitles, M. (1998). 'The perpetuation of residential racial segregation in America: historical discrimination, modern forms of exclusion, and inclusionary remedies', Journal of Land Use and Environmental Law, Vol. 14, No. 1, pp. 89-124.

Sellstrom, E. and S. Bremberg (2006). 'The significance of neighbourhood context to child and adolescent well-being: a systematic review of multi-level studies', Scandinavian Journal of Public Health, Vol. 34, pp. 544-554.

Tolnay, S.E. (2003). 'The African American "Great Migration" and beyond', Annual Review of Sociology, Vol. 29, pp. 209-232.

van Lenthe, F.J., L.N. Borrell, G. Costa, A.V. Diez Roux, T.M. Kauppinen, C. Marinacci, P. Martikainen, E. Regidor, M. Stafford, T. Valkonen (2005). 'Neighbourhood unemployment and all cause mortality: a comparison of six countries', Journal of Epidemiology and Community Health, Vol. 59, pp. 231-237.

Vang, Z. (2010). 'Housing supply and residential segregation in Ireland', Urban Studies, Vol. 47, No. 14, pp. 2983-3012. 
Vang, Z. (2012). 'The limits of spatial assimilation for immigrants' full integration: emerging evidence from African Immigrants in Boston and Dublin', Annals of the American Academy of Political and Social Science, Vol. 641, pp. 220-246.

Watson, D., O. Kenny and F. McGinnity (2017). A social portrait of Travellers in Ireland, Research Series 56, Dublin: The Economic and Social Research Institute.

Wight R.G., C.S. Aneshensel, C. Barrett, M. Ko, J. Chodosh, and A.S. Karlamangla (2012). 'Urban neighbourhood unemployment history and depressive symptoms over time among late middle age and older adults', Journal of Epidemiology and Community Health, Vol. 67, No. 2, pp. 153-158.

Yao, J., D.W.S. Wong, N. Bailey, and J. Minton (2018). 'Spatial segregation measures: a methodological review', Tijdschrift voor Economische en Sociale Geografie, available at: https://onlinelibrary.wiley.com/doi/abs/10.1111/tesg.12305 




Whitaker Square,

Sir John Rogerson's Quay,

Dublin 2

Telephone $+\mathbf{3 5 3} 18632000$

Email adminवesri.ie

Web www.esri.ie

Twitter RESRIDublin

ISBN 978-0-7070-0483-9 